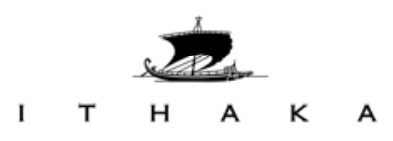

I T H A K A R E P O R T

\title{
University Publishing In A Digital Age
}

July 26, 2007

Authors:

Laura Brown, Rebecca Griffiths, Matthew Rascoff

Preface:

Kevin Guthrie 
TABLE OF CONTENTS

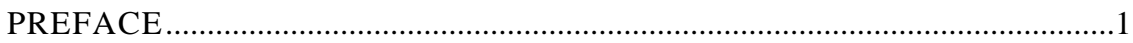

EXECUTIVE SUMMARY .........................................................................

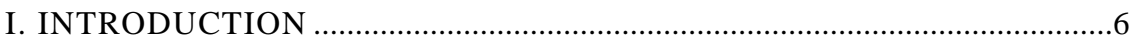

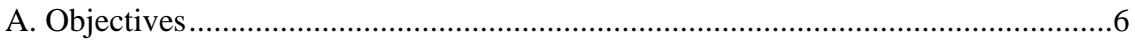

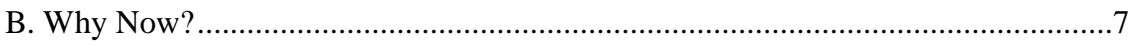

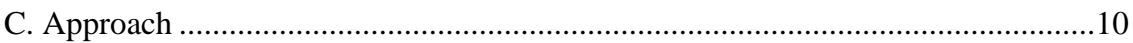

II. WHAT THE WORLD LOOKS LIKE TODAY AND

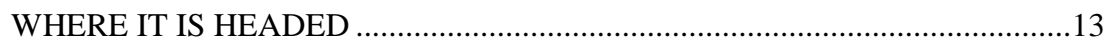

A. The future of scholarly communications ............................................................

B. Some libraries are striving to support these needs ............................................15

C. Many university presses have struggled to adapt to changing needs ....................16

D. University presses can continue to play a critical role in publishing ....................21

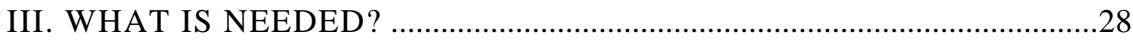

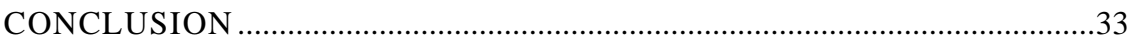

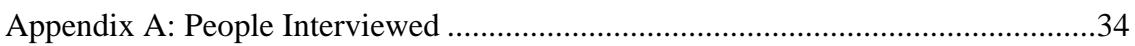

Appendix B: Comparison of Press and Library

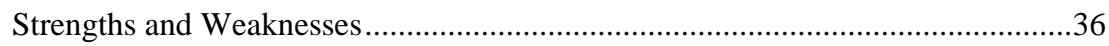

Appendix C: Recommendations to Press Directors..................................................38

Appendix D: Interview Guides (Press Directors, Librarians, and Administrators) ...40

Appendix E: University Press Director Survey Results .......................................47 


\section{P R E F A C E}

This report has been a collaborative effort between Laura Brown, the former president of Oxford University Press USA, and Ithaka's Strategic Services group. It was sponsored financially by Ithaka and JSTOR. Laura is a JSTOR Trustee, and I serve as JSTOR's chairman, in addition to being Ithaka's president. Both Ithaka and JSTOR are keenly interested in the current state and future of scholarly publishing, and the Strategic Services group of Ithaka specializes in gathering, analyzing and sharing information on topics at the intersection of higher education and technology. This seemed to us a critical moment for university presses and university publishing, and so we undertook this study.

Along with Laura Brown, Matthew Rascoff and Rebecca Griffiths carried out the research for this report. The research effort included a survey of university press directors and an extensive series of interviews with press directors, librarians, provosts, and other university administrators. The original draft report was written by Matthew, Rebecca and Laura, and I worked closely with them to produce this final draft for comment. This draft benefited substantially from suggestions offered by 18 outside readers and commentators. We are very grateful for the considerable time contributed by these commentators to improve the document.

Despite the extensive background research that was conducted, this is not a report presenting findings from an objective, empirical survey of the field. Instead, it is a qualitative review, informed by the survey and interviews as well as the knowledge of the investigators. Laura especially brought to this project a wealth of experience in publishing and a perspective on the important role that university presses have played in scholarly communications. She would be the first to say that she came to the study with assumptions, and perhaps even a vision, but she would also confess that many of those assumptions have been challenged and some have been turned upside down.

One of the proposals presented in this report suggests that it would be beneficial for the community if there were a powerful technology, service and marketing platform that would serve as a catalyst for collaboration and shared capital investment in university-based publishing. We regard this as a potentially transformative concept regardless of who or how it might be carried out. In the interest of full disclosure, we want readers to be aware that we see the possibility of JSTOR playing a role in establishing such a platform given its mission, experience, and existing relationships and infrastructure. However, this report has not been written, nor has the research been conducted, in an effort to provide justification for any JSTOR effort. If discussion motivated by this report were to convey that such a platform is unnecessary, or that JSTOR had no useful role to play in building it, that would be just as valuable (to the community as well as to JSTOR) as if the discussions encouraged the development of such a platform by JSTOR or any other enterprise. 
One provost, when he read the first draft of the report, asked if we could get the report to his Library Director and his Press Director so that they could have a conversation about it. Another responded with a much more radical concept of how scholarly communications should be transformed. If the report did nothing but motivate such thinking and conversations in many provosts' and presidents' offices around the country, we would consider it a success.

Please do not hesitate to contact me or my colleagues here at Ithaka with comments of any kind.

Kevin M. Guthrie

President

Ithaka

kg@ithaka.org 


\section{E X E C U T I V E S U M M A R Y}

This report began as a review of U.S. university presses and their role in scholarly publishing. It has evolved into a broader assessment of the importance of publishing to universities. By publishing we mean simply the communication and broad dissemination of knowledge, a function that has become both more complex and more important with the introduction and rapid evolution of digital and networking technologies. There is a seeming limitless range of opportunities for a faculty member to distribute his or her work, from setting up a web page or blog, to posting an article to a working paper website or institutional repository, to including it in a peer-reviewed journal or book. In American colleges and universities, access to the internet and World Wide Web is ubiquitous; consequently nearly all intellectual effort results in some form of "publishing". Yet universities do not treat the publishing function as an important, mission-centric endeavor. Publishing generally receives little attention from senior leadership at universities and the result has been a scholarly publishing industry that many in the university community find to be increasingly out of step with the important values of the academy.

As information transforms the landscape of scholarly publishing, it is critical that universities deploy the full range of their resources - faculty research and teaching activity, library collections, information technology capacity, and publishing expertise - in ways that best serve both local interests and the broader public interest. We will argue that a renewed commitment to publishing in its broadest sense can enable universities to more fully realize the potential global impact of their academic programs, enhance the reputations of their specific institutions, maintain a strong voice in determining what constitutes important scholarship and which scholars deserve recognition, and in some cases reduce costs. There seems to us to be a pressing and urgent need to revitalize the university's publishing role and capabilities in this digital age.

We began this project with a set of hypotheses and views based on our own experience and prior discussions with people in the community. These hypotheses were tested through an extensive series of interviews with administrators, press directors, librarians, and other stakeholders on campus. We also conducted a survey of press directors to understand better their relationships to their host institutions, progress in getting online, and ability to develop new programs. Some of what we learned through this process confirmed our sense of how the world is changing, but we also heard views that we had not expected, particularly how critical many were of university presses and the difficulties they have had in adapting.

\section{What the world looks like and where we are headed}

Formal scholarly publishing is characterized by a process of selection, editing, printing and distribution of an author's content by an intermediary (preferably one with some name recognition). Informal scholarly publication, by comparison, describes the dissemination of content (sometimes called "gray literature") that generally has not passed through these processes, such as working papers, lecture notes, student newsletters, etc. In the past decade, the range and importance of the latter has been dramatically expanded by information technology, as scholars increasingly turn to preprint servers, blogs, listservs, and institutional repositories, to share their work, ideas, data, opinions, and critiques. These forms of informal publication have become pervasive in the university and college ${ }^{1}$ environment. As scholars increasingly rely on these channels to share and find information, the boundaries between formal and informal

\footnotetext{
${ }^{1}$ Please note that throughout this paper we use the term "university" as shorthand for both universities and colleges.
} 
publication will blur. These changes in the behavior of scholars will require changes in the approaches universities take to all kinds of publishing.

Universities have traditionally participated in the formal publication of their intellectual output through a network of presses, but most publishing of this output has long taken place outside the university sector, especially in the sciences. For a variety of reasons university presses have become less integrated with the core activities and missions of their home campuses over the years - a drift that threatens to widen as information technology transforms the landscape of scholarly publishing. The responsibility for disseminating digital scholarship is migrating instead in two directions - towards large (primarily commercial) publishing platforms and towards informal channels operated by other entities on campus, mostly libraries, academic computing centers, academic departments, and cross-institutional research centers. While these entities all play a critical role in scholarly communications ${ }^{2}$, university presses have developed publishing skills and experience over many years that are also very valuable in this new context and that would be costly, if not impossible, to replicate. We hope to highlight those skills in this report and suggest how they can be adapted to the digital age.

Publishing in the future will look very different than it has looked in the past. Consumption patterns have already changed dramatically, as many scholars have increasingly begun to rely on electronic resources to get information that is useful to their research and teaching. Transformation on the creation and production sides is taking longer, but ultimately may have an even more profound impact on the way scholars work. Publishers have made progress putting their legacy content online, especially with journals. We believe the next stage will be the creation of new formats made possible by digital technologies, ultimately allowing scholars to work in deeply integrated electronic research and publishing environments that will enable real-time dissemination, collaboration, dynamically-updated content, and usage of new media.

Alongside these changes in content creation and publication, alternative distribution models (institutional repositories, pre-print servers, open access journals) have also arisen with the aim to broaden access, reduce costs, and enable open sharing of content. Different economic models will be appropriate for different types of content and different audiences. It seems critical to us that there continue to be a diverse marketplace for publishing a range of content, from fee-based to open access, from peer reviewed to selfpublished, from single author to collaboratively created, from simple text to rich media. This marketplace should involve commercial and not-for-profit entities, and should include collaborations among libraries, presses, and academic computing centers.

What will, or should, the future scholarly communications system look like? First, every university that produces research should have a publishing strategy, but that does not mean that it should have a "press". Much of the content produced in the future will be disseminated electronically, and a new constellation of skills (including some that currently reside in presses, as well as those from libraries and IT groups) will be required to do this most effectively. Second, in the digital environment certain activities and assets (e.g. technology development, marketing) will be consolidated onto large scale platforms. These new digital publishing activities are central to the research and teaching missions of universities, and it therefore seems critically important that the university community be able to influence strongly the

\footnotetext{
${ }^{2}$ In the past, terms such as scholarly communications and scholarly publishing were often used to depict research outputs that met certain criteria, such as certification, selection, and preservation. We argue here that the lines between formal and informal publication are breaking down, and thus the definitions of these terms are in flux. We use them in this paper to refer to the broad spectrum of ways that scholars share their research with one another.
} 
development of these platforms to insure that they support long held university values, rather than allowing them to be driven primarily by commercial incentives. And third, as the environment evolves, university presses will no doubt change. Some universities will encourage and enable their presses to grow and take more of a leadership role. Other institutions may decide to open new presses. Others may close their presses or let their presses evolve into more specialized enterprises with a focus on editorial and credentialing services while depending on others for core infrastructure and marketing services. What seems clear is that to succeed presses are going to need to be a more important partner in helping their host institutions to fulfill their research and teaching mission.

\section{What needs to be done}

In our interviews we detected significant detachment from administrators about publishing's connection to their core mission; a high level of energy and excitement from librarians about reinventing their roles on campus to meet the evolving needs of their constituents; and a wide range of responses from press directors, from those who are continuing to do what they have always done, to those who are actively reconnecting with their host institutions' academic programs and engaging in collaborative efforts to develop new electronic products. Many press directors have a sense of what needs to be done to jumpstart their new enterprises, but lack the financial capital, technical staff, and technological skills to pursue this kind of agenda. Librarians and press directors acknowledge that they have limited experience in collaborating effectively with one another and operate on different business models that make collaboration challenging, but at the same time we found that they have an appreciation for the unique skills and experience that each brings to the table. Finally, there was a strong sense that a new third-party enterprise or at least a catalytic force is needed to: facilitate the investment of capital; lead the community toward a shared vision of the scholarly communications landscape; help institutions find their place in that new system; marshal the necessary ongoing resources; and help motivate collaboration both within campuses and across institutions.

Administrators, librarians and presses each have a role to play (as do scholars, though this report is not directed at them). Senior administrators must provide strong leadership and embrace the fact that in this digital era, publishing, broadly defined, is a centrally important activity of any university. They will have to manage university assets and resources strategically if universities are to continue to exert the appropriate level of influence on the assessment and dissemination of knowledge and scholarship. Press directors and librarians must work together to create the intellectual products of the future which increasingly will be created and distributed in electronic media. Their efforts should be closely and intelligently connected to their campuses' academic programs and priorities in order to ensure their relevancy and institutional commitment. All three parties should work together to create a shared electronic publishing infrastructure that will save costs, build scale, leverage expertise, promote innovation, and integrate the productive resources of universities to maintain a robust, diverse and collaborative university publishing environment.

Clearly this is too ambitious an agenda for institutions to pursue individually. Creating these sorts of platforms requires scale and investment of substantial capital, and commercial entities are far ahead of the university sector in investing the necessary level of resources. Each institution must determine what it can do locally, and if and when it should combine forces with other institutions. One of the objectives of this study was to gauge the community's interest in a possible collective investment in a technology platform to support innovation in university-based, mission-driven publishing. This infrastructure could serve as the foundation for new forms of university-centered academic publishing in the digital age. 


\section{I . I N T R O D U C T I O N}

\section{A. Objectives}

This is the final report of an assessment of university-based publishing and the future role of the university in the scholarly publishing system. This paper has four purposes:

First, we hope to make the case that universities should become more actively involved in publishing scholarship. It may not be obvious to many administrators that they should be in this "business" at all why not stick to the core purposes of producing scholarship and providing education, and leave the details of getting their byproducts into print (or onto servers) to others? Many administrators have made this function a relatively low priority because they have more pressing concerns, do not have a framework for the role their institutions should play in scholarly communication, and associate the publishing enterprise with university presses, which, for a variety of reasons, are not strategically engaged in the core activities of their host institutions. We will argue, however, that universities give up too much by withdrawing from publishing. They give up the opportunity to enhance institutional reputation and prestige. They reduce their ability to influence what gets published - and, therefore, not only what gets read but also who gets hired or promoted. They give up an opportunity to enhance the quality of what is published through the rich dialogue that is enabled by bringing editors into the fabric of relationships among scholars. And, as is often decried by open access advocates, universities sometimes must pay excessively high prices to gain access to published scholarship. (Open access efforts may be a solution to some of these problems, but we will argue that there is no one-size-fits-all solution across disciplines and types of content.) There is a great need, as well as a great opportunity, to revitalize the university's role and capabilities in publishing.

Our second purpose is to galvanize action and investment to support revitalization of university publishing. The university-based publishing enterprise of the future must look very different from that of the past. This adaptation will require new kinds of leadership from universities and their central administrators. Administrators need to recognize the role of universities in publishing and develop strategies for the successful investment of resources, both financial and human. In some cases, that may mean making major structural and strategic changes to an existing press. In other cases it may mean forming new collaborations between different entities on campus or even across institutions, or disaggregating and recombining publishing related activities across multiple campus entities. It will no doubt require new infusions of capital, but this investment can create economies of scale that could help, in the end, to lower the costs and extend the reach of scholarly publishing. These decisions must be based on careful consideration and must be communicated clearly to those responsible for carrying them out. Several universities have already begun taking steps in this direction, and we will highlight examples of their activities.

Third, we wish to explore some of the challenges and opportunities specific to university presses, as we believe that they can remain a vibrant part of the scholarly system if they are able to adapt quickly to the new electronic environment. The financial challenges of university presses have been well documented elsewhere. ${ }^{3}$ We concentrated primarily on exploring how the presses see themselves, how they are seen

\footnotetext{
${ }^{3}$ As John B. Thompson writes, "The decline in sales of scholarly monographs has undoubtedly been one of the most significant trends with which academic publishers have had to deal over the last two decades — more than any other single factor, it has transformed the economic conditions of scholarly publishing. The unit sales of scholarly monographs have fallen to a quarter or less of what they were in the 1970s, and what was once a relatively straightforward and profitable type of publishing has become much more difficult in financial terms." See John B. Thompson, Books in the Digital Age: The Transformation of Academic and Higher Education Publishing in Britain and the United States. Cambridge [UK]: Polity, 2005, pp. 93-94. See also Peter Givler, "University
} 
by others in the university community, and what unique strengths presses have to offer, with an eye towards identifying opportunities for them to translate their skills and assets to the future needs of the academy. We have also sought to understand the factors that have impeded their transition to electronic media, especially in monograph programs, in an effort to identify realistic measures going forward.

Fourth, and finally, we aim to start a conversation and gauge interest in a possible collective investment in a technological platform to support innovation in university-based, mission-driven publishing. We found considerable interest in cross-institutional collaboration, and a feeling that some third party "glue" is needed to make this happen. Our discussions with administrators, publishers, faculty, and librarians revealed real enthusiasm for the concept of a service that could aggregate published university content online, create a dynamic, efficient space for the tools of scholarship developed within universities, and spread the costs of investment among multiple institutions. We would now like to expand this conversation to the wider community, to test and refine the idea, and determine whether it may merit further exploration and possible investment.

The study was sponsored by JSTOR and Ithaka and was led by Laura Brown, former president of Oxford University Press USA, in collaboration with Ithaka's Strategic Services group. We gratefully acknowledge the assistance of Peter Givler of the American Association of University Presses in distributing the survey to university press directors and encouraging their participation.

\section{B. Why Now?}

It is worth explaining why we believed it was important to undertake this study at this point. The publishing landscape, and scholarly communication in general, is rapidly changing. We believe this is a pivotal moment for university-based publishing, and for university presses in particular. Following are some of the specific changes we observed that motivated this research:

\section{Scholars' use of information is moving online}

Changes in the research and teaching habits and working styles of the higher education community have increased expectations about the availability of content in electronic form. ${ }^{4}$ Scholars want to search the scholarly literature; they want $24 / 7$ access, and they want to access content remotely - from their office desks and from home. Behavioral changes (especially among younger faculty) have taken place quite rapidly, much more so than universities have adapted the ways they produce and qualify scholarship. Scholars rely primarily on print for cover-to-cover reading of monographs, but such thorough reading represents only one part of research activity.

This does not imply, and we are not predicting, the so-called "death of the book". ${ }^{5}$ Print may well remain the preferred format for certain types of usage, such as cover-to-cover reading and display. What it does mean, though, is that scholarly publishers must get their previously published, as well as current content, online and that in the future they will need to operate print and electronic programs simultaneously.

Press Publishing in the United States," in Scholarly Publishing: Books, Journals, Publishers and Libraries in the Twentieth Century, edited by Richard E. Abel and Lyman W. Newman, Wiley, 2002. Available online at http://aaupnet.org/resources/upusa.html, accessed April 2007. See also Albert Greco, “The market for university press books in the United States: 1985-1999”, Learned Publishing, Vol. 14, No. 2, 1 April 2001, pp. 97-105.

${ }^{4}$ To cite but one example, Ithaka surveys shows that 86 percent of scholars agree strongly that electronic research resources are

"invaluable research tools," up from 73 percent in 2000.

See http://www.ithaka.org/research/faculty-studies/ for more information on this study.

${ }^{5}$ See Clifford Lynch, “The Battle to Define the Future of the Book in the Digital World,” First Monday, Vol. 6, No. 6, 4 June 2001. Available online at: http://www.firstmonday.org/issues/issue6_6/lynch/, accessed April 2007. 


\section{Emergence of new publishing models in the electronic environment}

Most presses already have harnessed digital technologies for back-end production ${ }^{6}$, enabling shorter print runs, better inventory control, and print-on-demand. These new print production processes support changes in publishing - from cost reduction to better availability - but do not alter the nature of the products themselves. Digital technology, however, has also fostered changes in the way scholarship is created, disseminated, and consumed, and these advances are beginning to have a transformational impact on publishing models.

The first stage of this transformation - the translation of traditional print products into electronic formats - is well underway, led by journal publishers who have developed hybrid print/electronic publishing models. Most readers now prefer to access journal literature online, and as comfort levels grow with scholarship distributed electronically, demand is increasing for other content types to follow the same curve. $^{7}$

The second stage of the transformation - the creation of new product types enabled by digital technologies - has just begun. New publishing models are emerging in response to demand for real-time dissemination, dynamic material, more collaborative research and authoring environments, and usage of rich media. For example, MIT's Open Courseware (OCW) represents such an innovation where digital technologies enabled MIT to publish course materials for global distribution in a way that never would have been contemplated in the print era. Scholarly publishing of the future will need to support content created in new and complex ways, including everything from regularly updated reference material, multimedia projects, and large interlinked centers that add new works regularly, to resources with usergenerated content (the so-called Web 2.0).

Alongside these profound changes in content creation and publication, alternative distribution models have also arisen to broaden access, reduce costs, and enable open sharing of content. These alternatives from pre-print and working paper services to library institutional repositories, open access journals, and author self-publishing and self-archiving tools - often compete with traditional publishing functions and have the potential to disrupt the selecting, credentialing, and economic models on which scholarly publishers rely.

\section{Flight to scale threatens all but the largest publishers}

The scholarly communications sector has long supported a vibrant mix of large and small for-profit and not-for-profit publishers, but in the last decade this ecosystem has shown signs of strain. Commercial publishers have found the market saturated and turned to price increases and consolidation as the two main avenues to grow revenues (as have some large not-for-profit publishers). Through their scale, fiscal health, and access to capital markets, the largest publishers (most of which are commercial) are able to offer more generous terms and better services (better distribution and marketing, more formats, etc.) to scholarly societies and authors for the rights to publish their work. Consequently, high-quality scholarly content is gravitating towards a handful of large publishing platforms, ${ }^{8}$ and some of these publishers are

\footnotetext{
${ }_{7}^{6}$ By "back-end” we refer to digitization, printing, fulfillment, and storage.

${ }^{7}$ In a study of scholarly communications in the history discipline conducted in 2006 we heard from several faculty members that, for their students, "if it isn’t online it doesn't exist."

${ }^{8}$ We define "publishing platform" as a combination of infrastructure (storage, servers, processing power), software (content creation tools, content management systems, publishing applications), and the business models that support them. The appeal of such a "platform" is often enhanced by the aggregation of content it supports.
} 
using their market power to raise prices. Raym Crow, a publishing consultant, notes that "commercial publishers play a role in publishing over 60 percent of all peer-reviewed journals, owning 45 percent outright and publishing another 17 percent on behalf of non-profit organizations." 9 Moreover, "In the STM (scientific, technical, and medical) market, seven major commercial publishers, responsible for approximately 30 percent of all peer-reviewed titles, account for over 60 percent of the market's total revenue." 10 To provide a longitudinal perspective, Theodore C. Bergstrom writes that in economics, there were 30 English-language journals in 1960, almost all of which were published by not-for-profit publishers. In 1980, the 120 English-language economics journals were evenly divided between not-forprofits and commercial publishers. By 2000, there were 300 journals, more than two-thirds of which were published by commercial firms. ${ }^{11}$ Small not-for-profits in turn have found the market squeezed by the growing share of academic library budgets claimed by large publishers. Demand for the products of small not-for-profits, especially monographs, has eroded, leaving them with even less financial headroom to develop new products. ${ }^{12}$

In response to the increased capital-intensity of electronic scholarly publishing and the value to users of aggregating large amounts of content for web searching (among other trends), the industry is consolidating. To take just one prominent example, in February 2007 John Wiley \& Sons, Inc. completed an acquisition of Blackwell Publishing (Holdings) Ltd. The merged companies publish approximately 1,250 scholarly journals and hundreds of scholarly books every year, making them the third largest scholarly journals publisher in the world (after Elsevier and Springer). ${ }^{13}$ As they grow, these publishers become more formidable competitors to university-based publishers, who do not have access to investment capital, to the same level of technological sophistication or extensive marketing capabilities, or to as broad a set of mergers and acquisition options as their commercial counterparts.

The segmented nature of the scholarly communications marketplace exacerbates the power of the largest publishing entities to exploit highly resilient niche "monopolies". When a journal is firmly established, there are no substitutes for it. For example, the owner of a prestigious journal title is in a position to attract the best papers and then to charge monopoly rents for access to that research. Due to faculty influence, libraries feel tremendous pressure to continue subscribing to top tier journals regardless of prices. One might argue that authors should stop submitting papers to these journals, but their incentives (i.e. the criteria on which their tenure and promotion are based) dictate otherwise. As more scholarship migrates to the largest publishers, these niche monopolies are likely to be consolidated, reinforcing their power relative to libraries.

What is at risk is a diverse marketplace that offers publishing opportunities for a wide range of content at reasonable cost. Highly specialized scholars produce research that may be of interest to only a small

\footnotetext{
${ }^{9}$ Crow, Raym, "Publishing Cooperatives: an alternative for Non-Profit Publishers.” FirstMonday, volume 11, number 9 (September 2006), http://firstmonday.org/issues/issue11_9/crow/index.html, accessed March 17, 2007.

${ }^{10}$ ibid.

${ }^{11}$ See Theodore C. Bergstrom, “Free Labor for Costly Journals?” The Journal of Economic Perspectives, Vol. 15, No. 4., Autumn, 2001, pp. 183-198. Available online at: http://links.jstor.org/sici?sici=0895-

3309\%28200123\%2915\%3A4\%3C183\%3AFLFCJ\%3E2.0.CO\%3B2-Z, accessed April 2007. Large publishers tend to be commercial and small publishers tend to be not-for-profit.

${ }^{12}$ The decline in sales of monographs is caused by a number of additional factors which we will not explore in detail here. Again, see John B. Thompson, Books in the Digital Age: The Transformation of Academic and Higher Education Publishing in Britain and the United States. Cambridge [UK]: Polity, 2005. See also Robert B. Townsend, "History and Future of Scholarly Publishing."

Perspectives, American Historical Association, October 2003, accessed June 1, 2007.

http://www.historians.org/Perspectives/Issues/2003/0310/0310vie3.htm

${ }^{13}$ See “Wiley Completes Acquisition of Blackwell Publishing (Holdings) Ltd.” http://www.wiley.com/WileyCDA/Section/id301452,newsId-2292.html, accessed February 2007.
} 
number of peers, and its commercial value is therefore quite low. The value in terms of scholarly impact, however, may be much higher - and in some cases the impact is not evident for years or even decades after the research is first published. University-based and other not-for-profit presses are accustomed to grappling with the often conflicting claims of scholarship and cost recovery. If these publishers disappear, authors will be left with fewer and perhaps less desirable options, and many universities will not have a place at the table.

The academic community seems to be looking to open access models as a solution to these challenges. But while open access may well be a sustainable solution in STM disciplines, where federal and private research grants can conceivably be extended to support publication fees, one model will not serve as a panacea. A more desirable future, in our view, features a diverse set of publishing models ranging from fee-based to open depending on the nature of the content and the interests of stakeholders. Universities should have a stake in developing these models.

\section{Role of university presses is in question}

University presses, the traditional publishing arms of universities, have struggled to keep up with these emerging trends. The need for university presses is being questioned at some institutions. Recently, influential university decision-makers have recommended a consolidation of university presses as a response to the need for scale. ${ }^{14}$ Administrators are looking to other parts of campus (most commonly libraries) to assume publishing related responsibilities for digital content. Some are re-evaluating the governance of their presses, and moving or considering moving their presses into different reporting lines or parts of the university administration.

The financial stability of presses is increasingly uncertain, as demand for their traditional products declines and administrators' appetites for subsidizing them diminish. (A concurrent trend is that getting a monograph published has become ever more challenging for young scholars and those in less mainstream fields.) The open access movement is raising questions about the traditional financial model of publishing, with some arguing that the proper price for university scholarship is zero. While many presses have been remarkably nimble in making do on a diet of modest subsidies, shoe-string budgets, and programs that painstakingly try to balance cost-recovery goals and scholarly value, those days may be numbered. Ten years from now, how many university presses will be able to compete for authors, or meet the expectations of consumers of scholarly information online, if they only continue doing what they are doing today? Very few, we expect.

\section{Approach}

This report is intended to be a commentary on the state of university publishing and a call to action. Because university presses historically played a large role in publishing research, especially in the humanities and social sciences, we have focused a considerable amount of attention on understanding where presses are now and what role they currently play in scholarly communications. We also found it useful to explore the factors that have in many cases hindered university presses from evolving in step with the changes in community life brought by information technology. Finally, we attempted to develop a view of what university publishing could look like in the future, taking into consideration the assets and

\footnotetext{
${ }^{14}$ For a version of this argument, see Paul N. Courant, "Scholarship and Academic Libraries (and their Kin) in a World of Google," First Monday, Vol. 11, No. 8, 7 August 2006. Available online at: http://www.firstmonday.org/issues/issue11_8/courant/index.html, accessed April 2007.
} 
skills that could be contributed by presses as well as other entities on campus, most notably libraries, individual faculty members, academic departments, cross-disciplinary initiatives, and new entities growing up alongside and across these established units.

We began with a set of beliefs and hypotheses based on our own experience and previous research efforts, and tested these through four months of research in late 2006 and early 2007. Our data-gathering approach was twofold: First, we distributed a survey to the directors of the American university presses. Among the 88 recipients of the survey from presses based at U.S. universities, 53 responded, for a completion rate of 60 percent. $^{15}$

Second, we sought the in-depth perspectives of three important constituencies - provosts and presidents, directors of university presses, and directors of academic libraries - by conducting interviews in person and via telephone with representatives of each group. We selected our interviewees for diversity: they included representatives of institutions that have presses of various sizes, and some that do not have a press. At each institution we visited, we attempted to consult with the librarian, the director of the university press (if there was one), and the provost or president of the university, or other senior university administrators (such as graduate school deans or VPs for administration or research) to whom publishing operations sometimes report. For the most part we targeted leaders that are reputed to be forward thinking and creative (as opposed to representative of their peer group), so our findings are skewed towards a bold view of how quickly the world is changing. In these meetings we followed a general discussion guide (see Appendix D), but we also sought to have a dialogue in order to explore certain topics in greater depth and bounce ideas back and forth. A list of our interviewees is included as Appendix A.

It is worth noting that we did not interview faculty specifically as part of this exercise. We have, however, gathered an extensive body of data about faculty needs and behavior through previous work at Ithaka. For example, we have conducted three surveys of faculty in 2000, 2003, and 2006, which provided us with an understanding of how faculty usage of online resources has changed over time. ${ }^{16}$ We also conducted studies of scholarly communications practices in economics, history and biological sciences, each of which involved in-depth interviews with 15-20 faculty and graduate students. ${ }^{17}$ This past work has helped to inform our current views and hypotheses about the perspectives on publishing from scholars themselves.

Through our research activities we refined our starting hypotheses and developed new ones. Some of what we heard was unexpected to us, particularly the strength of some of the criticisms we heard about university presses, and the optimism expressed by academic libraries. In this paper we have aimed to provide a balanced report of what we heard, taking into account the extent to which our interviewees are representative of their functional peer groups. We do not wish to portray too gloomy a picture of the current state of university publishing, as we see many promising activities and excellent people engaged in this enterprise, but we also do not wish to downplay the more critical opinions we heard. Our aim is to provide an accurate diagnosis of what we see happening and to focus on the future: what should happen to

\footnotetext{
${ }^{15}$ To provide a sense of how these break down, 2 responding presses had revenues $>\$ 25$ million, 6 between 8-\$25 million, 16 between \$3-8 million, and 29 had revenues below \$3 million.

${ }^{16}$ See http://www.ithaka.org/research/faculty-studies/ for more information.

${ }^{17}$ While these studies are not currently publicly available, many of the lessons from this work are reflected in our thinking and conclusions in this paper.
} 
U N I V E R S I T Y P U B L IS H I N G I N A D I G I T A L A G E

address the publishing needs of faculty and students in the next five to ten years, and how the various constituents involved can create new structures and programs to meet those needs. 


\section{I . W H A T T TH E W O R L D L O O K S L I K E T O D A Y} A N D W H E R E I T I S H E A D E D

\section{A. The future of scholarly communications}

In this section we will provide a description of what the world of university publishing looks like today and where it appears to be heading. These views are largely drawn from our research and have been refined through feedback from a group of people asked to comment on initial drafts of this report. We try to summarize consensus views and recount noteworthy statements from our interviewees. We will also try to note cases where the views of our interviewees may not be representative of their peer group.

\section{Everything must be electronic}

Most of our interviewees were in agreement that information technology is profoundly transforming the ways in which universities disseminate their primary outputs, the types of content that are produced and shared, and the ways scholars consume research. As one director of a major library put it, "The tipping point has tipped to electronic. Everything needs to be online.” While this viewpoint is more strongly held by enthusiasts of information technology, it strikes us as a fair representation of the direction in which scholars, especially the younger generation, are headed. Content may still be used in different formats (many scholars find articles online and then print them locally) and on different devices (iPods, handheld readers), but increasingly it must be at least discoverable online to reach readers.

\section{Scholars will rely on deeply integrated electronic research/publishing environments} Looking to the future, scholars will increasingly seek to work in electronic research and publishing environments. These environments will provide them with the tools and resources for conducting research, collaborating with peers, sharing working papers, publishing conference proceedings, manipulating data sets, etc. Several interviewees noted that continuous publishing (also described in this paper as “dynamic content”) will enable scholars to continually update or correct "published” works, requiring new ways of thinking about and documenting versions and editions. ${ }^{18}$ It seems likely that much of this activity will be organized around disciplines, as suggested by enterprises such as arXiv in physics and RePec in economics. AnthroSource, developed by the American Anthropological Society with help from the University of California Press, is an attempt to create such an environment for anthropologists. We heard descriptions of elements of a future in which discipline-based portals offer scholars a range of electronic tools for data manipulation, content creation, and social networking, and a layered, interlinked platform containing a wide variety of content - from fee-based to free - including:

- traditional peer-reviewed published material (monographs, journals, reference works)

- multimedia projects

- raw primary source material (data sets, gray literature)

- primary source material designed with the interpretative and conceptual insights of scholars

- conference proceedings and other non-peer-reviewed output from universities

- pre-print workspaces that allow scholars to collaborate in advance of publication (working paper repositories)

- post-print conversation spaces that encourage scholarly communication (message boards, author sites, newsletters, blogs )

- dissertation repositories

- subject matter repositories

\footnotetext{
${ }^{18}$ Online reference resources such as the Stanford Encyclopedia of Philosophy have developed new procedures to enable stable citations and reference linking. See http://plato.stanford.edu/.
} 
Faculty have a strong desire for greater support in creating, validating and publishing their digital research output. University administrators need to think about how best to provide these services. They also need to think about how new forms of scholarship should be recognized and rewarded.

\section{Multimedia and multi-format delivery will become increasingly important}

We heard from a number of sources that scholars increasingly wish to incorporate audio and video materials in their research and teaching. In the future, scholarship published online will be enhanced with embedded graphics, audio and video materials, all linked with datasets and applications needed to manipulate data, etc. Imagine, for example, an anthropological study of pre-literate societies with embedded audio clips of oral interviews, or a journal article in film studies that includes video clips, or a work of history that includes audio versions of speeches, or a work of science that includes complex animations. Building the infrastructure to support multimedia content - the storage capacity and connectivity, tools for creating and accessing content, archiving multimedia assets, etc. - requires substantial capital investment. Similarly, a new generation of devices for consuming information will require that content be organized and presented in new ways.

The librarians consulted for this study were more enthusiastic about the potential of multimedia than other constituents. Provosts tended to be more conservative, associating "publishing” primarily with books and journals. It is worth noting that in a previous study of scholarly communication in history, we heard about several projects that have attempted to pursue this kind of vision with mixed success. For example, the ACLS History e-Book has been very successful at making electronic versions of core literature available, but less so in propagating new multimedia based formats. Similarly, the Gutenberg-e prize works were expensive and time-consuming to produce, and we have heard that these resources did not seem justified by their level of impact. This is not atypical for new technologies, as expectations for new applications often race ahead of behavioral changes. This is especially true in academia, which has a strong conservative streak. However, when we look at the ways that younger scholars and undergraduates operate online, we have no doubt that this vision will eventually come to pass.

\section{New forms of content will enable new economic models}

Traditional economic models of publishing are being disrupted by the Web, and new ones are emerging. Universities must revisit traditional views about how publishing is supported. Creating and disseminating dynamic content imposes some new costs on the system (software tools, storage, bandwidth) and reduces others (printing, physical storage, distribution). The actors in the new system may be different, especially for user-generated content. Information technology provides an opportunity for universities to restructure the scholarly communications system in ways that better reflect the community's values than the current system. This means having more influence over what gets published and how it is accessed and priced.

Publishing increasingly occurs across a continuum, with subscription-based, highly controlled content at one end and free open access content at the other. One administrator described a future with a spectrum from open, contributed content such as self-published, non peer-reviewed papers, conference proceedings etc. at one end, and edited, peer-reviewed journals, reference works, monographs, and new types of products enabled by the electronic environment at the other. There are cases where charging for access to content provides a useful model for sustaining certain resources and imposing discipline on the way investment resources are allocated. Likewise, there are also cases where universities will decide that it is 
consistent with their mission to provide content for free. Interviewees generally were not opposed to the notion of fee-based content, but a couple honed in on the notion of "fair pricing" as an important goal.

\section{B. Some libraries are striving to support these needs}

Among the librarians consulted for this study, we perceived a high level of energy and excitement about the "reinvention" of librarians' mission, making them more relevant and reinvigorated with a better understanding of their purpose and potential. This new mission involves a combination of:

- serving faculty research, teaching, and publishing agendas (building collections to support faculty research, providing tools, delivering everything they want to the desktop, developing technological expertise for their publishing projects, supporting the infrastructure for their courses);

- serving student study needs (creating new physical and virtual spaces for private and group work, helping students to become more efficient researchers);

- preservation (e.g. launching institutional repositories, as $87 \%$ of librarians in a recent Ithaka survey cited archiving and preservation of an institution's intellectual assets as a "very important" reason for having IRs ${ }^{19}$ );

- making scholarship available to the wider world (open access, digitizing special collections); and

- lowering the cost of scholarship (alternative publishing, legal experts to negotiate contracts).

One librarian said, "What you are witnessing today is the dynamic reinvention of the role of the library.

We went through a period where we worried that Google was going to put us out of business, and that the ubiquity of electronic resources would make our physical spaces less relevant. We watched our budgets being eaten up by the high cost of journals. But we've responded to these threats. We're fighting back. Libraries are now one of the most vital centers on campus. We're working to bring down the cost of information through initiatives such as open access and institutional repositories. We're increasingly getting involved with publishing." It should be noted that the sentiments of this statement do not apply to all libraries, and overstate the degree of success librarians have had in actually reducing costs through these initiatives. Also, while some of the librarians we talked to felt energized by all the opportunities afforded by information technology, others felt disenfranchised by the quickly changing digital landscape and worry that they will be supplanted by Google and relegated to little more than computer clusters.

Librarians with whom we spoke view their role with respect to scholarly communications as making sure they have robust online collections; creating research environments (e.g. collections and tools) that will help faculty and graduate students create the scholarship of the future; finding ways for the institution to take back more control and lower the cost of scholarship; and developing infrastructure and tools to enable multimedia. Increasingly, these roles bleed into what might be considered "publishing”. The role of librarians has always been, in part, to provide services to the local community that help them find information, or learn how to find information. With the advent of online resources, librarians developed skills in accessing and managing online data. It therefore is not surprising that many faculty members and students have turned to librarians for assistance in producing electronic resources. One librarian stated that "Faculty are coming to us to help them with their electronic publishing needs. We have the technical expertise on staff to help them push the envelope of new forms of scholarship." Another stated that "The library's task is to create the online research environments of the future - collections, accessibility, tools." Some librarians see themselves as pioneers and innovators in bringing scholarship online.

\footnotetext{
${ }^{19}$ Based on a survey of librarians conducted by Ithaka in the fall of 2006. See http://www.ithaka.org/research/librarian-study/ for more information on the survey.
} 
Because their budgets are relatively large (certainly compared to those of presses), libraries can often find room for experimentation. We heard a number of press directors opine that libraries are receiving large sums to launch institutional repositories and pursue other online initiatives, many of which have unproven value, while presses fight to keep their meager subsidies and have very limited access to investment funds for anything new. These perceptions are probably overstated, as many librarians feel that their budgets are also increasingly squeezed, but it illuminates the need for better understanding of publishing resource allocation between presses and libraries.

At the same time, several librarians conceded to us that they are good at organizing information but lack expertise in choosing or prioritizing what merits publication. Libraries provide tools and infrastructure to support new forms of informal publishing, but these tend to be inward focused (toward the home institution) rather than externally focused (towards the best scholarship in a given discipline), limiting their appeal to users. As a result, institutional repositories so far tend to look like "attics" (and often fairly empty ones), with random assortments of content of questionable importance. Attempts by librarians to create new online resources by digitizing special collections often fail to take into consideration the potential market for those materials or what is really needed. One librarian remarked that putting these resources online for free is much easier than charging for them, because then they would actually have to consider who the user base would be. Another talked about the challenge of maintaining library-digitized material once launch funding has run out. Likewise, librarians have limited skills and experience in marketing content to build awareness and usage. Institutional repositories have struggled in this respect as well. And no library publishing alternative can begin to compete with the prestige that a university press imprint confers on scholarship, nor replace the credentialing power that presses have developed over decades. These are all areas in which the librarians consulted believe that university presses can play an important and ongoing role.

\section{Many university presses have struggled to adapt to changing needs}

University presses historically acted as an important arm for publishing the research outputs of universities, both on their own campuses and on behalf of the entire scholarly community. This is most true of the humanities and social science disciplines. As the printed products of presses have experienced waning demand, as more library acquisition resources are expended on scientific journal literature distributed by large commercial publishers, and as libraries have begun playing a greater role in providing tools and infrastructure for disseminating new forms of scholarship, presses (especially smaller ones and those with only monograph programs) are facing a growing set of more formidable challenges. In this section we would like to explore the mission of university presses, their relationships to their host institutions, some of the challenges that have led them into their current predicament, and how they are responding. We would also like to focus on the transition of press content to the electronic medium, as this transition offers a window of opportunity to revitalize monographs, the core product of many presses.

It is important to note that there is a great deal of diversity among the university presses, so it is somewhat dangerous to make broad generalizations. Some presses have taken a much more active approach to revitalizing their role in the university than others. Those with journal programs tend to be more financially sound than those without. Large presses generally are faring better than small presses. That said, we will attempt to highlight some of the common traits, challenges and opportunities faced by presses, or at least certain segments of presses. We would like to explore two topics in depth: 1) relationship to university mission, and 2) how presses are making the transition to electronic formats and media. 


\section{Many presses have become disconnected from their own university's mission}

Press directors broadly agree that they must balance competing goals in their mission to serve the global academic community of authors and readers. Two challenges stand out. First, presses must find the best way to be good stewards of scholarship on behalf of the community (public good), while also creating value for their parent institution (private good). The second challenge calls for presses to advance their businesses through commercial discipline - they are one of the few parts of the university expected to behave like a business with cost recovery and long-term sustainability strategies built from the marketplace - while at the same time serving the not-for-profit demands of the community ("give us state of the art credentialing, editing, production, dissemination, and author royalties, but keep your prices low").

Over time, and in pursuit of the largest public service to the global academic community, presses have tended to grow disconnected from the administrations at their host institutions. This is due in part to the fact that they publish works from scholars mostly off their own campuses. The highest percentage of local authors published by a university press that we came across was 25-30 percent, but most were below 10 percent. Faculty members generally seek to publish their books with the most prestigious press in their field, regardless of affiliation. They actually often prefer to publish their books at presses other than their own, because institutional distance avoids any suggestion of favoritism and provides external validation.

The result is that the university press publishing is viewed, in the words of a provost, as "a general service function for higher education...each university that has a press is providing a platform for the community”. The 88 U.S. universities that operate presses do so on behalf of the entire system, and the 72 percent of universities surveyed that allow their presses to operate at a deficit do so at least partly for the common good. ${ }^{20}$

Not surprisingly, provosts put limited resources and attention towards what they perceive to be a service to the broader community. Presses are a small budget item competing for attention with large cost centers that are more directly connected with the university's local interests. One provost confessed that "the press has always been the next item on the list”. Many administrations have cut subsidies, moved press offices off campus, and not included presses in strategic planning for new initiatives that could have a publishing component. Provosts rarely meet with press directors - in some cases only a few times a year even at institutions where the press director reports directly to the provost. One press director commented that, in his long tenure at one of the larger presses, he had never been given the opportunity to set goals with his superiors in the university administration, or participate in the university's processes for setting priorities.

A couple provosts felt that presses are pursuing appropriate strategies. One said he was very pleased with the way the press at his university is performing, and that it is fulfilling its mission of publishing important scholarship and defending the monograph. Another provost endorsed the press' focus on publishing works from external faculty, saying "I would hate to think [that the press is] peculiarly for your own faculty." A third cautioned against changing too quickly, saying he "wants to make sure we don’t destroy something wonderful.”

\footnotetext{
${ }^{20}$ Based on our survey of directors of American university presses. Of course, most of the cost of university press publishing is shared by the institutions and individuals that benefit from it, by buying books.
} 
And while most provosts acknowledged flaws in the current credentialing system, they found it difficult to envision or embrace a clear digital alternative that meets their needs in making hiring, promotion and tenure decisions. A provost told us "There will be an enduring value to print. Books will exist for decades to come. Presses can afford to be conservative because of this." ${ }^{21}$ Another stated that "[There is] a slavish commitment to the [printed] book in the humanities" and "scholars are not pounding on the presses to make their scholarship available in electronic form.” (A recent Ithaka survey of faculty corroborated this view; it found that only about $25 \%$ expect eBooks to become very/extremely important to their research and teaching in the next five years ${ }^{22}$ ). One provost opined, “Am I supposed to give someone tenure based on what they've put on a blog?”

Even those provosts we consulted who are supportive of their presses worry about what may happen to their press after they retire. One provost of a university with a small press said, "the ax could fall on [the press] when I leave.” Another top administrator told us "I'm the only one defending the press. Who knows what will happen to the press when I retire? Then they'll have to deal with reality.” He went on to say that his likely successor has no interest in scholarly publishing or in the press. Another provost we consulted said, "the business model that sustained university presses since World War II is falling apart. Our structure has not rewarded innovation.”

A couple provosts were excited about the potential for presses to be a key component of a new scholarly communications system, and that they might serve as the glue across campuses. Others, however, were skeptical that presses could be revitalized by digital technologies. This is in part because presses seem too inextricably linked with the traditional systems of monograph publishing on which they depend for tenure and credentialing decisions, and in part because many presses have not demonstrated an ability to change with the times, much less to act as leaders in pioneering a new system of scholarly communications. One provost said he is "not sure the press needs to be at the table" of scholarly innovation. They suggested that presses should simply continue doing what they have done in the past - indeed, some said they should be defensive bulwarks against the pressures of change.

The librarians with whom we spoke tended to be more extreme in expressing their views on presses than were the administrators. The general view we heard from librarians regarding presses is that time is running out; they are anachronisms - far behind in their understanding of what scholars need. They have not kept pace with scholarly communication because they have failed to respond to the challenge of electronic publishing. Finally, they are too small to matter.

Some quotes illustrate how strongly this view is held. One librarian commented that the "Life expectancy of university presses is relatively short. The mission and potential of the university press is not an urgent question for most administrations. It is not tied to what goes on here on campus. The problem is, the presses are not totally broken, but by the time it is clear that they are broken, it will be too late.” Another argued that "Most of the presses will die. They've clung to the past; they're too traditional; they're too afraid of big competitors." A third stated that "Presses have become distant from their institutions. In many ways, they wanted this, understandably, so as not to become the 'vanity publisher' of their universities. But the result is that they have become marginalized.... If presses don't begin to reinvent

\footnotetext{
${ }^{21}$ One president we consulted pointed out that very few presidents and provosts of AAU (very large research) universities were drawn from the humanities. And yet we did not sense that senior administrators from non-humanities background were any less sensitive to the importance of their presses and the challenges in monograph publishing than those who came from the humanities.

${ }^{22}$ From an Ithaka survey of faculty conducted in the fall of 2006. See http://www.ithaka.org/research/faculty-studies/ for more information.
} 
themselves, and think disruptively, they won’t be around. There needs to be a catalytic force for innovation or they won't survive."

The cost recovery model of presses has become one major constraint. One librarian commented that "presses are trapped in the cage of 'What can I do to make money?' and they have so few resources to climb out of that cage. They are like hamsters scrabbling along and pushing their little wheels.” They are caught in a "catch 22", where they lack room for experimentation because their budgets are so tight, and thus cannot inspire interest in their administrators to fund anything new.

We also heard distinct notes of support and encouragement to develop collaborative solutions. One librarian perhaps summed this up best: "Presses have a huge potential but they are not taking advantage of that potential, and there is a narrow window to do something about it. Our faculty survey revealed how much respectability the university press imprint still carries, but how can presses 'cash in on' that prestige in the face of growing competition?” When asked what he would do if he ran a university press, he replied, "I would align the press with the strengths of the university, and I would work with all parts of the campus to create a research and dissemination platform for work that goes on here.”

Press directors are mostly aware of the problems described by provosts and librarians, but have struggled to formulate a new plan or lack the resources to implement one. They feel they are held to a different standard than all the cost centers on campus, that they are essentially penalized for pursuing a cost recovery model, which then becomes the basis for evaluating their performance. When they perform well (in financial terms), they are "rewarded" by having subsidies cut. When they run too large a deficit they are threatened with closure. Some have responded to these expectations by elevating cost-recovery in their selection criteria, publishing more trade books and shying away from the least marketable fields. This approach may improve their financial situation, while at the same time undermining the case for subsidies. Press directors acknowledge that they have not participated actively enough in the academic life of their campus, nor have they effectively demonstrated their worth to faculty and administrators. As a director said, "We don’t do a good job of telling our universities why we are important to them.” One director spoke of a "a feeling of divorce" from the university leadership, expressing what seems to be a common feeling among press leaders.

We also came across a number of press directors who are actively taking steps to reconnect with the academic leaders on campus, trying to align their publishing programs with the strengths of their parent institution, renewing their efforts to put content online, and experimenting with new products. We describe these efforts below in section 1. Even those that have not made as much progress showed excitement about pursuing new opportunities when prompted by our conversations. The presses still have much to offer, as we discuss in the section 3 below.

\section{Many presses are struggling to make the transition to the electronic medium.}

Journals were the first major form of scholarly publication to go online. Some university presses have made this transition: according to our survey, among the 18 presses that publish journals, 14 (78 percent) said that they publish journals electronically, and of these most said 100 percent of their titles are available online. However, some presses have struggled to keep journals when they went online, and many journals have moved to commercial platforms (see our discussion of this transition on page 11). Furthermore, although the electronic medium offers clear benefits for reference works (content can be continuously updated and searching is much more convenient), presses have put little of their subject- 
specific reference content online. ${ }^{23}$ Looking to the future, there is a risk that other forms of content (books, new formats) will follow a similar pattern.

The search for models to distribute books online has proven difficult. As with many new technologies, early distribution models were not well suited to the needs of users, and, for the content providers, revenue from these sources remained minimal. ${ }^{24}$ Many university presses jumped early on at the opportunity to produce eBooks but were disappointed by the results. According to our survey, 73 percent of presses said they publish at least some books electronically (primarily through licensing to aggregators such as NetLibrary and ebrary), but the average revenue contribution from these products is just over onethird of 1 percent. ${ }^{25}$ Consequently, presses for the most part retrenched to what they have always done produce print monographs - even as users have become ever more reliant on electronic resources. The director of a major library noted that "Scholars work piecemeal and they want everything online. Presses are still working almost exclusively cover to cover.”

In the past year there has been a resurgence of interest in electronic books, led by large and commercial presses and online retailers such as Amazon. Publishers have started to show through their actions that this format is important to them, and they want to control their assets. Oxford Scholarship Online (OSO) has demonstrated to the university press community that a large aggregation of quality monograph content, optimized for online scholarly use, generates strong usage and holds sufficient appeal to librarians to support a profitable business. Two of the largest commercial scholarly publishers, Springer and Elsevier, announced major electronic book products. Springer's product provides access to 15,000 electronic books via its SpringerLink platform (with 3,000 added per year), ${ }^{26}$ while Elsevier's product is anticipated to include 4,000 titles when it launches in $2007 .{ }^{27}$ Their strategy is to "journalize" the selling of monographs by licensing campus access for an annual fee, or selling perpetual access directly to libraries. Commercial trade publishers such as Random House and HarperCollins are developing full service solutions for controlling their content electronically (i.e. from producing digital content to selling it directly). Having invested in significant technological infrastructure, they are now beginning to offer services to prestigious smaller publishers, including some of the more trade-minded university presses. The goal of these commercial publishers appears to be to gain more control of their assets, amortize their technology development costs, and increase the value of their content by aggregating it with quality content from other publishers.

Leveraging its investment in digitizing books for its Search-inside-the-book program, Amazon has launched a new product called Amazon Upgrade, which allows customers who purchase a print copy of a book to access the electronic version for an extra fee. This provides immediate electronic access to the book's content to the reader and incremental revenues to the publisher (and to Amazon). ${ }^{28}$ Amazon also

\footnotetext{
${ }^{23} 82$ percent of survey respondents reported that they do not publish any reference works electronically.

${ }^{24}$ See John B. Thompson, Books in the Digital Age: The Transformation of Academic and Higher Education Publishing in Britain and the United States, (Cambridge [UK]: Polity Press, 2005).

${ }^{25}$ To be sure, presses have been taking up digital production technologies to support their print monographs programs. 83 percent of presses say that they are using print on demand or short run digital printing technology to improve their inventory management and reduce costs. See the Ithaka report, "The Evolving Environment for Scholarly Electronic Monographs,” available online at http://www.ithaka.org/about-ithaka/publications, accessed April 2007. Among those presses that do publish monographs online, the median number of monographs available online was 224, and the mean was 496, according to our survey of press directors.

${ }^{26}$ See "More than 15,000 eBooks," available online at: http://www.springer.com/west/home/e-content/ebooks?SGWID=4-40791-0-0$\underline{0}$, accessed April 2007.

${ }^{27}$ See "ScienceDirect Will Launch 4,000 Books Online in 2007," available online at:

http://info.sciencedirect.com/content/books/2007/, accessed February 2007.

${ }^{28}$ See http://www.amazon.com/gp/help/customer/display.html?nodeId=162540011, accessed April 2007.
} 
sells electronic books via its subsidiary Mobipocket. Google, too, has been mulling business models for selling access to the book content that publishers have provided for inclusion in Google Book Search. ${ }^{29}$

Without the resources to invest in their own solutions, small publishers are nevertheless trying to find the optimum way to control their assets, develop a customer base, and maximize both revenues and dissemination of their content. A number of the presses consulted for this study have put renewed energy into developing strategies for creating, storing, distributing, and monetizing electronic content. ${ }^{30} \mathrm{New}$ production workflows to create electronic editions are growing up within university presses. New digitization, storage, and reversioning services such as Bibliovault and codeMantra have been launched to support the development and maintenance of this electronic content. Experimentation with large commercial e-book aggregators such as Amazon, Google, and ebrary (now offering, in addition to its licensing model, a platform for publishers to sell directly to libraries) is growing across the university press sector. And of course the opportunities for licensing e-content continue to abound (e.g. Questia, Books 24/7, etc.).These represent big choices and tough decisions for publishers without the resources to invest in the preferred end-to-end solutions of their larger competitors. For smaller university presses, and for those that do not publish journals, these decisions are particularly challenging because they involve so much new terrain, and because there is so little time and capacity within the press to develop the complex skills that enable them to navigate that terrain. But, it must be noted, those skill sets and decisions are also a challenge to the bigger university presses - a worry that we heard throughout our interviews. A director of a medium/large press said that for several years he had preferred to sit back and watch commercial publishers experiment with eBook models, but he is now feeling more pressure from libraries and from his Board to take action.

One could make an argument for small presses to let commercial publishers risk their capital in experimenting with new technologies and business models until the market matures, especially since most of the content at stake (humanities monographs) has limited commercial appeal. We are concerned, however, that the commercial publishers are pursuing different objectives that may not lead to desirable outcomes for universities; for example, universities have an interest in exploring ways to use new technologies to reduce costs of publishing so that the monograph continues to be a viable format for new authors and those in less mainstream fields. Commercial publishers are focused instead on maximizing scale. Moreover, the "wait-and-see" approach allows large commercial firms a critical head start in building large scale platforms with the ability to attract and control scholarly content. It would not be in the community's interests to see electronic monographs and new electronic formats follow the same path as journals.

\section{University presses can continue to play a critical role in publishing}

\section{Presses are beginning to change, but most still lack critical resources and capabilities}

Most of the presses we consulted are attuned to the problems described by provosts and librarians, and are trying to re-establish and reinforce their value to their universities. Our survey found that almost all presses aspire to align their publishing programs at least somewhat with the strengths of their parent

\footnotetext{
${ }^{29}$ While Google has not made any official announcements of such a product, a Google Book Search representative discussed the company's plans at a presentation at the 2006 AAUP conference.

${ }^{30} 23$ percent of university press directors reported that they plan to newly deploy electronic monograph publishing in the next 1-2 years, 50 percent plan to digitize out of print books, and 28 percent plan to invest in digital repositories, which are also a potential step toward electronic monograph publishing.
} 
universities, with the larger presses more in favor of this strategy and the smaller ones somewhat less. ${ }^{31}$ By reflecting the parent's academic strengths, the press can draw on the expertise of faculty and departments across the organization, develop scale and specialization that comes with tighter focus, and enhance the brand of the school and extend awareness of its influence in a particular academic field. Many in the university press world attribute this focused strategy to Frank Urbanowski, the long-time director of MIT Press. He is credited with redirecting MIT's editorial program away from a large number of subject areas with shallow representation and toward a highly focused set of disciplines that mostly matched MIT's academic contours. A press leader argued that university presses should move more toward the local interests: "university presses have a broad mission - to be stewards of scholarship [and serve the] public good. They used to have a specific mission - to act as the showcase for the research of their particular university [and serve the] institutional good. University presses have drifted away from this second mission and we need to get back to it.”

The director of a large press said, "The real priority is to align the press with the research centers of the university and to raise the profile of university research outside the university community. In this way we can return to the founding mission of the university press - to disseminate the scholarship of the university and strengthen the university's reputation.” A press director at a small press told us, "We have a lot of interesting initiatives on campus such as a lab for interdisciplinary research in a variety of disciplines including nanotechnology, entrepreneurship, bioscience, and the environment, and we are trying to figure out what publishing could come from these." Another director said, "We need to reflect better our university’s own intellectual ambition.”

The question often arises of how presses can align themselves more closely with their host institutions' without becoming "vanity publishers." This will be a difficult challenge to overcome as there is considerable concern and inertia pertaining to this question. Clearly they should strive to publish the best work in the fields in which they have programs. One way is by aligning their programs with the strengths of their universities, as MIT Press has done, so that these goals are compatible. Another is by using local faculty as editors and reviewers, offering them an opportunity to help build publishing centers of excellence in their subject areas. Another is by offering publishing services (possibly in collaboration with libraries and/or academic computing) to departments and research centers that wish to disseminate their intellectual output in new formats. For example, presses could help faculty and students develop program-related websites, preprint sites, or other complements to traditional peer-reviewed publications.

We found numerous examples of presses that are actively redesigning their editorial programs to reflect local academic priorities. A medium-sized press is planning to start new branded journals in public policy and veterinary science, areas that the press has not published in before but which are strengths of the parent institution. A large press is starting a new list in regional environmental studies—again, a leading program at its university. It is also defining templates, standards and procedures for faculty-initiated digital projects of various types, including critical editions, encyclopedias and other reference materials, interactive databases, and multimedia works. Another press director joined his president on a trip to China to consider publishing opportunities together.

\footnotetext{
${ }^{31}$ Half of very large and large presses said they aspire to align very closely with their university's strengths, whereas only one quarter (24 percent and 28 percent) of small and medium sized presses aspire to very close alignment. 9 percent of small presses and 11 percent of medium sized presses say they align "not at all” with their parent university; no large or very large presses reported this. The discrepancy between the larger presses and the smaller ones may be partially explained by the fact that it is easier for a larger press, with more publications and more series, to align itself with a university's priorities.
} 
Likewise, most press directors understand the need to shift to electronic publishing. Several spoke of developing "new infrastructure to support different kinds of publishing". "The future of university presses is electronic," said the director of a medium-sized press. "We need to think of new delivery models for university press content that will be content-deep and navigation-rich.” Some are considering what it will mean to remake the scholarly monograph in an online environment, enabling readers to access layers of documentary evidence and supplementary analysis. For example, OSO has already demonstrated the value of converting footnotes to web-enabled reference links. ${ }^{32}$ In the Gutenberg-e project, Columbia University Press and the American Historical Association explored the possibility of linking electronic monographs to secondary scholarship and underlying primary sources. ${ }^{33}$ Another more recent example of the kind of innovative scholarly publishing that technology could enable is a 2006 book called Gamer Theory by the media and cultural studies scholar McKenzie Wark. In partnership with the Institute for the Future of the Book, Prof. Wark has published a "networked" book draft that allows readers to add bloglike comments in virtual marginalia, to which Prof. Wark occasionally responds. He has integrated some of the critiques and commentary on the site into the print version of the book, published by Harvard University Press. ${ }^{34}$ Far more than just a digital copy of the text, the online book became the meeting-site of an ongoing scholarly conversation that both precedes and follows the official publication of the print edition. These examples are by no means proven models (in fact, Gutenberg-e highlighted some of the challenges of reinventing the monograph), but they are illustrative efforts at experimentation.

University presses have begun to act on their stated intentions. "We are moving at last, to the digital warehouse route," said one director, who was planning a digital warehouse (i.e. a place to store electronic versions and export them to reselling platforms) as a preliminary step toward electronic publishing. Another director sketched a plan to “journalize” his press's annual monograph publications by licensing electronic access to libraries via subscription, much as Springer has done though its eBooks collections on its SpringerLink platform. Yale University Press and Columbia University Press have recently announced agreements with ebrary for technology platform hosting that will allow them to market electronic versions of their monographs. ${ }^{35}$

There is once again widespread hope that electronic dissemination, done effectively, could revitalize the monograph. Press directors spoke of the desire to deliver scholarly content in the format that researchers are looking for so that it remains part of the research and teaching "workflow" ${ }^{36}$ Putting monographs in electronic form can increase accessibility and enable publishers to market content in different forms, such as leasing (the model Google Book Search said it was contemplating ${ }^{37}$ ), or selling access to chapters or chunks of text in addition to full volumes. Electronic monograph products could also be sold in price tiers that segment the market in a way that is not possible with print. With the low marginal costs of delivering access to electronic resources, publishers may be able to reach new customers or sell different access

\footnotetext{
${ }^{32}$ See OSO's online tutorial for an example of how this works. Available online at: http://www.oxfordscholarship.com/oso/public/tour/tour start.html, accessed April 2007.

${ }^{33}$ See http://www.gutenberg-e.org/aboutframe.html, accessed April 2007.

${ }^{34}$ The networked version of the book is available online at http://www.futureofthebook.org/gamertheory, accessed April 2007.

${ }^{35}$ See “ebrary Signs Blackwell Publishing, Yale University Press, and Columbia University Press,” February 26, 2007, available online at: http://www.ebrary.com/corp/newspdf/ebrary Blackwell Yale Columbia.pdf, accessed April 2007. The deal that these presses struck with ebrary contrasts with the earlier ebrary licensing model, which involved ebrary marketing and selling content. In this model, ebrary is a technology platform service provider to the presses.

${ }^{36}$ See Lorcan Dempsey's discussion of workflow in his blog entry "In the flow," available online at http://orweblog.oclc.org/archives/000688.html, accessed April 2007.

${ }^{37}$ AAUP conference, June 2006.
} 
options to different packages of content. ${ }^{38}$ Finally, in the long term electronic dissemination could reduce costs by enabling presses to reduce print costs, potentially eliminating print runs for niche-oriented books and offering these only via print-on-demand.

Not everyone is enthusiastic about these possibilities. Librarians may worry about extending the leasing model to monographs. Some publishers argue for the enduring worth of the sustained argument that the scholarly monograph represents. "The monograph program is the heart and soul of the press," said the director of a large press. "Books serve a different role than journals. They act as change agents, uniting disciplines and making bridges between subjects. They form the basis for a more general conversation and more galvanizing work.” The fear is that when scholarly books are "chunked" into smaller segments, the long argument form will disappear. We would argue that authors should continue to produce booklength arguments, but must accept that readers will not always read them end-to-end.

Moreover, earlier attempts to foray into eBooks have been disappointing. What will be different this time? One issue seems to be that making this transition in a truly meaningful way requires new capabilities and infrastructure, but presses still lack a number of elements required for this strategy to succeed. First, most still do not have a business model for electronic content (other than journals). Second, they lack the technological infrastructure and tools. Third, they need ways to conduct market research and strategies to market content online. Fourth, most lack the funds to build or buy this technological infrastructure or the skills to develop and implement an electronic marketing and distribution strategy. And because scholars and tenure committees in many fields, especially in the humanities, still resist electronic-only publication (which is not viewed as carrying the same prestige as print publication), presses will probably have to operate both print and electronic programs during a transitional period. But a renewed wave of investment from commercial publishers and reader manufacturers suggests that the time may now be more ripe for eBooks to take root, provided publishers can develop models that meet the needs of customers.

\section{Presses possess unique skills and assets}

The next question we explored with our interviewees is what university presses can bring to the table in a new world of university publishing. What are they good at, and will that continue to matter?

First and foremost, they excel at credentialing scholarship (bearing in mind that there are many fields and types of scholarship, in the humanities at least, which are not adequately covered by the existing arrangements). In a world where anyone can publish anything online, the role of identifying what is important and worth reading will remain critical. ${ }^{39}$ This is particularly true of book length arguments (monographs), but is also true for journal literature at a large minority of the presses. Presses have developed networks of reviewers and detailed processes, refined through years of experience, for the purpose of selecting content. ${ }^{40}$ While peer review has detractors, the fact that universities have relied

\footnotetext{
${ }^{38}$ It is worth noting that the lowest price bracket, for customers with least access to resources, may be free in a progressive pricing model. Free access to scholarly content in poor countries is most feasible online. In the journals world, open access for poor countries has been facilitated by such projects as HINARI, Agora, and OARE.

${ }^{39}$ It is worth noting that this credentialing service is most important when sales volume is so small that market criteria do not generally apply. The exceptions -- scholars whose star qualities are measured by their ability to publish with commercial presses -prove the rule.

${ }^{40}$ The credentialing process for monograph publications rests on at least three rounds of internal and external review - subject specialist editors at the presses choose the most promising works of scholarship from among those submitted, further refine their selection through rigorous peer review, and finally submit their choices (including the recommendations from the peer reviewers) to publishing boards often made up of faculty specialists at their parent institution who give final approval or rejection.
} 
upon this system for tenure and promotion decision for decades shows how strong and valuable it is. Presses also help to develop and improve scholarly work through the editorial process - organizing, refining, and sharpening arguments. This refinement is often based on a dialogue with the academic community (including peer reviewers) about what will make the work better, as well as the deep disciplinary knowledge and editorial skills that subject editors bring to the process. Through these processes they have developed brands associated with particular disciplines, which add value to the materials they publish (and, we would argue, their host institutions). Finally, many presses have strong regional publishing programs. These are particularly important for state universities, as they provide one bridge between the institution and the constituency it serves.

Presses also have experience evaluating demand for a product, setting a price, making production decisions accordingly, risking their capital to back up those decisions, and extracting from the marketplace enough revenue to sustain the publishing process. This experience is very relevant in an electronic world, where universities have invested vast amounts of money in creating online resources with little attention to how they will be used and by whom. Moreover, presses collectively possess deep knowledge about the size and characteristics of the markets for scholarship in nearly every discipline. This expertise is valuable in deciding how resources should be allocated to address the needs of these markets, whether for print or electronic resources.

Presses are also good at getting what they publish out to the market. They have relationships with wholesalers and retailers, including online ones such as Amazon, with the ability to reach a global audience. They have accumulated extensive experience in marketing - i.e. drawing attention to the books they publish through publicity and promotion, with special attention to increasing dissemination within the academic community. They also have a great deal of experience in managing their intellectual property to balance their goals of maximizing exposure while protecting copyright and their ability to sustain the enterprise.

It is worth reiterating that print will likely be a preferred technology for cover-to-cover reading for some time to come; many people will continue to derive pleasure from building a library of books that represent their interests. Traditional production skills, such as designing book jackets and managing distribution of print copies, will continue to be needed, even if this ceases to be the primary format in which content is read. Moreover, book marketing and distribution will continue to be very important to reaching markets that do not have access to large aggregated electronic offerings, which are chiefly targeted to academic libraries.

Publishing consultant Joseph Esposito provides a useful summary of what presses have to offer. He writes, "[Presses] make an investment in a book or journal, which then starts an entire process. It is a complex process; it took many decades to evolve, it takes years to learn, and it requires talent to master..." 41 This is an important reminder that the craft of publishing is not to be undervalued, and, if effectively abandoned by universities, would be extremely difficult to rebuild. Finally, presses have an existing base of networks and scholarship that offers enormous potential as a foundation for building a platform for disseminating research.

\footnotetext{
${ }^{41}$ Joseph J. Esposito, “The Wisdom of Oz: The Role of the University Press in Scholarly Communications,” (Ann Arbor, MI: Scholarly Publishing Office, University of Michigan, University Library vol. 10, no. 1, Winter 2007.) Available online at: http://hdl.handle.net/2027/spo.3336451.0010.103, accessed May 2007.
} 


\section{Collaborations between the press and library can create value}

There are natural partnerships between the press and library due to their complementary skills and assets (see Appendix B for a detailed description of the strengths and weaknesses of each). One librarian commented that "Press/library collaborations must be interactive, nimble, pushing the window on new forms of scholarship - creating new knowledge using technologies, and reinventing business models.” James Neal, university librarian at Columbia, offers a thoughtful perspective on this topic in his paper "Symbiosis or Alienation: Advancing the University Press/Research Library Relationship Through Electronic Scholarly Communication." ${ }^{42}$

Since the mid-1990s, there have been several noteworthy press/library collaborations aiming to develop infrastructure, products, tools, and services. Some examples include Project Muse at Johns Hopkins, Columbia International Affairs Online (CIAO), and the development of the Encyclopedia of North Carolina, which was published by the University of North Carolina Press with financial support and image licensing expertise from the UNC Library, and will likely be published online through a partnership of the press and the library. "We [the library and press] worked together well on a project [The Encyclopedia of North Carolina]. This was a good collaboration. I think what we need to do is figure out the line between building special collections ourselves with tools to make them more accessible, and creating editorial layers that filter that content. The former is what we do well. The latter is what presses do well. How can we work together to build on these mutual strengths?”

At Penn State, the press director now reports into the library, which has enabled several areas of collaboration through a newly established Office of Digital and Scholarly Publishing. A joint imprint of the press and the library, Metalmark Books, is republishing select books from the library's Pennsylvania history collections. A monograph series, Penn State Romance Studies, was launched via a collaboration between the press, library, and several academic departments. Both series are available free online (with the technology and hosting provided by the library) and for purchase in print (via print-on-demand). The library's digitization unit is converting PSU Press backlist titles, which will enable the press to move more of its titles into this "National Academies Press" model. ${ }^{43}$ And DPubS, an open-source electronic publishing platform, which was developed by the Cornell Library in partnership with the Pennsylvania State University Libraries and Press, is being updated to support the online publication of this and other material. $^{44}$

These collaborations face many difficulties, especially without high level support, and we came across a number that were less successful. These challenges stem from their disconnected leadership structures and the different cultures reflecting the ways each face their respective markets. One librarian stated, "We [presses and libraries] need to articulate a vision of a new system of scholarly communication, and then we need to do some experiments together that illustrate what is possible. In order to do this, we need to get the administration to pay attention. But most provosts do not have a scholarly communication agenda,

\footnotetext{
${ }^{42}$ See James Neal, "Symbiosis or Alienation: Advancing the University Press/Research Library Relationship Through Electronic Scholarly Communication.” Co-published simultaneously in the Journal of Library Administration (The Haworth Information Press, an imprint of The Haworth Press, Inc.) Vol. 35, No. 1/2, 2001, pp. 5-18; and: Libraries and Electronic Resources: New Partnerships, New Practices, New Perspectives (ed: Pamela L. Higgins) The Haworth Information Press, an imprint of The Haworth Press, Inc., 2001, pp. 5-18.

${ }^{43}$ Which is to say, offering a free version of page images online, with payment required for downloadable PDF files or print. For details on the National Academies Press model, see that press's FAQ, available online at http://www.nap.edu/about/about_pdf.html\#10, accessed May 2007.

${ }^{44}$ See “Current Projects,” available online at: http://www.libraries.psu.edu/digital/scholarlycomm/projects.html, accessed April 2007.
} 
U N I V E R S I T Y P U B L IS H I N G I N A D I G I T A L A G E

and if the university's attitude toward presses doesn't change, this collaborative vision among presses, and between presses and libraries, will never work." 


\section{I I . W H A T I S N E E D E D ?}

We have identified a set of actions to enable universities to play a more effective role in publishing. In this section we describe these actions and explain why they are important. This section will conclude with a brief summary of recommended steps that presidents, provosts, press directors and librarians could take on their campuses.

\section{Take a more active role in publishing}

There are at least five reasons why, collectively, universities should play an active role in publishing their own research outputs and should take part in a community-wide publishing system:

- As non-profit organizations, universities can make publishing decisions that balance the priorities of mission and profit. Because they are chartered to serve an academic mission, they aim to publish quality scholarship in markets where there may be little or no profit, but great research or educational impact.

- Determining what constitutes important scholarship is a critical aspect of what universities do. Credentialing provides a screening mechanism to let researchers know what is considered high quality and "important" among the infinite quantity of information available on the Web. It also informs critical decisions about tenure and promotion. New mechanisms may emerge that detach peer review from publishing, but there is considerable uncertainty as to when and how this might happen.

- Universities generally share the ultimate aim of maximizing the production of and access to high quality research, not profits or growth. As mission-centered publishers, universities can aim to charge fees that cover most of their costs and sustain the enterprise (albeit usually with some subsidy), and are affordable to as many libraries and consumers as possible. By not extracting profits, non-profit publishers may keep costs lower for the university system. Also, by returning the publishing revenues from university-sponsored research back to the university community, the university can use the fruits of its scholarly activity to invest in new publishing and research activities.

- Publishing operations situated within universities are uniquely positioned to leverage relationships with faculty and other assets. For example, editors located on campus have the opportunity to develop relationships with faculty, exposing them to new scholarship, whether it is being developed by local faculty themselves, by colleagues of local faculty, by departmental or cross-disciplinary research initiatives, or simply by a visiting academic presenting at a seminar. Out of these networks of scholars and authors can arise ideas and publishing opportunities. Co-locating presses and scholars enables scholarly publishing opportunity much as co-locating entrepreneurs and venture capitalists in Silicon Valley or Cambridge enables business innovation. Co-location within the same institution also allows for new business models such as joint ventures between content producers and publishing bodies that share the risks and rewards of the enterprise.

- Finally, university publishing operations can provide opportunities to extend the brand of the institution in the world. They can insure that major new programs and centers have global reach and impact. They signal an institution's commitment to research and scholarship in particular fields.

\section{Develop effective strategies for scholarly communications}


University leaders should take a strategic approach to the communication and dissemination of the knowledge they produce. This strategy should encompass what services are needed for scholars to create and disseminate content, how these services should be priced, what level of subsidization (if any) is appropriate, and where funding will come from. It should take a coherent position on issues pertaining to intellectual property. It should identify what activities should remain within the university and what should be outsourced to third parties (either commercial or not-for-profit). Finally, this vision should encompass peer review and its relationship to publishing. There should be consistency in the value placed on scholarly publishing (i.e. for tenure and promotion) and the resources devoted to making it possible.

Each institution's publishing strategy should reflect its core mission and circumstances - i.e. public versus private, large vs. small, research vs. teaching oriented. Some may feel that it is appropriate to be "fast followers"; others may wish to stake out more of a leadership role. Clearly the more a university's publishing portfolio evolves to mirror and extend that institution's reputation and intellectual strengths, the more ambitious administrators can be for their presses or other publishing entities. Provosts should develop strategies that enhance the reach and reputation of the institution through its publishing initiatives.

\section{Create organizational structures necessary to implement these strategies}

As a first step, administrators need to take inventory of the publishing-related activities currently taking place within their institutions. The decentralized organization of most universities breeds inefficient and sometimes opaque investment with a lot of "reinventing the wheel" in the area of publishing processes and services. To streamline these activities one must understand what products are produced, how they are created, what services are provided, who provides them, what funding is going into these activities and where it is being spent.

Next, administrators should identify the leadership, managerial, editorial, and technical skills required to carry out the strategy. The set of skills residing in presses, libraries, faculty, graduate students, and technology departments today is more a reflection of historical roles than future needs. New publishing strategies are likely to involve new configurations of activities on campus, best achieved (at least in the short run) through collaborations between various entities and people on campus, including libraries, presses, academic departments, and individual faculty. Combining skills and assets across these historically siloed units can enable more efficient and dynamic content creation and dissemination.

Administrators will need to be actively involved in encouraging more collaboration and providing the necessary incentives. Press and library directors, for their part, will need to learn to work together effectively. Some universities have tried to encourage this kind of collaboration by bringing the press inside the library, or creating centralized leadership for both bodies in the form of a chief information officer or head of academic information and services. We do not wish to advocate a specific configuration or reporting structure for these activities, but we would argue that these activities must be connected to program strengths of the university if they are to remain relevant to their campuses.

\section{Create models that scale / collaboration across universities}

We heard a pervasive view that one of the key factors behind the difficulties of university presses is scale. They lack the scale to compete effectively with commercial presses, to take risks with new business models, and even to have the bandwidth to think strategically and boldly about how to deal with the forces of change. One librarian commented: "What's missing is experiments at scale. Presses cannot 
remain competitive in the electronic environment given their small size. It is possible to imagine many little presses going out of business and a few large ones getting big enough and sophisticated enough to compete.”

Experiments must be conducted at sufficient scale to demonstrate their potential value. In the online environment, the value of certain resources rises exponentially with scale due to the network effect. To cite a common example of this phenomenon, fax machines became useful as they became pervasive. Or think of JSTOR, where the full value of the aggregation would not have been evident with a prototype of ten journals. By bringing together a critical mass of both content and users, platforms such as HighWire Press, Wiley InterScience, ScienceDirect, and Project Muse have been able to create great value for both sides. Most presses lack the technological infrastructure for creating, loading, storing, preserving, and distributing dynamic electronic content. They also lack the capacity to market this content effectively. No single U.S. university press (at least at their current size) can justify building this capacity internally, nor would this be desirable from a user perspective. Without a compelling framework for cross-institutional collaboration, most have been stuck in a mode where they can only put a limited amount of content online, and that content is not extensive enough to form a destination in itself, or to justify enhancement through deep linking or interoperability, or to spark excitement that would lead to substantial investment.

In the journals world, this problem of scale and the spread of investment over a large infrastructure has been overcome for not-for-profit publishers through the emergence of third party aggregators and service providers such as Project Muse, HighWire Press, and JSTOR. But there is still no clear model or end-toend not-for-profit solution for presses that enables them to produce and market eBooks effectively, much less new forms of dynamic content. A shared electronic publishing infrastructure across universities could allow them to save costs, create scale, leverage expertise, innovate, unite the resources of the university (e.g. libraries, presses, faculty, student body, IT), extend the brand of American higher education (and each particular university within that brand), create a blended interlinked environment of fee-based to free information, and provide a robust alternative to commercial competitors. This platform would be designed to meet the specific needs of scholars. It would also enable the community to speak with a more unified voice with powerful entities, and could coordinate the identification and adoption of standards for technology and metadata.

\section{Develop online publishing capacity}

There are six reasons why this is crucial:

1. This is where the scholars are going;

2. there is an opportunity for universities to have more of a voice in the dissemination of their output;

3. there is an opportunity to publish more low demand but significant scholarship by lowering costs of publication;

4. online publishing can generate new revenue streams by tapping into unmet demand for monograph content (following the experience of journal backfiles);

5. publishers can make current products more exciting and can make publishing spaces that are capable of delivering the scholarly products of the future; and

6. there is an opportunity to increase access to scholarship through new pricing models.

Presses and libraries cannot do everything at once, but they should immediately develop a plan to move forthcoming lists online (much as journals developed a transitional print plus electronic model). This plan 
should envision ways for material conceived for print publication to become more accessible and newly relevant to scholars in electronic form. Presses should also develop plans to bring their backlists online (much as JSTOR has reinvigorated the historical journal literature), although this will take time and a sizable amount of capital.

Looking ahead, presses and libraries should work together to build publishing environments and develop skill sets that enable the creation and dissemination of innovative types of scholarly products and tools now beginning to breed in the electronic environment. These new virtual laboratories - created on campus and built together by libraries, presses, and faculty - can assemble and interlink a variety of content types, from traditional peer-reviewed formats such as monographs, journals, and reference works, to conference proceedings, newsletters, wikis, subject matter repositories, preprints, interdisciplinary centers, large primary source collections, gray literature, datafiles, multimedia products, and other new and hybrid formats.

\section{Invest capital strategically}

Universities have always directed portions of their budgets to publishing activities, whether through subsidies to their own presses, underwriting faculty publications, support of on-campus journals, digitization of library collections, or a variety of other initiatives. In allocating funds to various enterprises on campus, administrators should do so with a strategic vision for how publishing-related activities fit together. In the recent past, libraries have been able to find room in their budgets to launch institutional repositories and to digitize local collections. We heard a concern by many, including librarians, that this money has not all been well spent, as institutional repositories mostly have attracted limited content of uncertain value ("the attic"). Most presses, however, have such small and constrained budgets that there is no room for experimentation, let alone for making the kinds of transformative investments that are needed to reinvigorate existing programs or launch new ones. ${ }^{45}$ Coordinating spending would enable the money to be used more effectively.

The transition from print to electronic scholarship requires investment capital in order to develop new infrastructure, build new capabilities, and repurpose existing assets (whose value can be enhanced considerably by being put online). Funding is required to link resources together and maximize their value to scholars. Funding is needed to create the tools and infrastructure needed to support the kinds of research and collaboration environments described above. Over time, initial funding should lead to cost savings through greater efficiency, economies of scale, less reinventing of the wheel, more transparent understanding of how money is being used, and through recapturing some of the publishing space from vendors with high profit margins. One would also expect to see higher productivity among researchers, though this benefit may not be translated into financial gain.

Developing a compelling strategy for scholarly communications can also lead to new sources of funding. For example, in raising money for a major new program or center, development campaigns can build in funds to support publishing activities that disseminate the research outputs of that initiative. Presses and libraries could work with development officers to create scripts for potential funders about how dynamic publishing helps to accomplish their goals, have global reach and impact, and brand campus initiatives. Furthermore, universities can tap into the current focus among foundations and governments on the need

\footnotetext{
${ }^{45}$ In response to our survey question, "If your press felt the need to invest in new programs, infrastructure, or capacity building, what level of funding would you have access to?" 45 percent of presses reported "none" and a further 29 percent reported "less than $\$ 500,000 ”$.
} 
to build cyberinfrastructure following two influential reports (one on the sciences and engineering, another on the humanities and social sciences) to seek support for building the tools and infrastructure required for new forms of publishing. ${ }^{46}$

\section{Provide leadership}

None of these elements is likely to materialize without leadership from the three constituents discussed here, particularly from presidents and provosts. Due to the siloed structure of universities, real collaboration is difficult to enact without impetus from the top. A good illustration is the MIT OpenCourseWare (MIT OCW) initiative, which represented an innovative new form of university publishing and could never have been so successful without strong leadership from Chuck Vest and Bob Brown, the president and provost of MIT at the time MIT OCW was launched. ${ }^{47}$ At the very least, provosts need to encourage leadership from their reports and empower them to act.

\section{Summary of Recommendations}

- Recognize that publishing is an integral part of the core mission and activities of universities, and take ownership of it.

- Take inventory of the landscape of publishing activities currently taking place within your university.

- Develop a strategic approach to publishing on your campus, including what publication services should be provided to your constituents, how they should be provided and funded, how publishing should relate to tenure decisions, and a position on intellectual assets.

- Create the organizational structure necessary to implement this strategy and leverage the resources of the university.

- Consider the importance of publishing towards an institution's reputation, especially when associated with core academic strengths.

- Develop online publishing capabilities for backlist and frontlist content and for new emerging formats.

- Develop a shared electronic publishing infrastructure across universities to save costs, create scale, leverage expertise, innovate, extend the brand of U.S. higher education, create an interlinked environment of information, and provide a robust alternative to commercial competitors.

- Commit resources to deliver an agreed strategic plan for scholarly communication.

\footnotetext{
${ }^{46}$ See Daniel E. Atkins, et al, "Revolutionizing Science and Engineering Through Cyberinfrastructure: Report of the National Science Foundation Blue-Ribbon Advisory Panel on Cyberinfrastructure", January 2003, available online at http://www.nsf.gov/od/oci/reports/toc.jsp, accessed May 2007; and John Unsworth, et al, "Our Cultural Commonwealth: A Report of the American Council of Learned Societies Commission on Cyberinfrastructure for the Humanities and Social Sciences”, available online at http://www.acls.org/cyberinfrastructure/OurCulturalCommonwealth.pdf, accessed May 2007.

${ }^{47}$ See http://ocw.mit.edu/index.html.
} 


\section{O N C L U S I O N}

We recognize that the list of recommendations made here may feel daunting and that many of the ideas described in this paper have been percolating fruitlessly in the academic community for some time. Efforts have been made to create the "products of the future," sometimes only to find that the market was not ready for them. It is one thing to say that the organization needs to have a coherent vision of scholarly communications, quite another for provosts, press directors and librarians to agree on what that is and to put it into effect - especially when elements of this vision must be embraced across institutions.

What is different now? The use of the Internet has become almost ubiquitous. The basic infrastructure is there, and the question now is what the next layer (or layers) will look like. The recent report on cyberinfrastructure in the humanities and social sciences explored this question and focused attention on the state of scholarly communications in these fields. In addition, the terrain may now be more fertile for elements of the electronic research environments described in our report to take root, as the necessary ingredients (e.g. growing interest in eBooks) are falling into place. Finally, there is more recognition that the challenges are too big to "go it alone," and that individual presses or even universities lack the scale to assert a desirable level of control over the dissemination of their scholarly output.

In our discussions we found strong interest in the notion of creating a third party entity to catalyze and lead these changes. This entity could provide some combination of the following elements: first and foremost, a technology platform and a competitive business model for putting current and legacy content online; market research to identify what new products are needed, how to build them, and how to reach new markets; marketing capabilities for reaching these new markets; business development capabilities; and strategic consulting to translate these opportunities into practical options for individual institutions. This entity could act as a partner for library and press directors in helping them put forward a compelling vision to their university leadership, helping them develop plans of action, and could provide the shared electronic space in which to implement these plans.

A good first step is for people from institutions that wish to take a leadership role to convene and take action towards launching pilot projects, ideally out of faculty initiatives. These discussions could include press directors, librarians, IT staff and faculty. Getting these conversations started, and building momentum behind the concept of a third party entity, will require direction from presidents and provosts. We hope that this paper will help to make the case that this focus and attention is warranted. 
A P P E N D I X A: P E O P L E I N T E R V I E W E D

\section{University Administrators}

Timothy A. Barbari

John T. Casteen III

Ronald Daniels

Christopher Eisgruber

Richard M. Englert

John Etchemendy

Bernadette Gray-Little

Andrew D. Hamilton

Wyatt R. (Rory) Hume

Steven Knapp

Earl Lewis

Harold L. Martin

James J. O'Donnell

Michael K. Young
Associate Provost for Research

President

Provost

Provost

Provost (interim)

Provost

Provost

Provost

Provost

Provost

Provost

Senior Vice President for Academic Affairs

Provost

President
Georgetown University

University of Virginia

University of Pennsylvania

Princeton University

Temple University

Stanford University

University of North Carolina-Chapel

Hill

Yale University

University of California

Johns Hopkins University

Emory University

University of North Carolina

Georgetown University

University of Utah

\section{Press Directors and Staff}

John R. Alley Jr.

Douglas Armato

Thomas Bacher

Geoffrey Burn

Richard Brown

Kathryn Caras

Stephen A. Cohn

John Donatich

Peter J. Dougherty

Ellen Faran

Eric Halpern

John Herbert

Alex Holzman

Michael Jensen

Penelope Kaiserlian

Kathleen Keane

Barbara Kline Pope

Steve Maikowski

Janet Rabinowitch

Rebecca Simon

William P. Sisler

Michael Spooner

Sanford G. Thatcher

Kate Douglas Torrey

Lynne Withey

Eric Zinner
Executive Editor

Press Director

Press Director

Press Director

Press Director

Director of Electronic and Serials Publishing

Press Director

Press Director

Press Director

Press Director

Press Director

Press Director

Press Director

Director of Publishing Technologies

Press Director

Press Director

Press Director

Press Director

Press Director

Associate Director, Journals

Press Director

Press Director

Press Director

Press Director

Press Director

Editor-in-Chief
Utah State University

University of Minnesota

Purdue University

Stanford University

Georgetown University

Indiana University

Duke University

Yale University

Princeton University

MIT

University of Pennsylvania

University of Utah

Temple University

National Academies

University of Virginia

Johns Hopkins University

National Academies

New York University

Indiana University

University of California

Harvard University

Utah State University

Pennsylvania State University

University of North Carolina

University of California

New York University 


\section{Librarians and Library Staff}

Larry Alford

Martha Sites Blodgett

Daniel Greenstein

Deborah Jakubs

Artemis Kirk

Carol Mandel

Sarah C. Michalak

James Neal

Alice Prochaska

Winston Tabb

Karin Trainer

Karin Wittenborg

\section{Others}

Peter Givler

James Hilton

Jerome McGann

Brenna McLaughlin

Michael Steinberg
University Librarian

Associate University Librarian

University Librarian

University Librarian

University Librarian

University Librarian

University Librarian

Vice President for Information

Services and University Librarian

University Librarian

University Librarian

University Librarian

University Librarian

Director

Chief Information Officer

John Stewart Bryan Professor

Communications Manager

Director, Cogut Humanities Center
Temple University

University of Virginia

University of California

Duke University

Georgetown University

New York University

University of North Carolina

Columbia University

Yale University

Johns Hopkins University

Princeton University

University of Virginia

Association of American University

Presses

University of Virginia

University of Virginia

Association of American University

Presses

Brown University 


\section{A P P E N D I X B: C O M P A R I S O N O F PRE S S A N D L I B R A R Y \\ S T R E N T H S A N D W E A K N E S E S}

Libraries and presses have different and often complementary strengths and weaknesses that could be harnessed to deliver a compelling new publishing enterprise. Libraries, at the nexus of faculty research needs, understand scholars as users of information (robust subject collections as much as possible - to support research agendas, 24/7 accessibility, preservation, etc.). Presses understand faculty as authors (conferring prestige through selection, improving work through peer review/editing, protecting copyright, maximizing attention, generating royalties). The table below outlines how we see the particular strengths of libraries and presses in terms of scholarly communication in general, and publishing in particular. This will obviously vary by institution; we see this as a catalyst for conversations between libraries and presses that could lead to an effective division of labor between the two.

\section{Libraries:}

\section{Strengths}

- Technology (people, tools and infrastructure)

- Organizing information (metadata)

- Information storage and preservation

- Close to host institution - at the center of the university's academic and educational agenda. Direct reporting line to provost; deeply connected to academic departments, professional schools, campus museums, and other entities.

- Have networks of subject specialists familiar with faculty research, instructional needs and publishing trends.

- Understand how to build collections, how disciplines work, and the interdisciplinary way collections interact.

- Multimedia content

- Special collections (own enormous amount of content of value to scholars; good at digitizing this content - including delicate work on rare manuscripts and other material - and offering it for free)

- $\quad$ Operate at granular level with usage. Understand the way users find and retrieve information; understand the usability of information. Well funded (from university budgets and, increasingly, from outside sources). One of largest cost centers within university.

- Operating model (as a cost center) in line with way most of the university conducts business (thus the library talks the same language as the administration)

- Excel at service - bring that mentality to everything they do. Have created a vigorous national and institutional advocacy agenda to maximize the dissemination and bring down the costs of scholarly information (e.g. open access, open source)

- Good at collaborating across institutions (ILL, etc.), and have experience in building shared technology

\section{Weaknesses}

- Commercial discipline - "Libraries would benefit from the financial discipline that comes from a focus on the bottom line. There is a lot of waste in libraries. Libraries, because they have a spend-itdown focus, are a better site for innovation and risk-taking, but libraries don't know how to sustain innovative projects."

- $\quad$ Evaluating demand (service mentality prioritizes service functions over revenue generating and usage-determined activities).

- $\quad$ Creating demand (lack the marketing skills, networks, and processes to attract attention for projects. Not market-facing).

- Sustainability (librarians are accustomed to spending down a departmental budget and have limited experience generating revenues from other channels).

- Do not really understand faculty as authors (copyright protection and prioritization of revenue generation for royalties versus maximization of exposure from open access - authors need nuanced balance between these two sometimes contradictory extremes)

- $\quad$ Do not understand publishing process (library idea of publishing is more like digital production. Little sense of how to acquire or incentivize authors, spend capital to make a return on investment, etc.)

- Lack editorial selection, peer-review, and manuscript development systems that 
platforms (e.g. union catalogs, bibliographic utilities, bibliographic databases)

\section{Presses:}

\section{Strengths}

- Commercial discipline - one of the few places on campus that offer a capture mechanism for universitycreated content. Understand how to monetize scholarship, risk capital for return on investment, operate within the disciplines of a P\&L, and protect sustainability of the enterprise.

- Acceptable channel for revenue generation

- Understand publishing process

- Know how to evaluate demand

- Editorial selection and vetting (upstream at the manuscript level and downstream at the book/journal level )

- Credentialing

- Conferring prestige

- Editorial development/improving the quality of content

- Relationships with faculty as authors/creators of scholarly content

- Marketing/awareness building across multiple audiences, but especially within the academy. Cultivate long-established national and international networks among wholesalers, retailers, libraries, individuals

- $\quad$ Fair pricing - finding the best balance between maximizing exposure for a work, rewarding content creators and producers, and keeping down cost of scholarship.

- $\quad$ Keeping works in print

- Understand demand for scholarship by discipline

- Understand copyright protection and rights management confer status/prestige on published products. Do not contribute to credentialing system for scholarship.

\section{Weaknesses}

- $\quad$ Not connected deeply to parent institution; lack status as essential academic department of university; not close to administration. Operating model (commercial) not in line with how most of university conducts business (cost center).

- $\quad$ Lack financial resources/investment capital necessary to experiment, recruit top talent, build new electronic infrastructure, and conduct market research.

- Lack scale: too small to achieve economies, leverage investments

- Far behind the curve in electronic publishing: lack technology tools, infrastructure, people/skills, market knowledge

- Not innovative: cost of failure too high given limited resources

- With exception of a few presses, have ceded the territory of scientific, technical, engineering, and medical publishing to commercial competitors; distant from professional schools on campus

- With exception of a few presses, not good at fundraising (building endowments, attracting substantial money for new initiatives, etc.)

- Developing and promoting a long-term strategy

- $\quad$ Creating new products with information technology

- $\quad$ Slow to move and tradition-bound 
A P P E N D I X C: R E C O M M E N D A T I O N S T O PRE S S D I R E C T O R S

Recommendation 1: Tell a compelling story

Within higher education, much of the recent agenda for change in scholarly communication has been centered in libraries. From open access advocacy, to institutional repositories, to tools for the creation of electronic content, libraries are leading the university's response to the high cost of published scholarship and the demand for robust technology platforms on which to build the electronic scholarship of the future. University presses have a big role to play, but they need to make that role more concrete and persuasive to the academic community by making clear how they can:

- lower the cost of scholarship through fair pricing

- return the revenues of scholarly publishing back to the parent institution for reinvestment in educational, research, and publishing activities

- offer cost recovery and sustainability models that depend heavily on commercial discipline, accountability and recognized value (as opposed to the gift economy or institutional funding)

- extend the reach of their institution's prestige and reputation through the press's imprint and through applying the university brand to university-sponsored publishing projects

- ensure that universities can rely on support for credentialing through the high standards and mature vetting and peer-review system developed by their presses

- ensure that young faculty have opportunities to publish, even in niche fields where the commercial return may not justify publication

- offer faculty and graduate students the opportunity to develop as authors through mentoring and professional training programs sponsored by the press

- offer faculty, academic departments, and graduate students publishing environments in which to build "virtual labs" that enable a continuum of research and dissemination options for dynamic online content

- develop compelling cases to bring outside funding to the university through the inclusion of a branded publishing component in research grants

- Team up with libraries to pursue a powerful coordinated advocacy agenda and technology infrastructure.

For all of these reasons, presses should position themselves to be a much bigger part of the university's portfolio of strategies to manage scholarly communication as a core component of its mission.

Recommendation 2: Create a strategic plan

Articulate a long-term vision that inspires local constituencies (and those who hold the pursestrings). Universities need to have a better grasp of what is possible for their presses. To that end, every press should create, and regularly update, a 5-year strategic plan, complete with ambitions for their publishing programs and a financial framework. This document can form the backbone of discussions with owners about where the press is headed, how it contributes to the "public good” agenda for higher education, and how it aligns with the interests and ambitions of the particular university. It will create a framework for long-range discussions about publishing priorities, investment and subsidy expectations, and shared criteria for success. Each press will have a different approach to this vision, which will depend on conditions at the host university.

Recommendation 3: Realign with university 
Presses should take advantage of being "inside the tent," and having access to scholars and scholarship while it is still in formation. They should make sure they have a copy of the university's strategic plan, and initiate discussions about ways to help the university deliver that plan through publishing solutions. They should fight to be at the table when major new academic programs are being planned, and to have a publishing component built into major research and capital campaigns. They should take an inventory of the exciting new academic ventures at their institutions, and consider which ones might lend themselves to publishing programs. They should reach out to the professional schools to form publishing alliances and joint ventures.

A key question this raises is how to ensure that presses do not evolve into vanity publishers (the concern that got them where they are now). What we heard is that university presses do and should act as the sector of university publishing that relies on peer review and rigorous standards of selection - that is the prestige of the imprint. Other types of publishing will arise from the parent institution, and university presses may play a role in this publishing through service functions (editorial, marketing), or through collaborative linking to unrefereed content on campus, but the press proposition remains the protection of standards of selectivity, credentialing, and refinement (cooked rather than raw content), as well as setting a price for that selectivity and refinement. And to the extent that the programs of the press can be realigned with the institution's academic priorities, the desires to be close to the institution and publish the best scholarship can be compatible.

\section{Recommendation 4: Focus}

Publishing the occasional book in a discipline that is not at the center of the press's priorities is a distraction and does not serve the interests of the author either. Presses should carefully select areas where they can excel, set ambitious targets, and concentrate on building those programs. These programs will no doubt include traditional areas of excellence built over time by presses. But every university, no matter how small, also provides ample opportunities for press specialization in areas that reflect its intellectual ambitions. The best drama school in the country might well set out to publish the best drama list. Georgetown University Press has built the leading Arabic studies list in collaboration with the university's Arabic studies department. A university that has set a goal to build interdisciplinary programs could work with its press to create model online interdisciplinary publishing centers in targeted areas.

\section{Recommendation 5: Reframe conversations with development offices}

Presses should seek to work with development officers to build a publishing component into campaigns related to a major new academic program or center. They should help to create scripts for potential funders about how dynamic publishing helps to accomplish their goals, create global reach and impact, and brand campus initiatives.

Recommendation 6: Collaborate with libraries to co-develop tools and programs Work together to identify content of institutional value. Co-develop products, tools and professional educational and training programs for faculty, researchers, and students around traditional and electronic publishing issues, procedures, etc. Co-develop joint programs for preservation and archiving or collaborate in support of third party platforms that ensure preservation. Co-develop tools for content creation and online collaboration. 
A P P E N D I D D: I N T E R V I E W G U I D E S ( P R E S S D I R E C T O R S,

L I B R A R I A N S, A D M I N I T R A T O R S )

\section{$\underline{\text { Press Directors }}$}

\section{Demographics}

1. How big is your press (staff, revenues, number of books published, number of journals published, other metrics)?

2. Who are your press's peers?

3. To whom do you look for examples of future directions for your press?

4. How long have you been director?

5. What are the major issues your press is facing?

\section{Relationship to host}

1. Is your press a unit of the university or do you have an independent governance structure?

2. If you report into the university, to whom do you report (provost, library, VP for administration, research, finance, etc.)?

3. What is the history of this reporting relationship?

4. What are the challenges associated with this relationship? How does it affect the way you run your press?

5. What do you see as your press's role within the university?

6. What does your university (provost, president, faculty) see as your role?

\section{Collaborations}

1. What entities on your campus do you work with directly (library, development, public relations, VP for research, other units)? How often do you meet with them?

2. What is the nature of your collaboration with other units (library, academic departments, institutes, IT, distance learning) across the university?

3. Has your library (or other units of the university) ventured into electronic publishing (e.g., with a digital repository)?

4. Has your library expressed interest in a collaboration with your press?

5. Are you interested in a collaboration with your library?

6. If yes what would you do together? What about this prospect do you find appealing?

7. Have there been any successful examples of collaboration between your press and the library?

8. What are the obstacles to your greater involvement with your library or other units across campus?

9. What cross-institution collaborations are you involved with for products and for services (other presses, scholarly societies, etc.)?

10. What regional collaborations have you been involved with (state and local, industry, museums and cultural institutions, tourism boards)?

11. What model of collaboration would you find most appealing: One led by another press, a new organization, a third party existing organization, a consortium of presses? 
1. What kinds of electronic publishing are you currently involved with (print on demand, short run digital printing, electronic books, electronic journals, etc.)?

2. What kinds of e-publishing would you like to be involved with?

3. What are the main impediments to your involvement in these areas?

(At this point, share a list of university press services)

4. Which among these services does your press require?

5. What services do you wish [your current online vendors] offered?

6. Where are the areas of greatest unmet need?

7. For your books program, what digital technologies are you currently using in your books publishing program, backend (digital production, digital asset management, print on demand, short run digital printing) and front-end (online marketing, electronic distribution)?

8. For your books program, what databases is your content included in? What has your approach been to licensing your content for electronic distribution?

9. What are your views on Google Print/Book Search?

Electronic publishing: journals

1. Do you publish journals on behalf of societies or on your own behalf?

2. For journals you publish on behalf of others, to what extent are you involved with the editorial side? Are you more of an editorial driver or service provider?

3. What are your distribution channels for journals (print, electronic, licensing, distribution on behalf of others)?

4. When did your press decide to put its current journal issues online? How was the decision made?

5. What vendors do you work with? Do you generally build or buy technological solutions?

6. If you have one, what services does your online provider offer?

7. Why did you choose [your current online vendor]? Which factor was the most important? What importance did you place on...

a. The other journals already distributed by the vendor (same discipline)?

b. The financial terms of the agreement?

c. The specific or unique services offered by the vendor?

d. The vendor's marketing skills?

e. Reputation?

f. For-profit or not-for-profit status?

8. Have you considered any other online service providers since then? Why? What did you like about the others? Which vendors are most advanced in terms of electronic publishing? Which are the best electronic journals platforms? What distinguishes these?

9. How long have you been at your current platform provider? If you have made a transition recently, what were your decision-making priorities? How satisfied are you with the service your publishing platform currently provides?

\section{Editorial program and publishing}

1. What is your editorial mix of trade, reference, regional, professional, journals?

2. Do you have a focus on any discipline or disciplines? What are they?

3. How did these come to be your areas of focus? 
4. To what extent are your books and journals programs integrated or separated? Is your books program growing because of journal relationships? Why?

5. Have you lost any journals recently? Have you acquired any journals recently? Why? Why do the ones you have stay with you?

6. How closely tied are your journals to their editors?

7. How do you decide how to value a journal? How do you decide when to bid on a journal?

8. Are you developing cross-media products that blend journal and book content?

9. Among the various kinds of content you publish where do your revenues/profits come from?

10. Are your editors generally specialists or generalists?

11. What are your host institution's disciplinary strengths?

12. How close is the match between your editorial program and the disciplinary strengths of your university? Do you think that matters?

13. If you work with scholarly societies, what do you view as the value of those relationships?

14. What are your plans for growth?

15. Why do you want to grow: more titles, more books/journals in print, more revenues, more profit, more prestige, more prizes, more submissions?

\section{Marketing}

1. How do you market your books and journals?

2. Of the marketing you do now, what is most effective?

3. What methods or tools could make your marketing more effective that you currently are unable to do?

4. How has this changed with the advent of the Internet? What are you trying to accomplish with your website? What other web presence do you have?

5. How does this differ from other publishers? Other university presses?

6. How do you research a new market?

7. What are your greatest marketing challenges? Opportunities?

8. What percentage of your expenses are devoted to marketing?

\section{Access to funding}

1. Where do your revenues come from (endowment, clients, licensing, university budget allocations, sales, fundraising)?

2. What is the percentage breakdown among the sources of revenue?

3. What other sources of investment capital do you have?

4. If you had a great publishing idea, are you confident that you could amass the capital required to invest in it and bring it to fruition? Where would that capital come from?

5. What are the major capital investments that you have made in the past 10 years? From where did the funding for these come?

6. Is the lack of investment capital a barrier to innovation at your press?

7. Are you currently in the process of fundraising?

8. Do you have a staff person devoted to development?

9. What is your relationship with your university's development office?

\section{Closing questions}


1. Where do you see your press being strong?

2. How would you say your press is branded?

3. How much of the content you produce has close brand ties to your press (e.g., the XYZ dictionary of ABC)

4. What do you view as your press's strengths, weaknesses, opportunities, and threats?

5. What are the obstacles to your achieving your mission in the very broadest sense (e.g., funding, capabilities, ability to persuade your administration/host university, other factors)?

6. What are the specific obstacles to your participating in electronic publishing?

7. What are your concerns about the future? What could be done to help assuage these concerns?

8. Are there any other questions we did not ask that we should have?

9. Whom else should we consult for this study?

10. Do you have any questions for us? 


\section{Library Directors}

Collaborations within the university

1. What is going on at your university in the area of online scholarly communications? Who is leading these projects? What is your library's involvement in these areas?

2. Has your library ventured into electronic publishing (e.g., with a digital repository)?

3. Have there been any successful examples of collaboration between your library and your university's press?

4. Have you expressed interest in a collaboration with your press? And they interested in a collaboration with your library?

5. If yes what would you do together? What about this prospect do you find appealing?

6. What are the obstacles to greater involvement between your library and your press?

7. What consortia or regional collaborations are you involved with?

\section{Open Access}

1. Do you sympathize with the open access movement?

2. Why should access be open?

3. What do you think the impact of open access will be on your library and your press?

4. What is your view of the sustainability of open access publishing?

\section{Closing questions}

1. Are there any other questions we did not ask that we should have?

2. Whom else should we consult for this study?

3. Do you have any questions for us? 


\section{$\underline{\text { University Administrators }}$}

\section{Mission}

1. How would you like to see the university publishing industry change?

2. What are your concerns about the future of the scholarly communications system? What are the opportunities?

3. What should be done to address these concerns?

4. Why is it important for universities to have presses?

5. What is the mission of your university press?

6. What you see as your press's role within the university?

7. How does your university support its press in that mission?

8. How does your press support the mission of your university?

9. Do you see the mission of your press more in the context of your university or in the context of the wider world?

10. How do you measure the performance of your press?

11. What are the main obstacles to your press's achieving its mission in the very broadest sense (e.g., funding, capabilities, ability to persuade your administration/host university, other factors)?

12. What are the major issues for your university press today?

13. How satisfied are you with the performance of your press?

14. What would you like your university press to do differently?

\section{Press-university relationship}

1. Do you expect your press to be subsidized, break even, or earn a surplus?

a. If subsidized, how much funding does your university provide the press per year?

b. If break even, how do you define break even? What costs does the press cover and what costs does it not cover?

c. If surplus, how much surplus?

2. To whom does your press director report - you, an independent board, or another person?

3. Why does your university have the governance structure for its press that it does?

4. What is the history of this reporting relationship?

5. What are the challenges associated with this relationship? How does it affect the way your school's press is run?

6. How often do you think about press-related issues?

7. How often do you meet with your press director?

8. Is your press something your president worries about?

9. What do your faculty think of your press? Do they tend to publish with your press?

10. Do faculty play a role in shaping your press's program?

Collaborations within the university

1. What is going on at your university in the area of online scholarly communications? Who is leading these projects?

2. Have there been any successful examples of collaboration between your press and other units at your university? 
3. Have you tried to encourage greater collaboration between the offices at your university (library, academic departments, institutes, IT, distance learning) and your press? How did this go?

4. Would you find this prospect to be appealing?

5. What are the obstacles to the greater involvement of the press with other units?

6. It seem that on many campuses, libraries are taking over some of the traditional functions of university presses. Is that true on your campus? Why?

7. Would you like your press to be more involved in electronic publishing?

8. Are you willing to invest in electronic publishing experiments by your press? How much do you think it would be appropriate for your university to risk?

\section{Collaborations across universities}

1. One influential provost recommended a massive consolidation of university presses. Do you agree?

2. What models of consolidation or collaboration would you find attractive? (We can test specific models at this point).

3. How would you assess the attractiveness of a potential collaboration with another press, institution or other organization?

4. What are the barriers to greater collaboration and scale economies for university presses?

5. Have you discussed the future of university presses with your peers at other universities?

6. What regional collaborations has your university you been involved with (state and local, industry, museums and cultural institutions, tourism boards)?

7. Are there natural collaborations your university is involved with, e.g., University of Cambridge and MIT, that you think it would make sense for your press to leverage?

8. If there were to be a collaborative model of university presses, which one would you find most appealing: One led by a press, a new organization, a third party existing organization, a consortium of presses?

\section{Open Access}

1. Are you familiar with the open access movement? Do you sympathize with it?

2. Why should access be open?

3. Did you sign one of the two provosts' petitions on open access that are currently circulating?

4. What do you think the impact of open access will be on your press? Do you think it will aid or hurt the financial footing of your press?

5. What is your view of the sustainability of open access publishing?

6. Is your university prepared to provide more subsidy to your press to make up for revenues lost to open access? How much more money would you be willing to budget for your press?

\section{Closing questions}

1. What is your university's research output? How do you measure this?

2. How concentrated is this output among certain journals?

3. Are there any other questions we did not ask that we should have?

4. Whom else should we consult for this study?

5. Do you have any questions for us? 
A P P E N D I X E: U N I V E R S I T Y P R E S S D I R E C T O R S U R V E Y R E S U L T S

Survey responses by press revenues

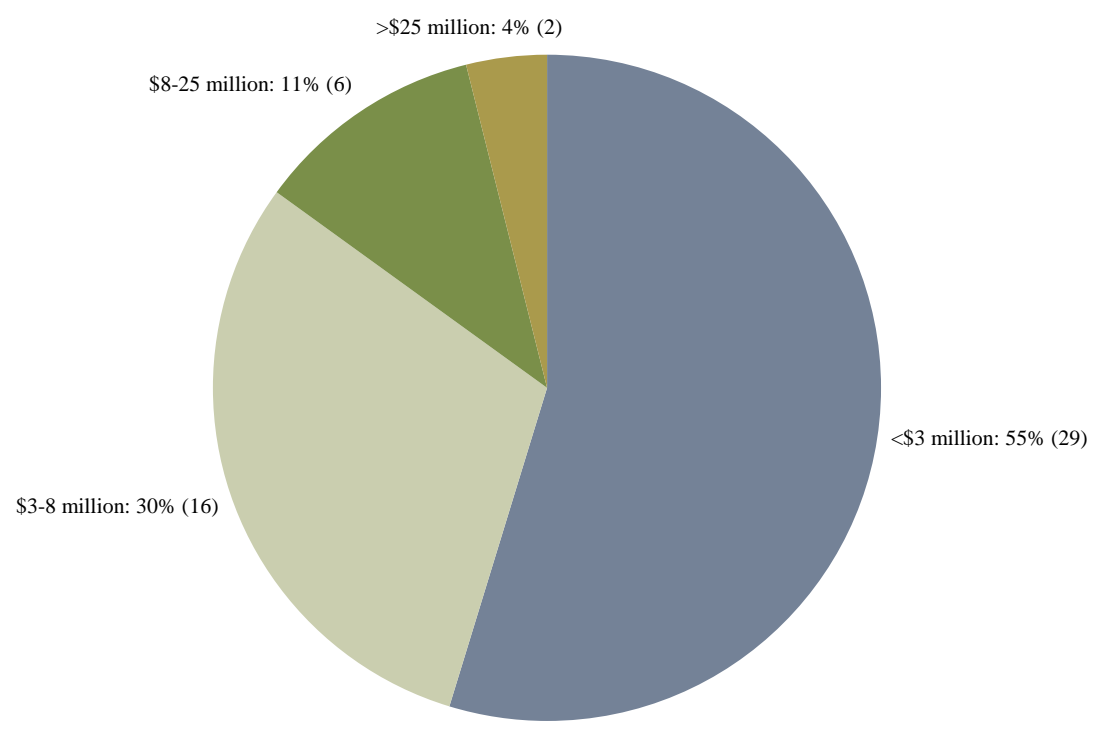

Survey responses by type of university host

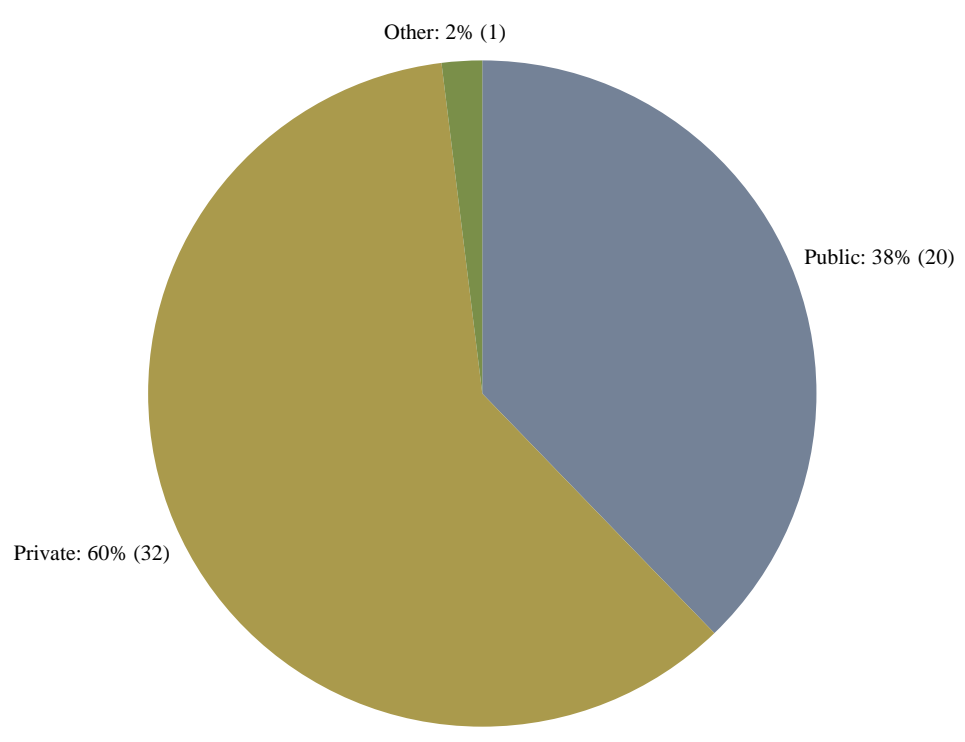


To whom does the press report?

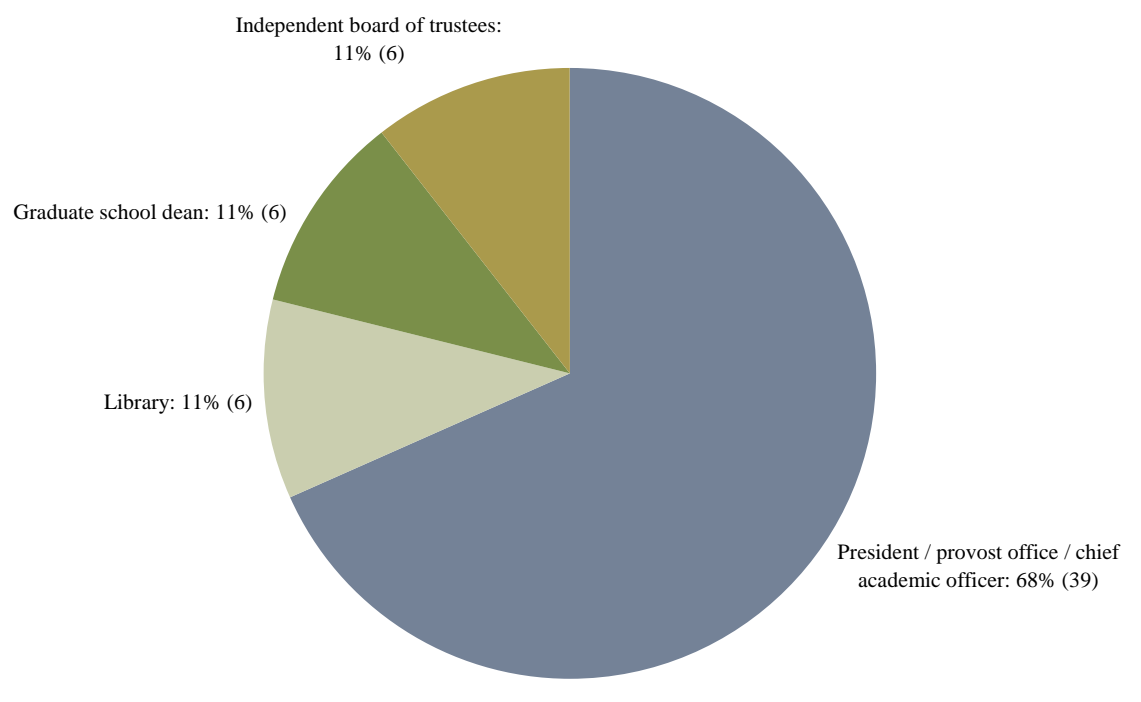

Has this reporting line changed in the past five years?

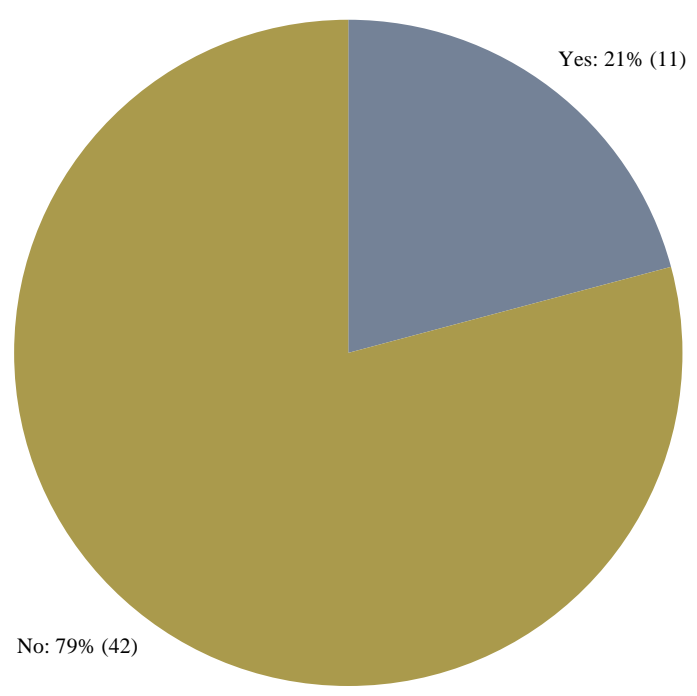


If so, what office did your press report to before?

(Only includes presses that answered "yes" to previous question)

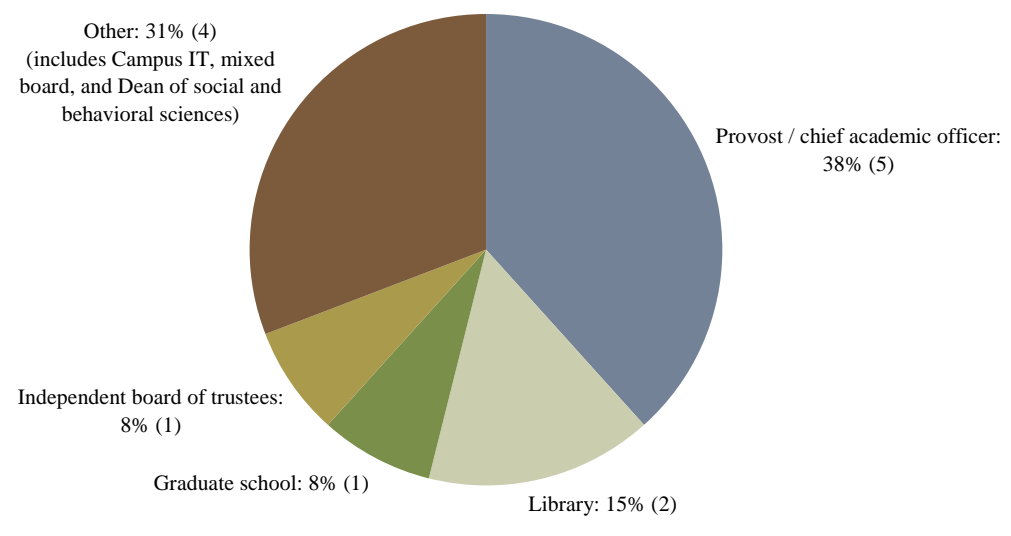

How closely do you, as press director, aspire to align your editorial program with the academic strengths of your university?

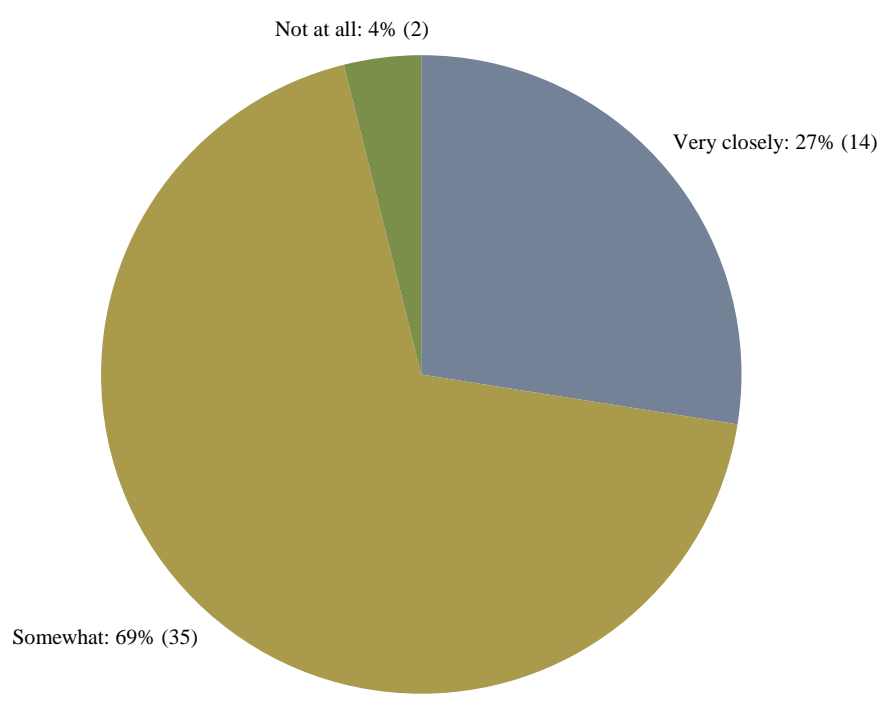


With which groups and departments does your press actively collaborate?

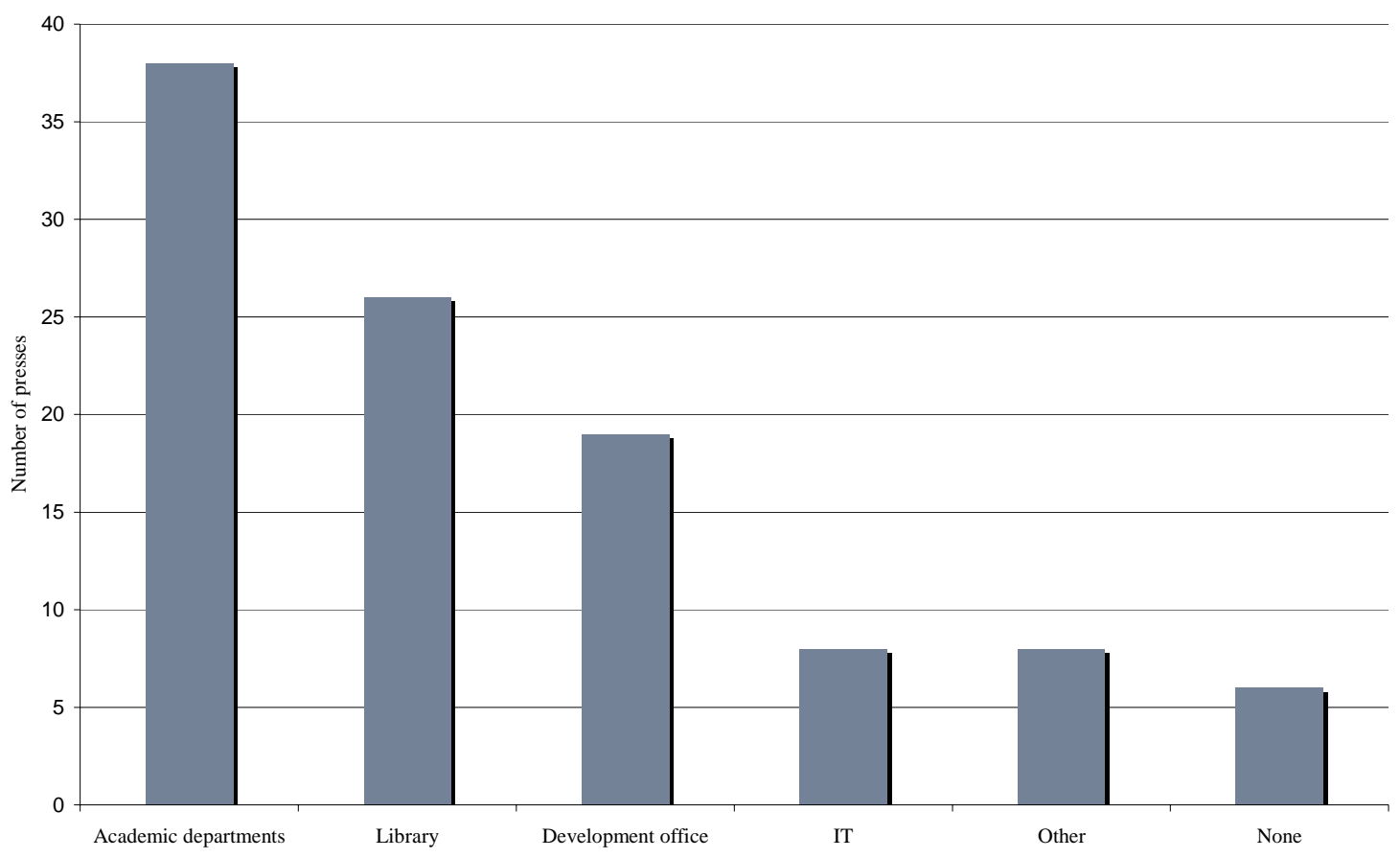

Please briefly describe the nature of these collaborations, distinguishing one-offs from those that are ongoing. (Comments are edited only to preserve anonymity.)

- The Press works with central development on all of its fundraising activities.

- IIBRARY - ELECTRONIC JOURNALS DATABASE 3 DEPTS - INDIVIDUAL JOURNALS EDITORIAL WORK DEVELOPMENT - FUNDRAISING COORDINATION

- We have many authors on campus, sponsor many lecture and book series with individual departments, and include on our board of trustees numerous members of the administration and faculty, including all members of our editorial board.

- Some of our areas of specialization parallel strengths in academic departments.

- With the library: we are developing a completely collaborative publishing program in the area of digital culture, that includes a jointly administered website. With academic departments: departments are represented in the press' publishing program through many series editors (eg. in health policy, Jewish studies, archaeology, German Studies)

- We develop book programs in cooperation with academic departments and professional schools (generally newer or rising rather than established departments). We cooperate on interdisciplinary research projects with the University's recently established [research institute], but that unit was only established in 2005, so there isn't much history there.

- We have several contracts in place with academic centers and institutes that specialize in certain areas...--15 books jointly published so far, etc.

- We are developing a series of books with the Special Collections department of the library.

- We work with faculty in appropriate departments. 
- We have taken over and completed a digital edition started at the Library, and we have arranged to digitize a work from their Special Collections. So far, this has been a one-off collaboration, but we look for others in future.

- We have an ongoing though still somewhat inchoate relationship with the Library on digital projects, as well as a longterm series of books.... We also have a long-term relationship with the Classics department for publication of books in philology and one lecture series.

- $\quad$ publication series

- Collaborate w/ University dep'ts and centers on various book series and journals. W/ IT on IT infrastructure, not publishing projects per se.

- digital projects; subvention requests

- book exhibits at library, occasionally; director teaches a publishing workshop in collaboration with the [university teaching center] each fall; occasional book exhibits at conferences in collaboration with academic departments

- Co-publication and distribution arrangements with Centers and departments on campus. Work with Development office on fundraising.

- We distribute books for them

- we publish several series in collaboration w/ academic departments; we distribute a small number of books upblished by the library; and we've done one big individual collaboration with the library (a copublished reference work) which I hope we can together translate into a collaborative online project.

- Library- Exchange program, ongoing. Humanities Ctr.- They fund interns; we do panels there for faculty and grad students; they support 4 books per year; ongoing. Art Museum- We do book distribution for them Ctr. for Doc. Studies- Joint publishing projects, incl. a biannual photography book based on a prize competition; a book series under contract--no books yet); ongoing Athletic Dept. is a set of one-offs: distribution of one of their basketball books to stores, coperative marketing on basketball-related bookspublished by us Med Center is again a set of one-offs: distrbution to stores of some books they have produced, cooperation with the Eye Center in creating a layperson's info book on eyes, etc.

- Press copublishes a database with a unit of the library. Technical support for this project is often provided by a university IT unit. Many publication programs in collaboration with departments and schools involve project acquitistion and sometimes direct funding (subvention) of costs. library: cooperative consultations, exhibits, programs it: e-commerce standards, compliance, fulfillment software, presswide hardware/software installation, maintenance, etc. academic depts: series and individual book collaborations, including with other institutions within the university system, as well as sharing of publishing expertise and advice development: active relationship with top development and foundation officials 
What percentage of your journal titles are in the following areas?

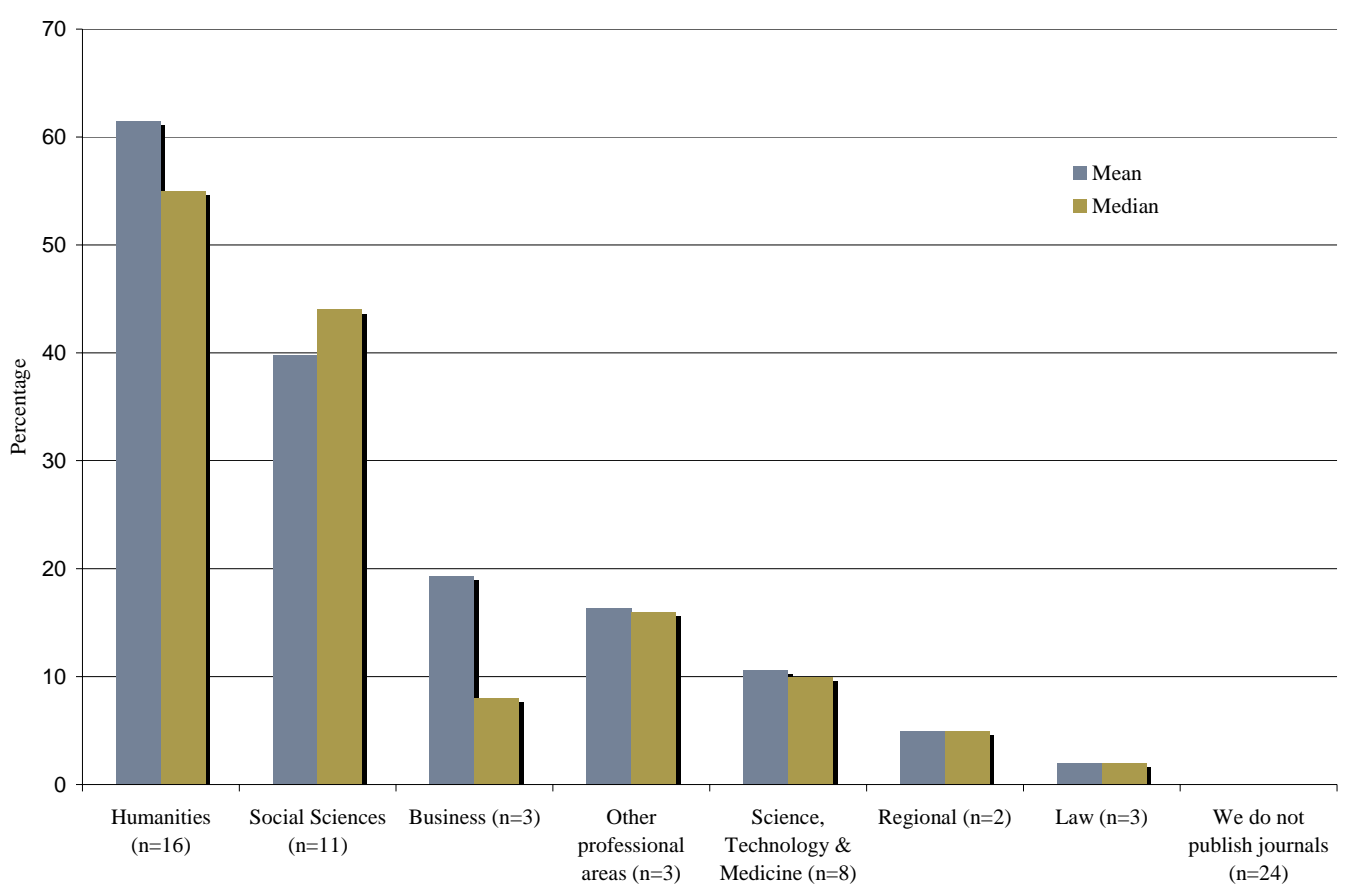

Approximately what percentage of your books published in the last five years are in the following areas?

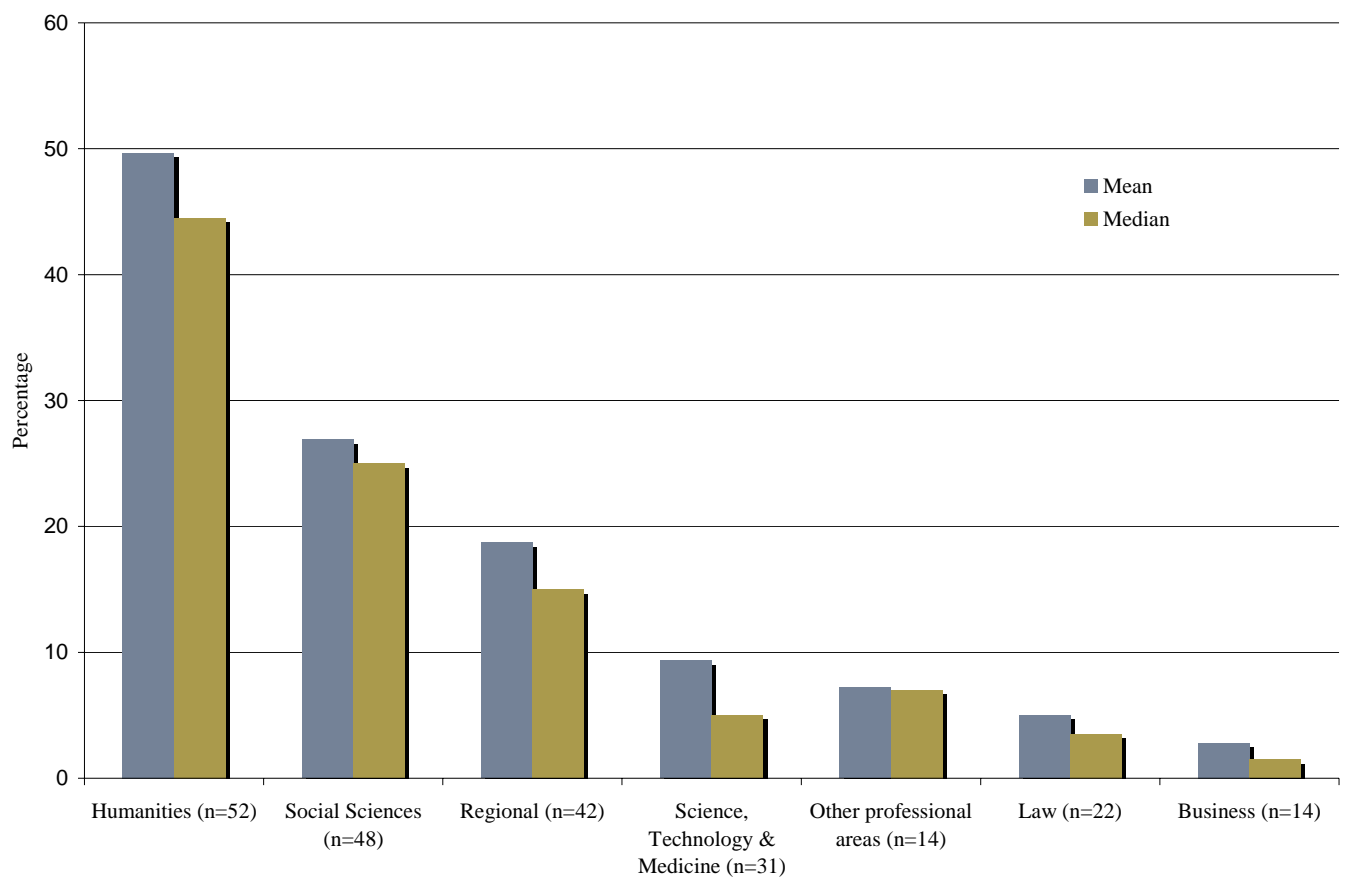


U N I V E R S I T Y P U B L IS H ING IN A D I G I T A L A G E

Please provide a rough breakdown of your sources of annual operating funds (in percentages)

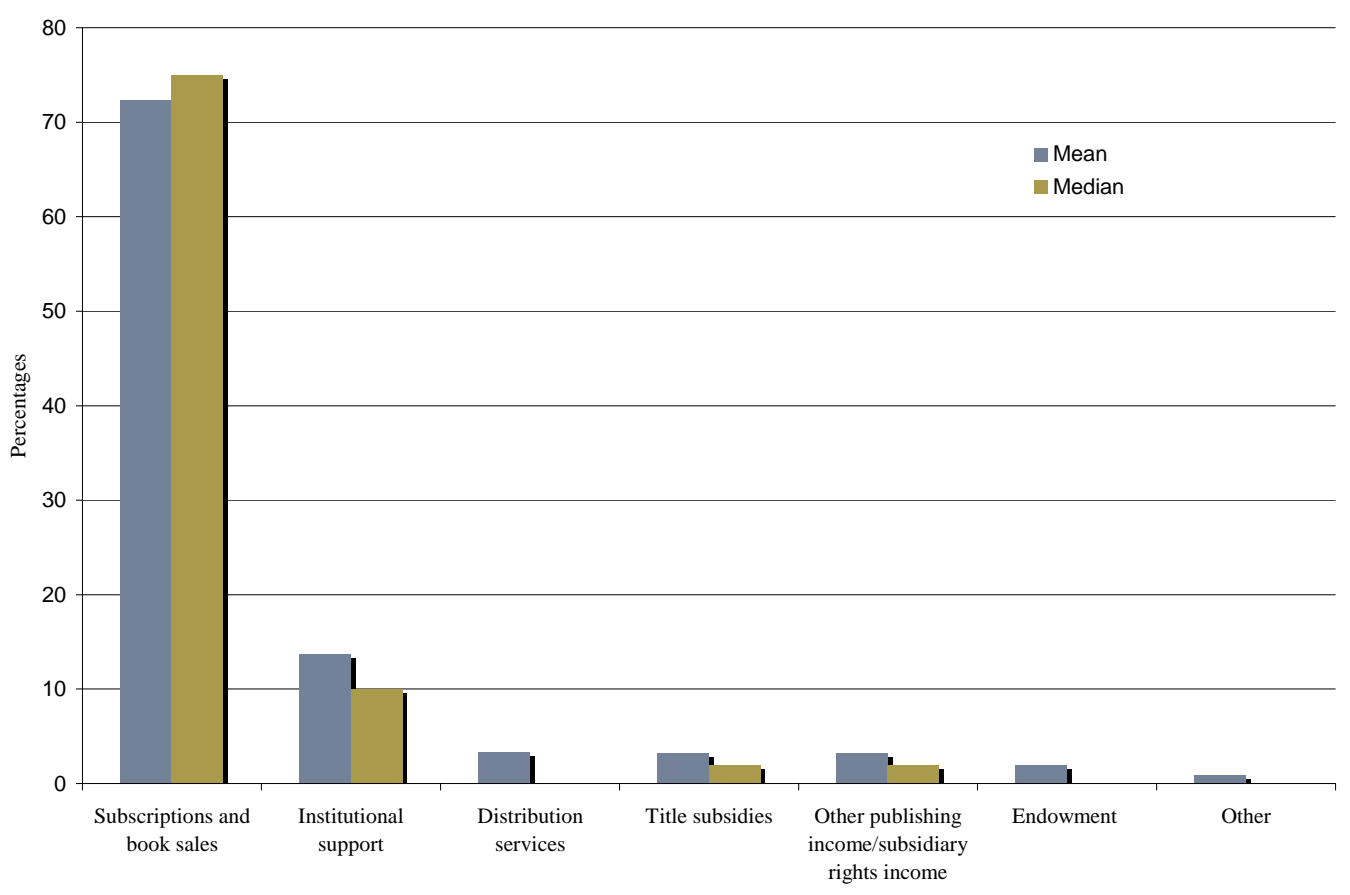

In terms of annual financial performance (excluding endowment and/or institutional subsidies of all sorts), do you currently:

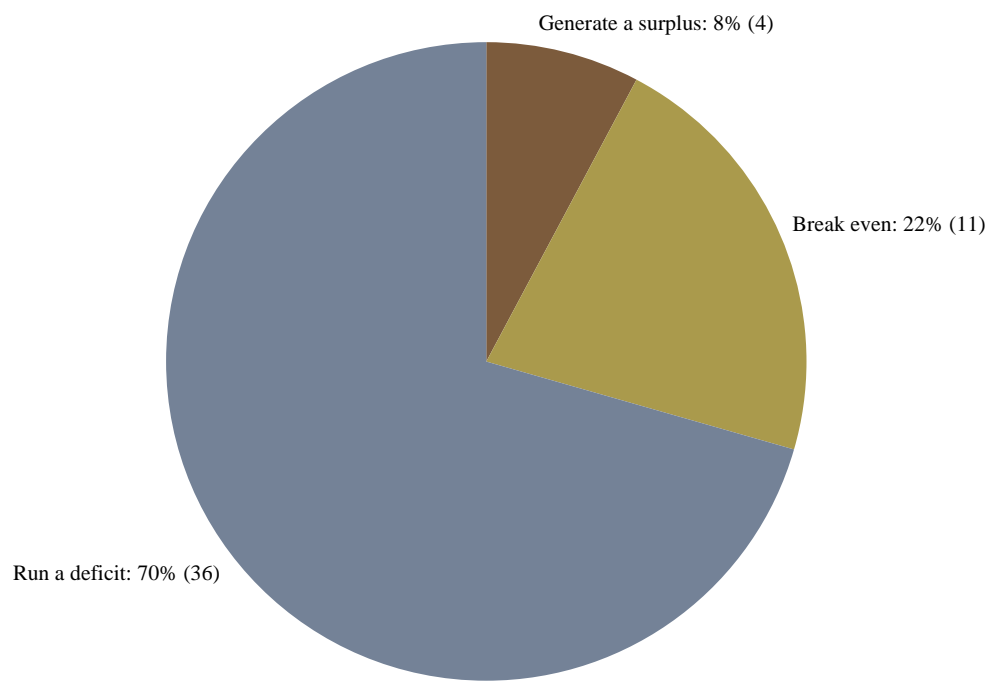


In the future (again, excluding endowment and/or institutional subsidies of all sorts), do you aspire to:

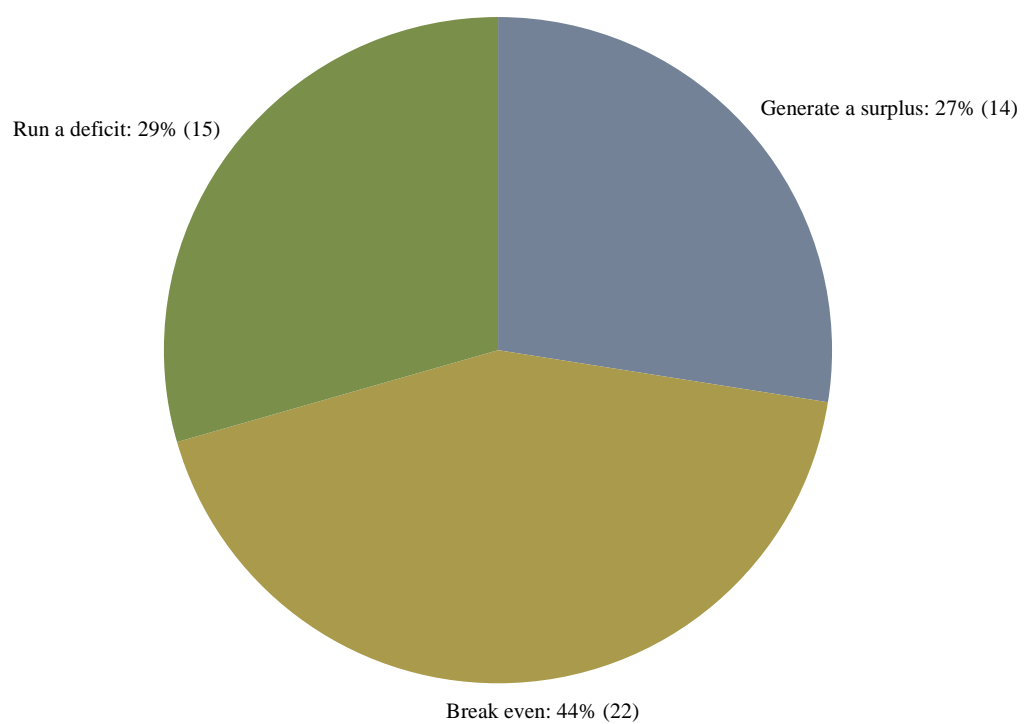

If your press generates a surplus, or were to generate a surplus, to what end would the surplus be used: (select as many as apply)

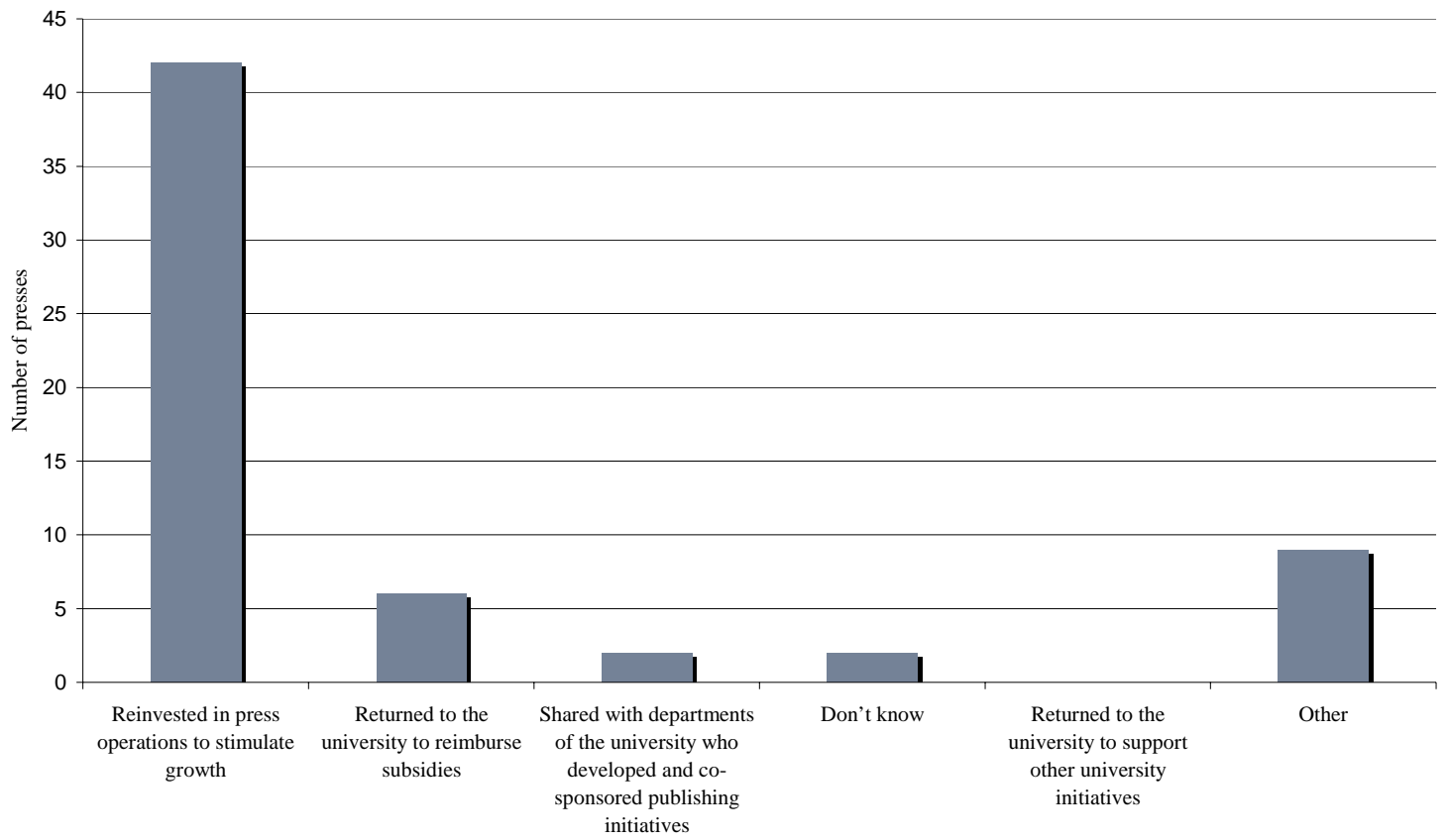


If your press has run a deficit beyond expected levels of endowment spending and institutional support in the past five years, how is this resolved? (check as many as apply)

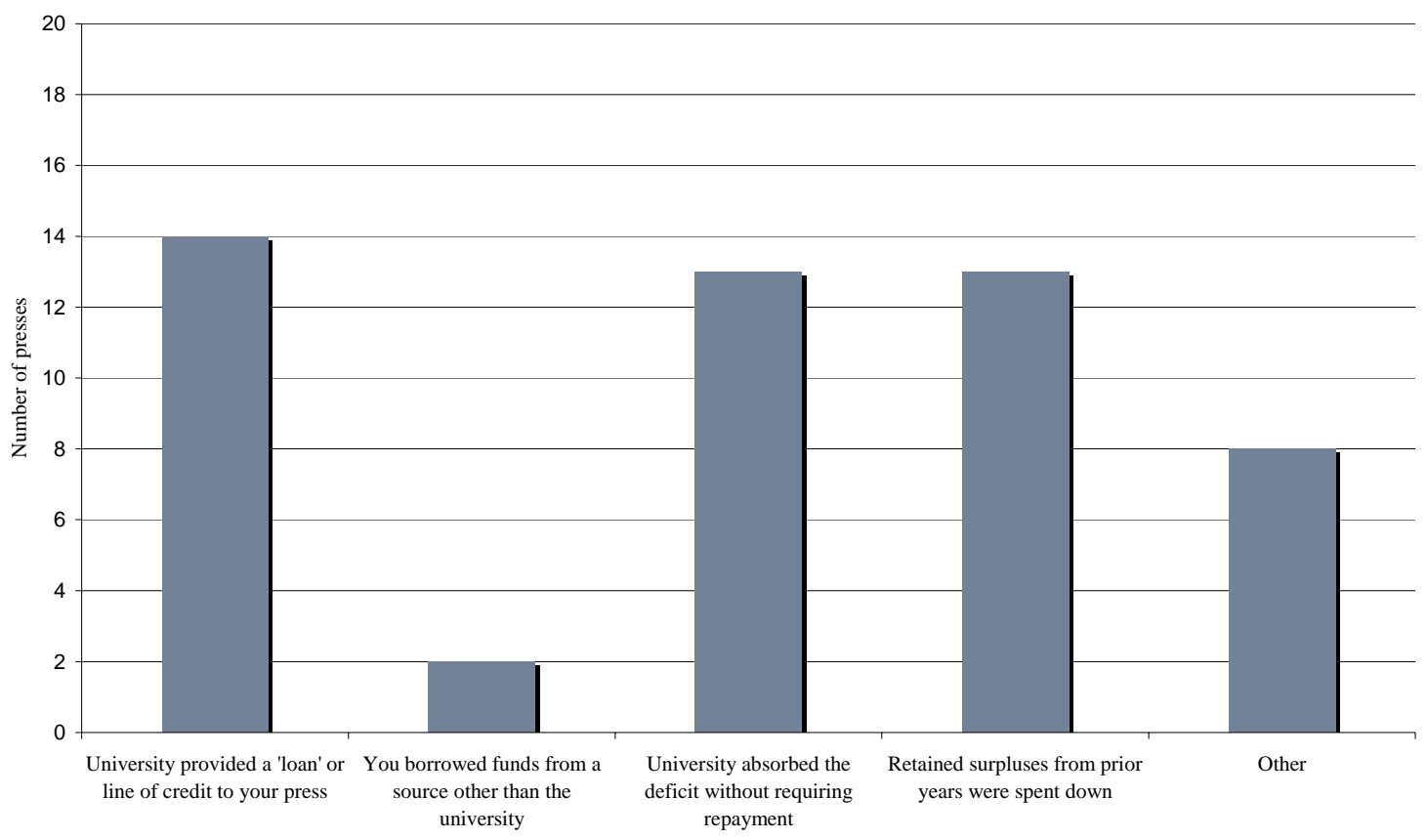

What are your expectations for parent institution support over the next five years?

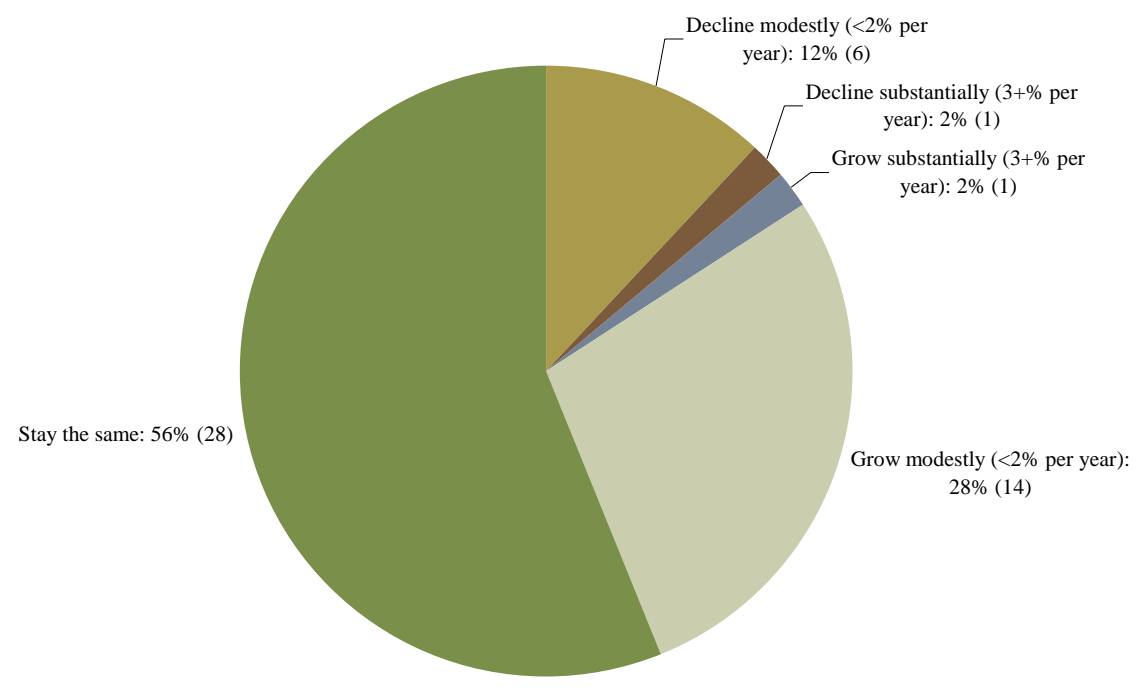


If your press felt the need to invest in new programs, infrastructure, or capacity building, what level of funding would you have access to?

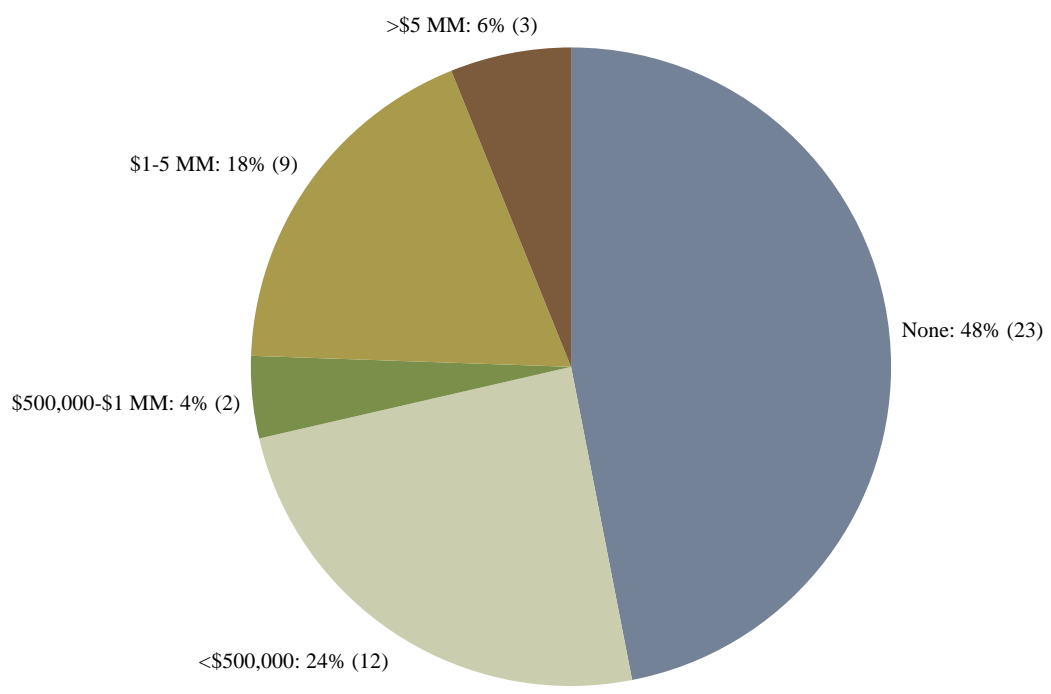

What share of your top line sales revenue comes from each type of publication?

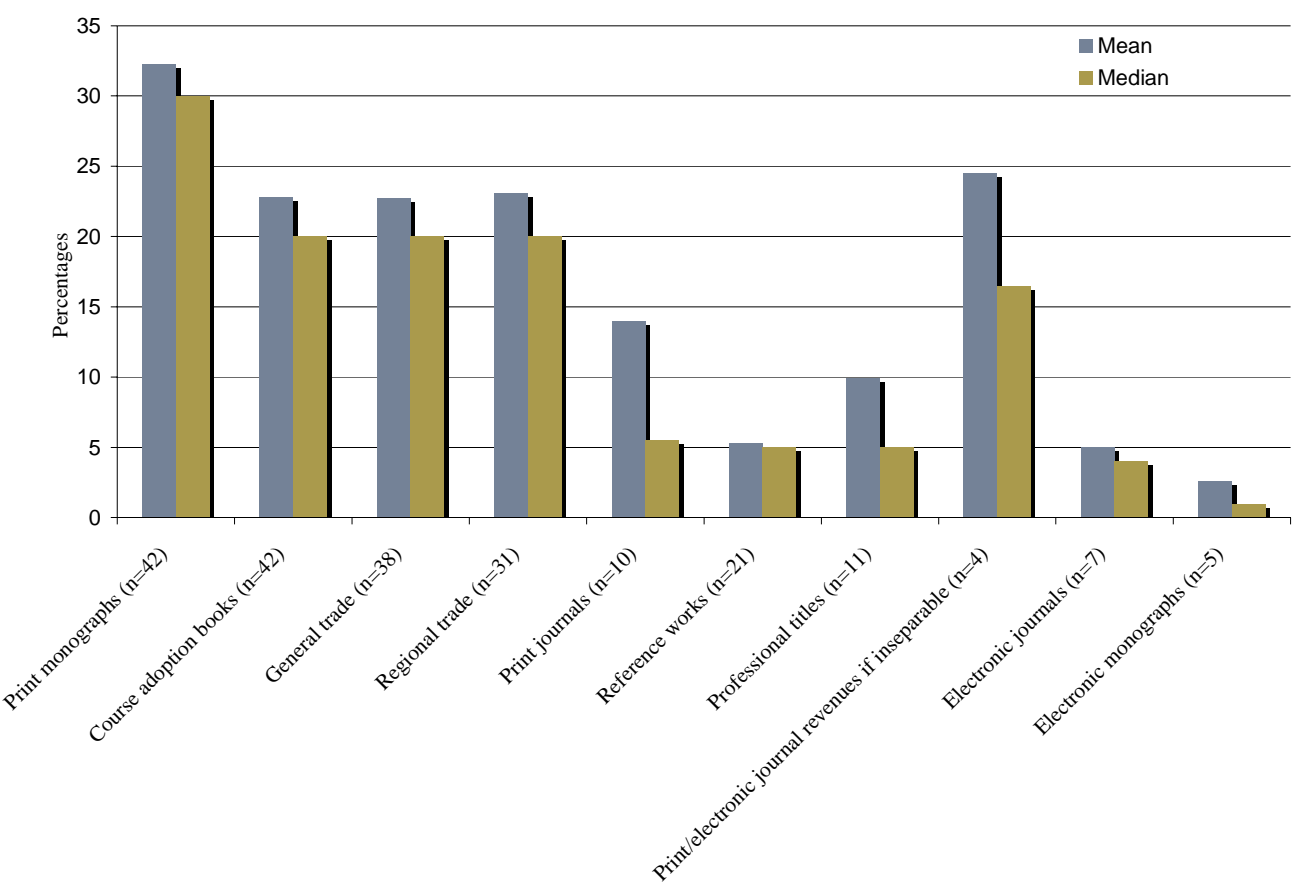


U N IVER I T Y P U B L IS H ING IN A D I G I T A L A G E

What percentage of your total sales revenues come from other publishing income (subsidiary rights) income? $(n=44)$

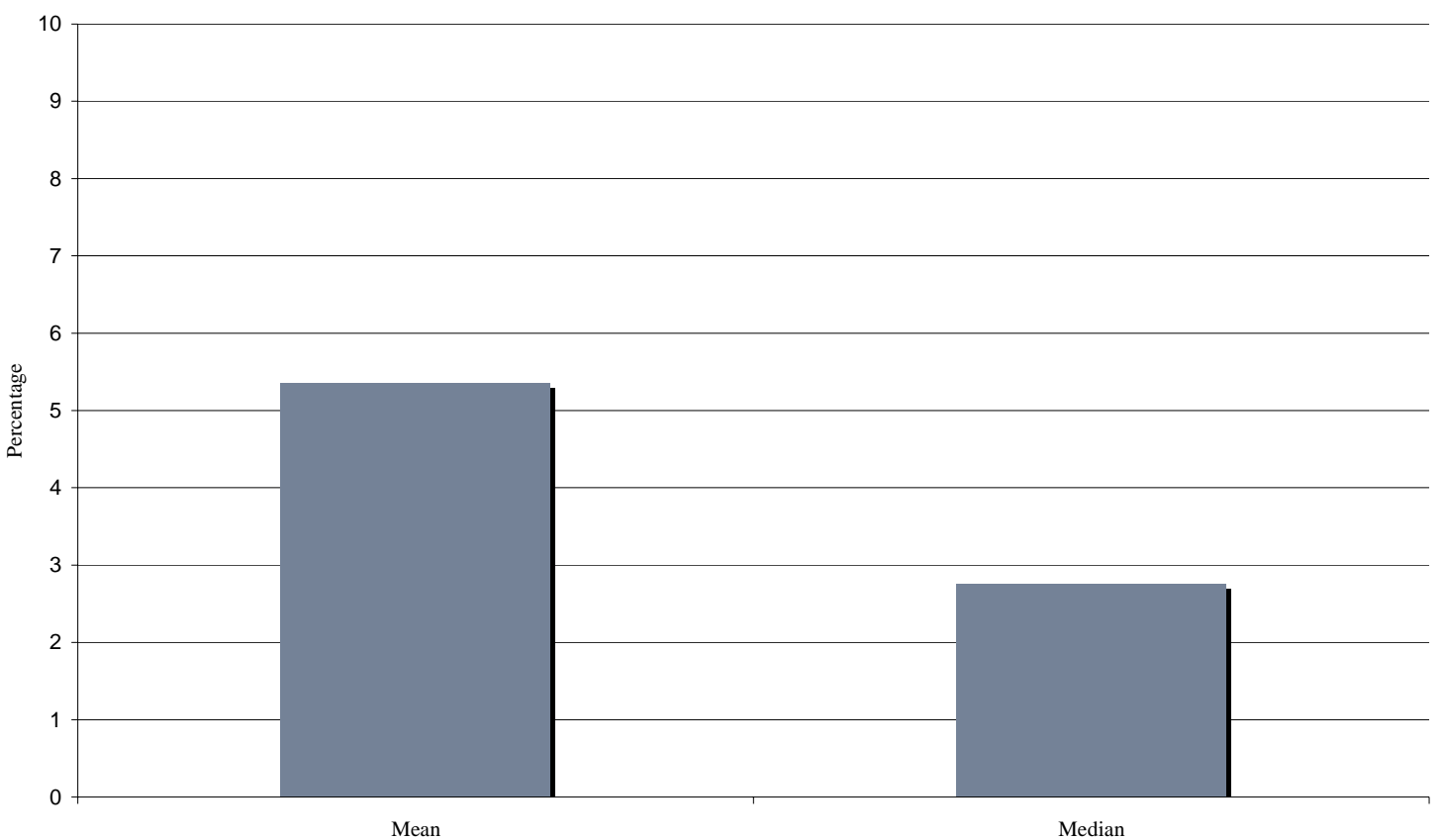

What percentage of other publishing income comes from electronic licensing? $(n=30)$

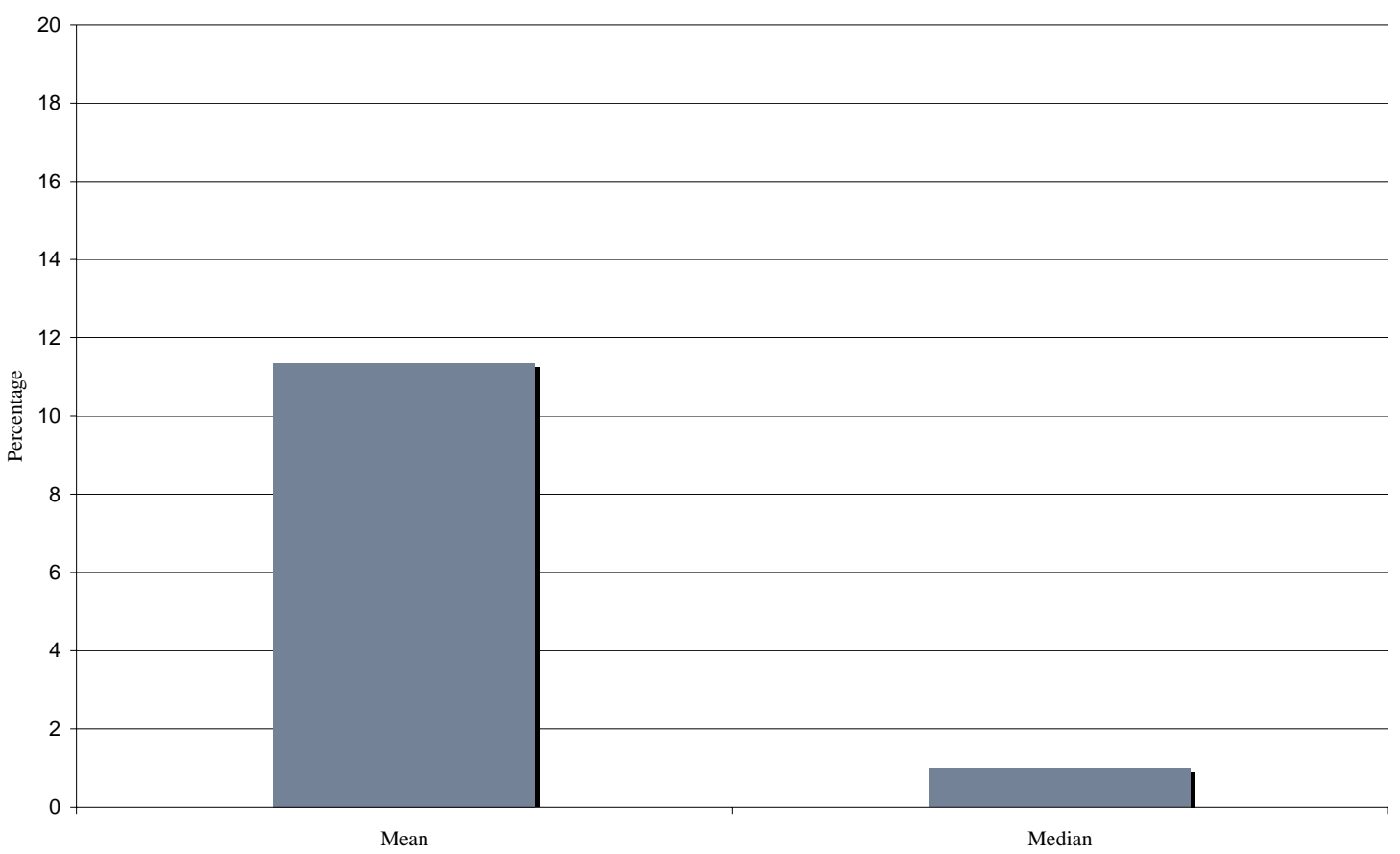


Do you publish any scholarly journals or other serials?

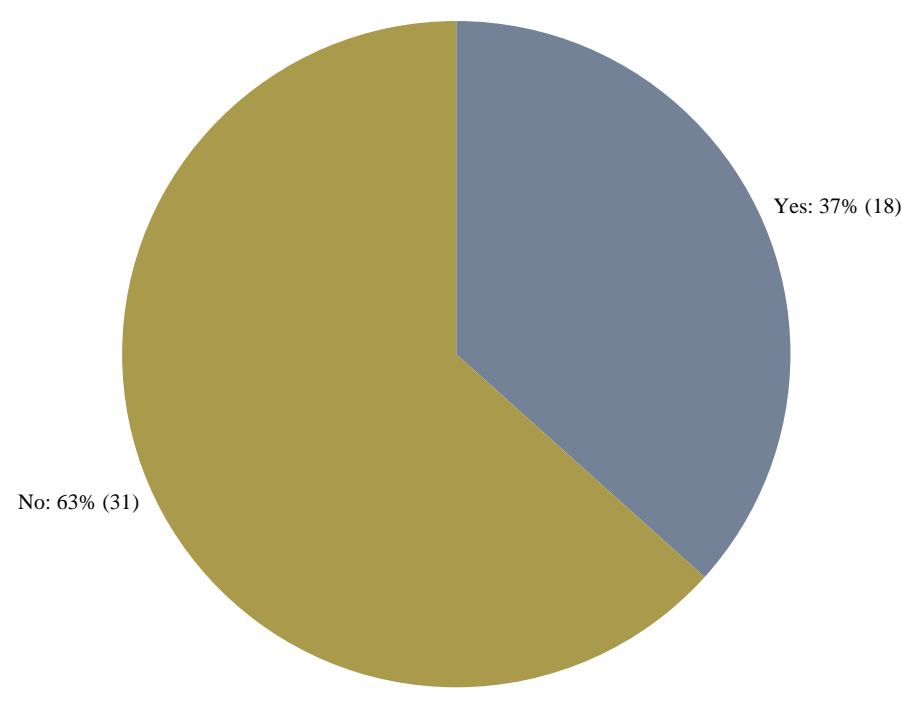

How many journals are owned by your press vs. published on behalf of others?

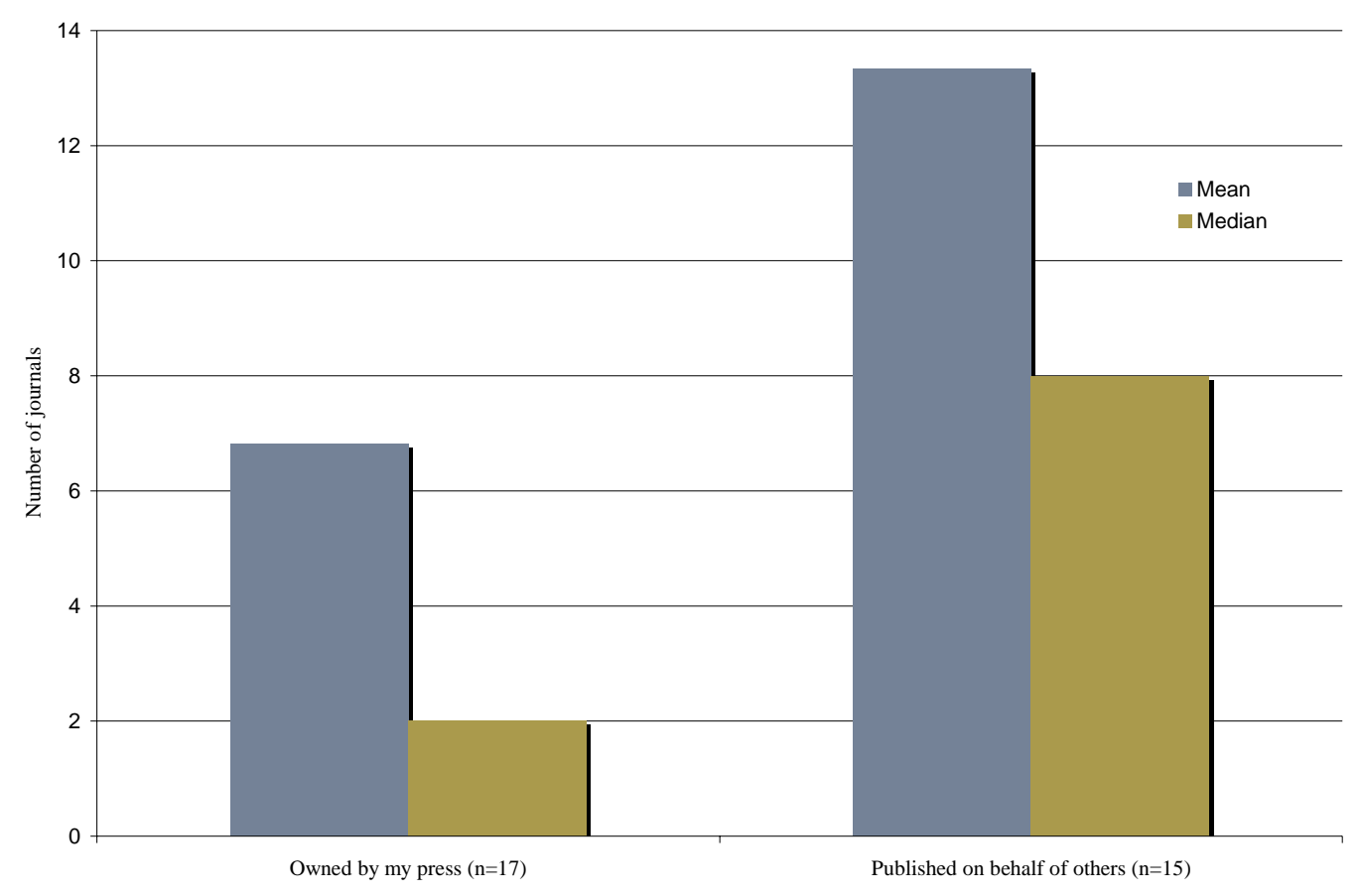


Are any of your journals available electronically?

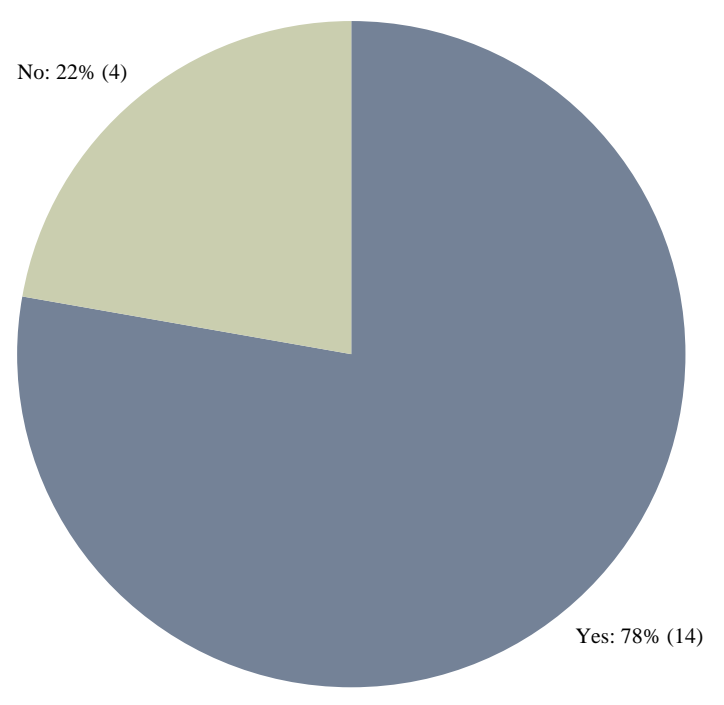

(If yes), How many titles are available electronically? $(n=18)$

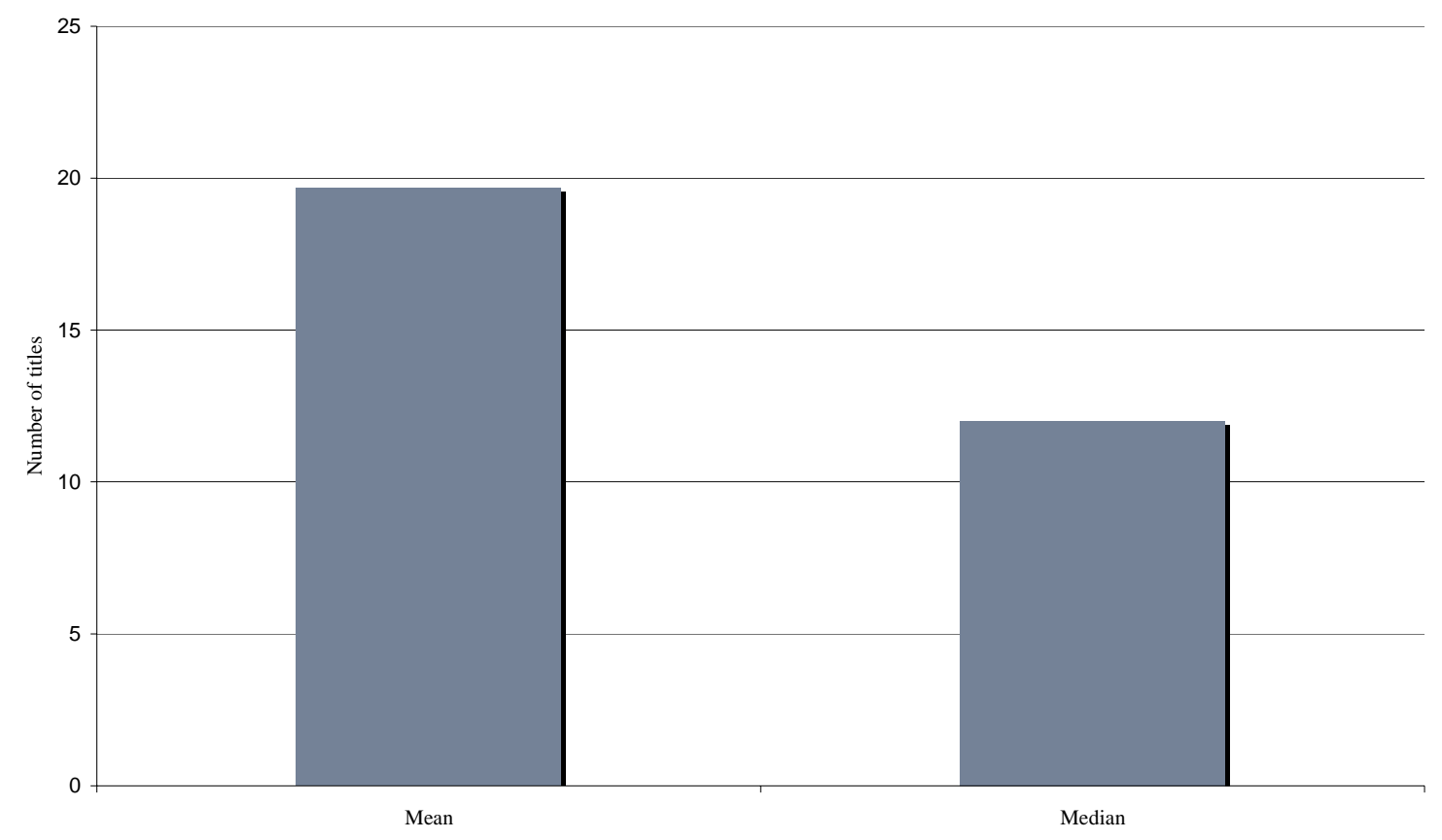




\section{(If yes), What percentage of your list is this?} $(n=18)$

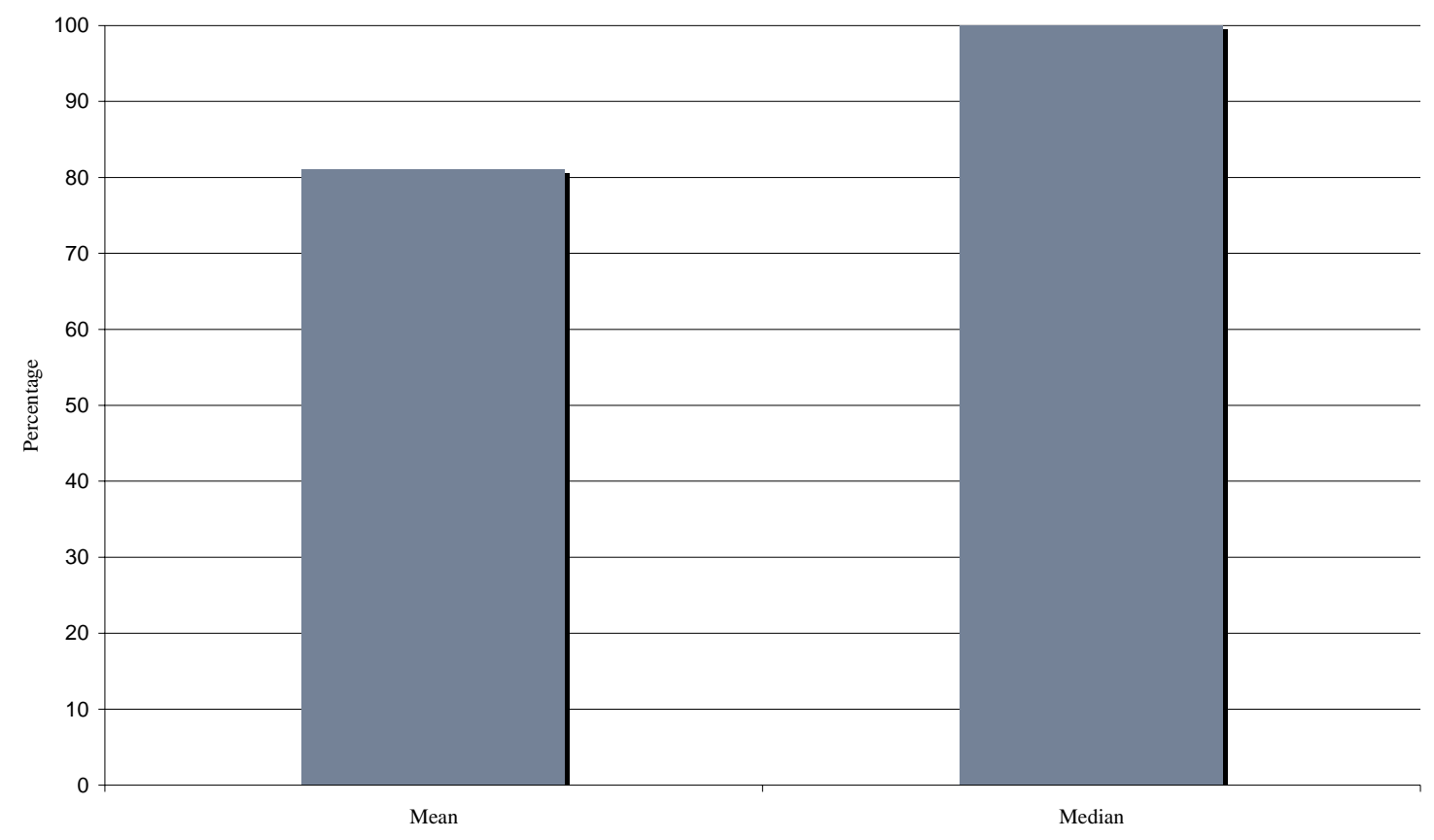

Are you experiencing a drop-off in institutional print subscriptions due to the availability of electronic journals?

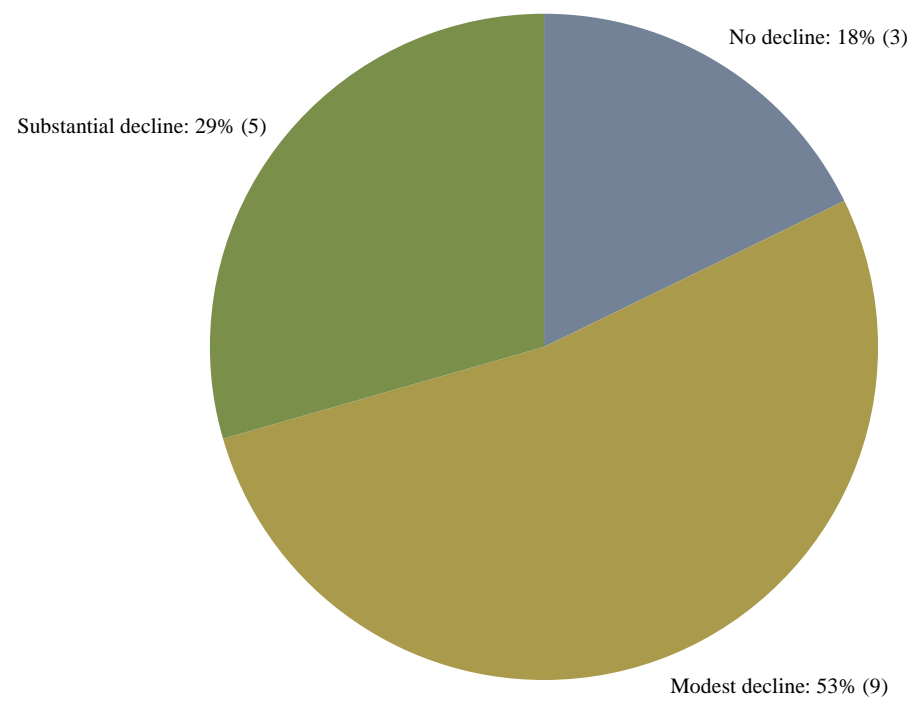


Do you anticipate that institutional subscriptions to the print (as opposed to electronic) versions of your journals will disappear in:

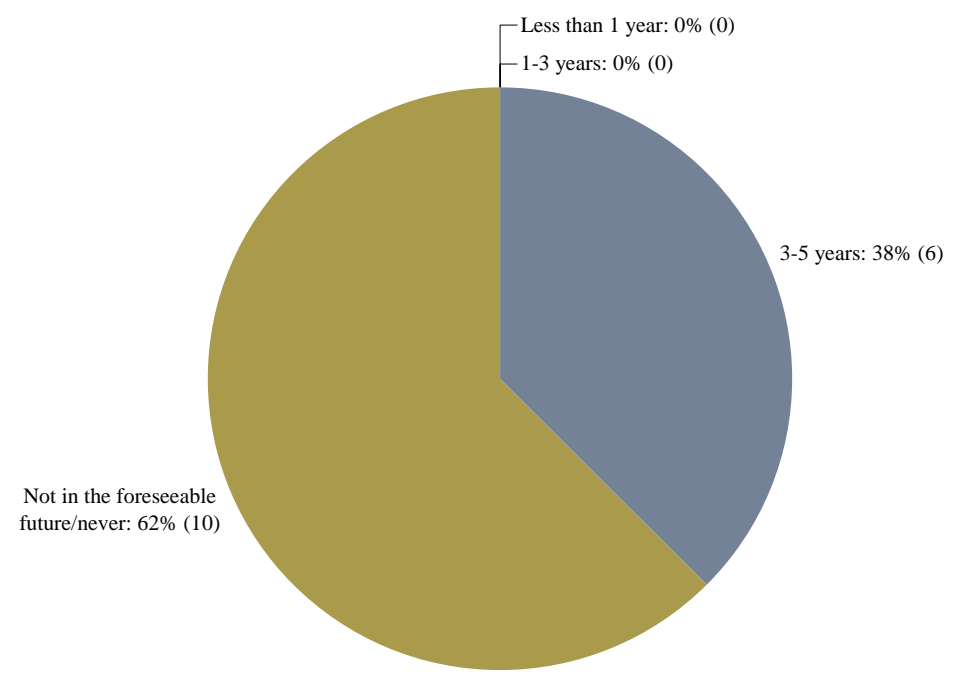

Could your press' current business model for scholarly journals accommodate a transition of all your institutional subscriptions to electronic-only (i.e. complete transition away from print)?

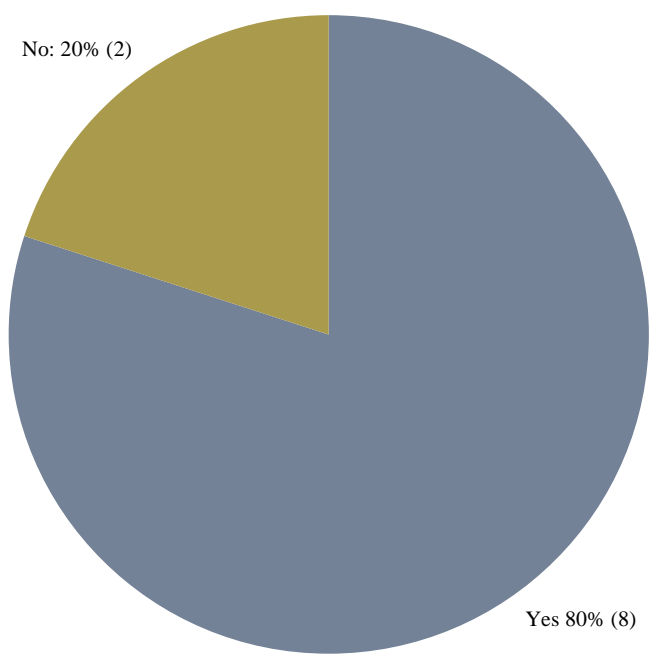


Does your press offer journal backfile products (including through aggregators and JSTOR)?

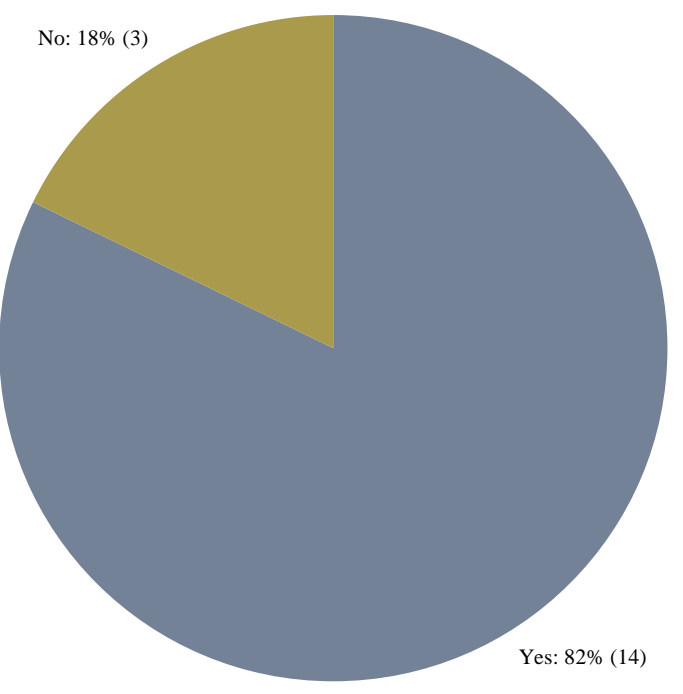

(If yes), How many titles?

$(n=14)$

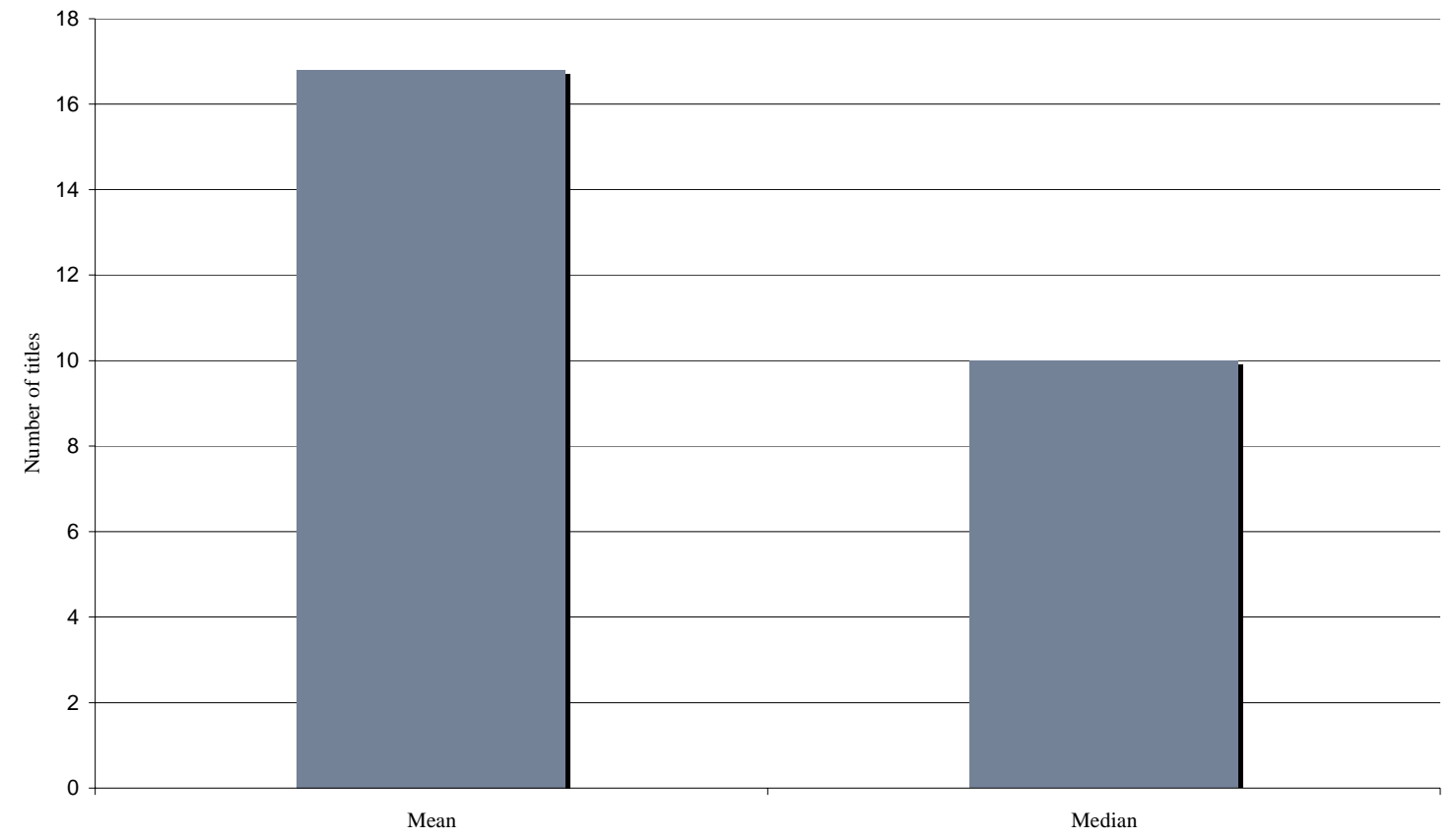




\section{(If yes), What percentage of your titles is this?}

$$
(\mathrm{n}=13)
$$

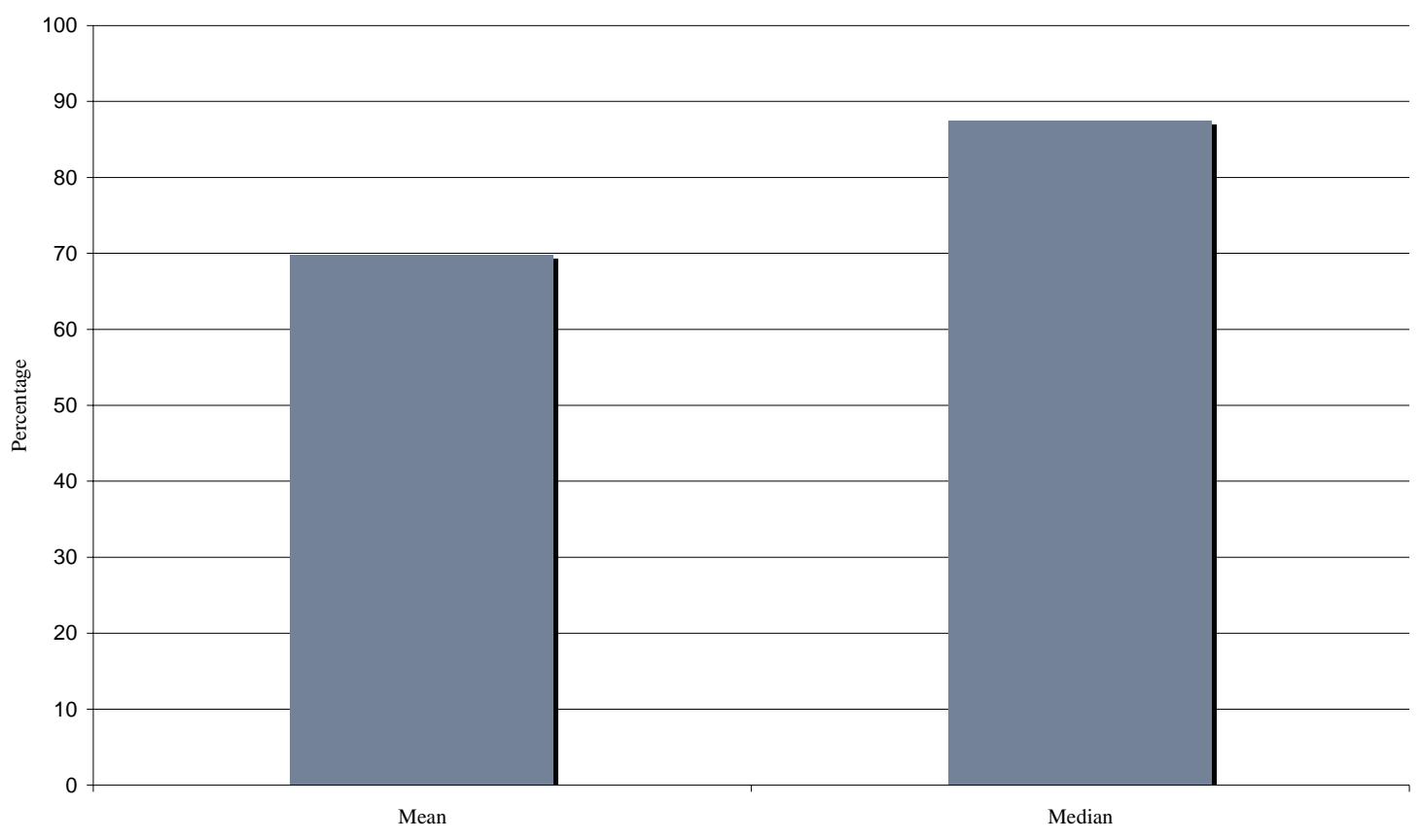

What digital production strategies do you employ for monographs and other books? (please select those that apply)

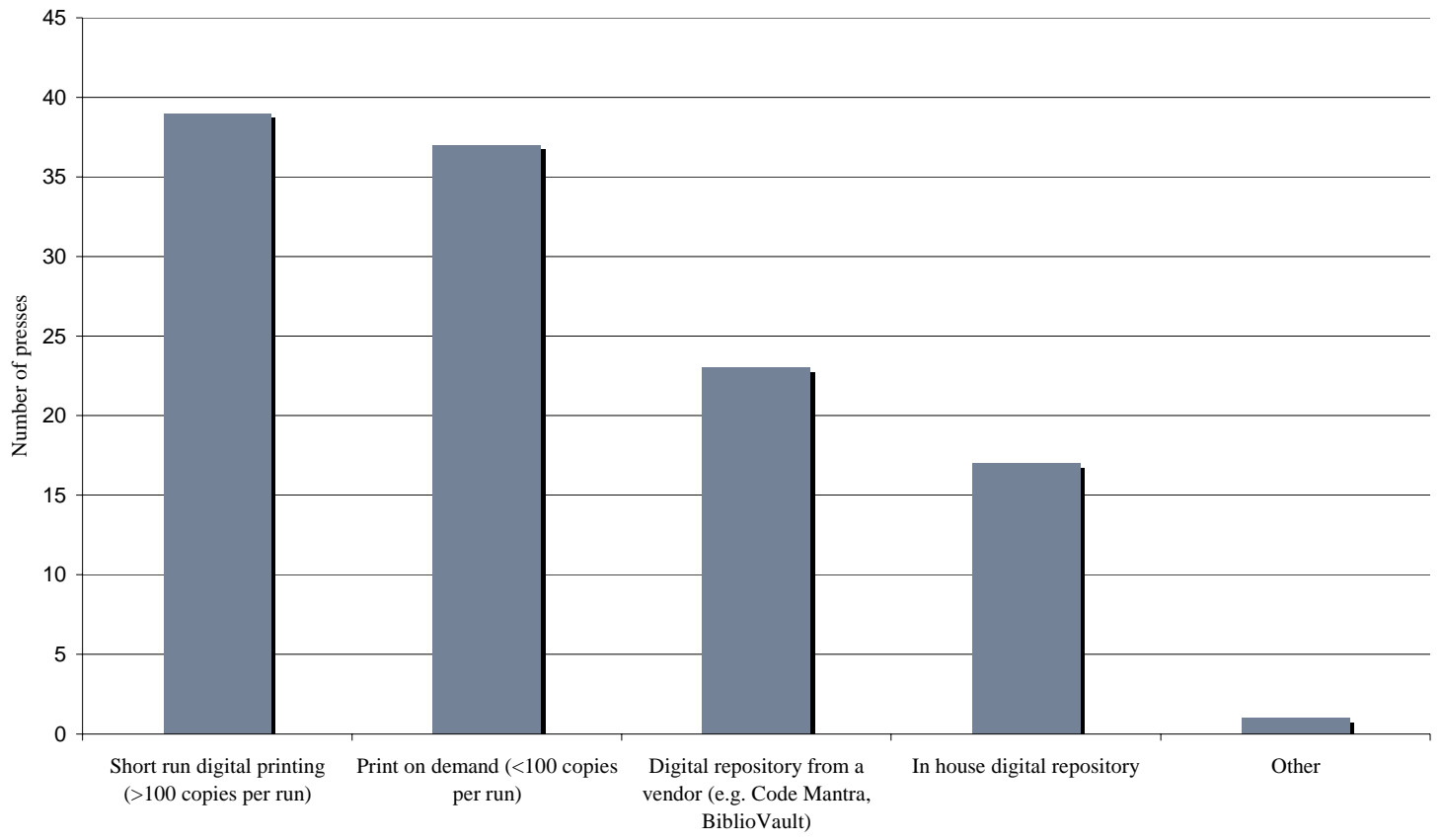


Do you publish any books electronically (e.g. through NetLibrary, eBrary, etc.)?

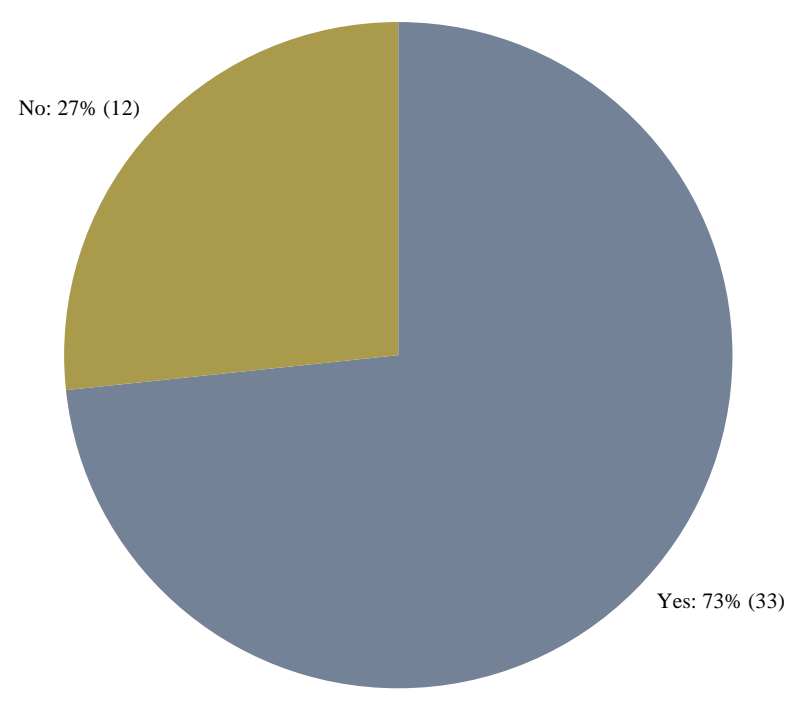

Approximate number of titles published electronically $(n=33)$

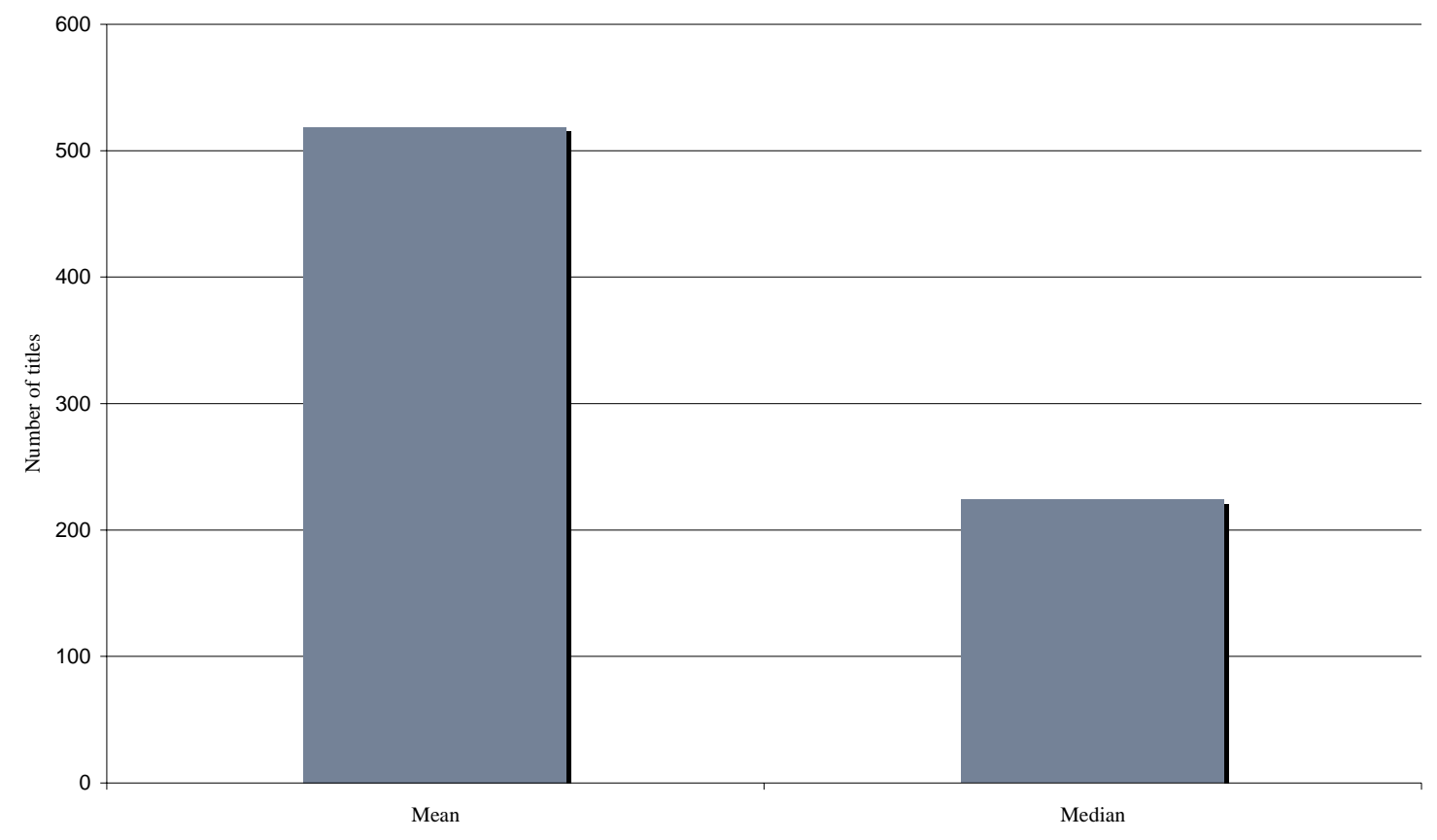


Percentage of total books in print

$$
(\mathrm{n}=31)
$$

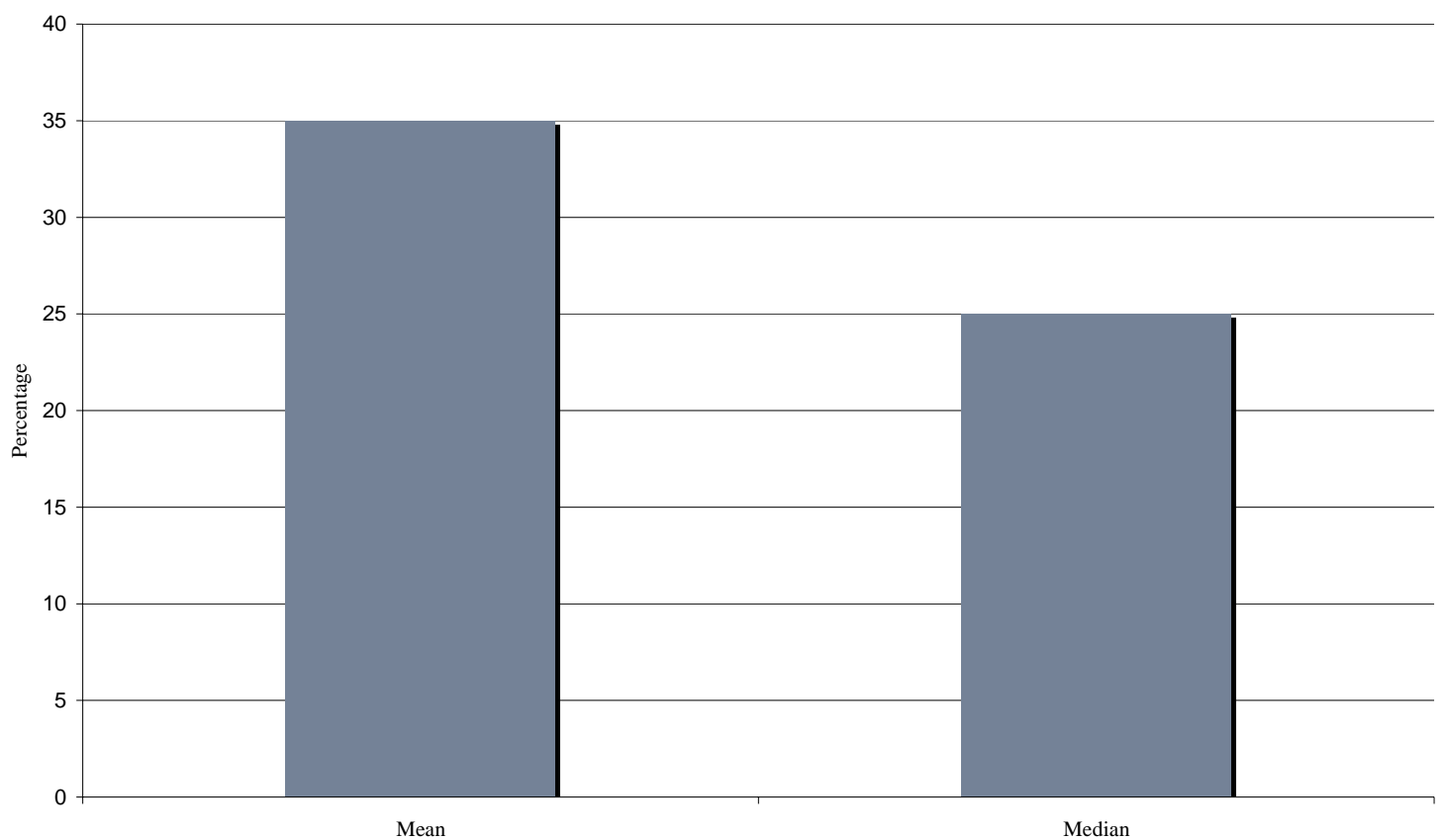

Do you publish any reference works or databases electronically?

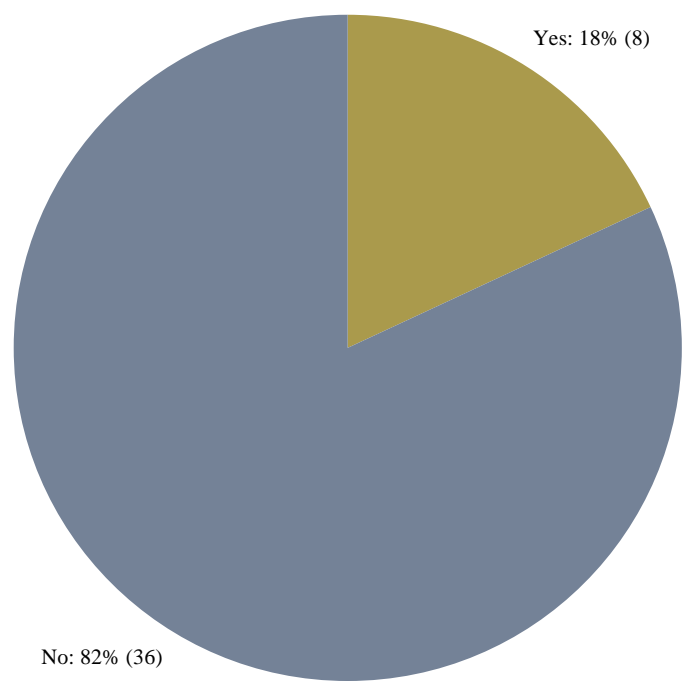


Approximate number of reference titles published electronically $(n=8)$

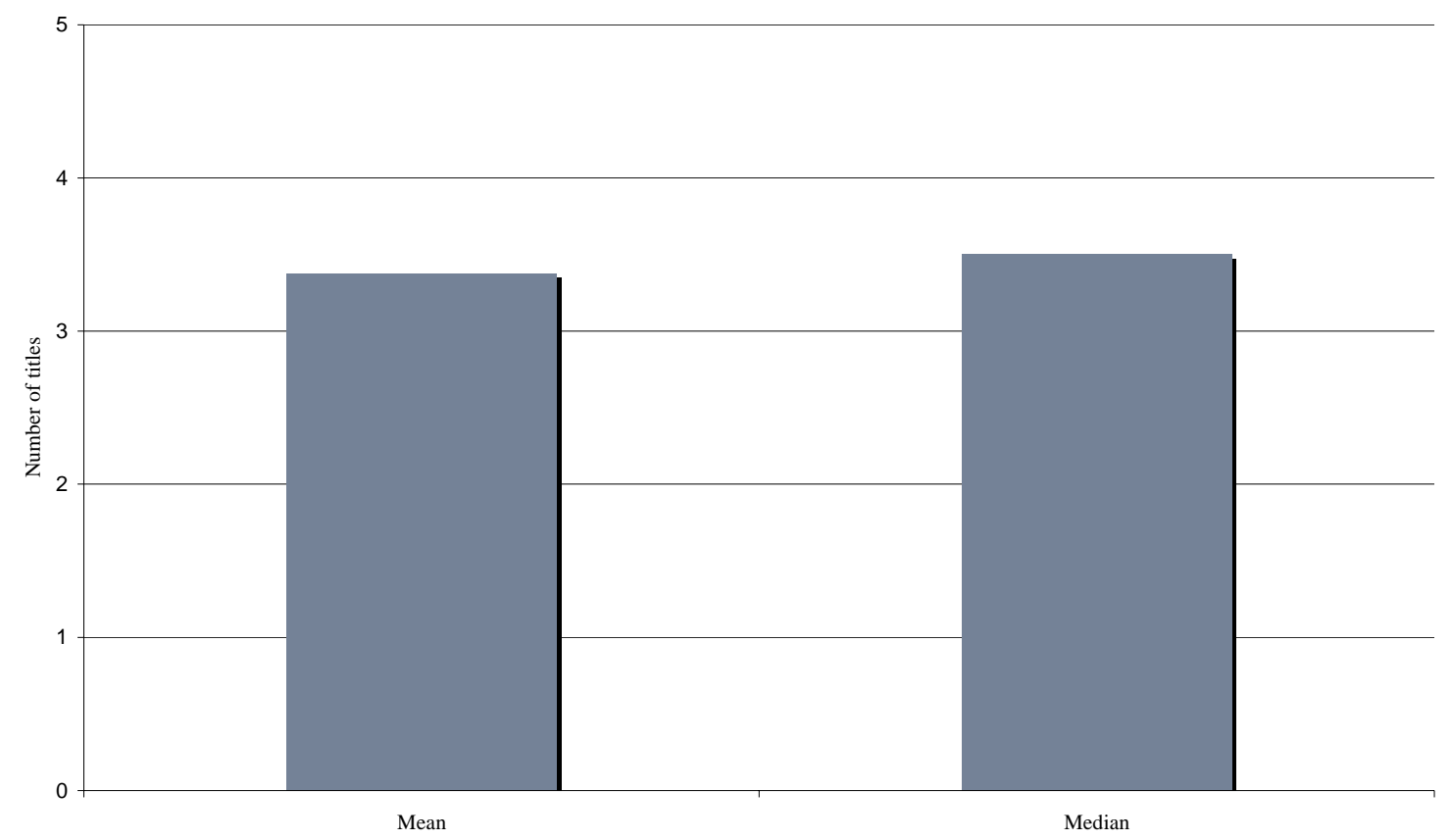

Percent of total reference titles that are published electronically

$$
(n=5)
$$

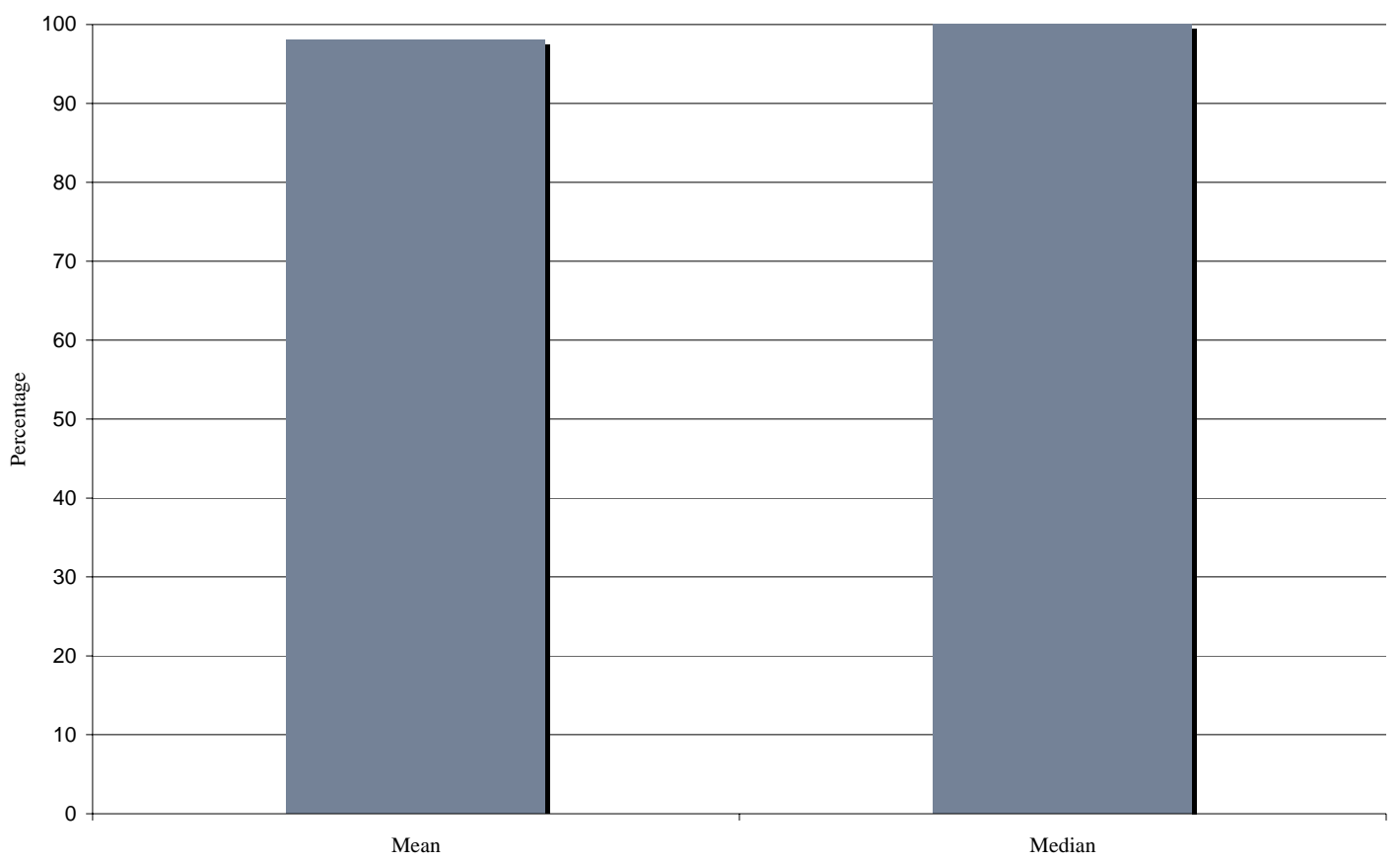


Which of these digital technologies do you plan to deploy NEWLY in the next 1-2 years? (please select those that apply)

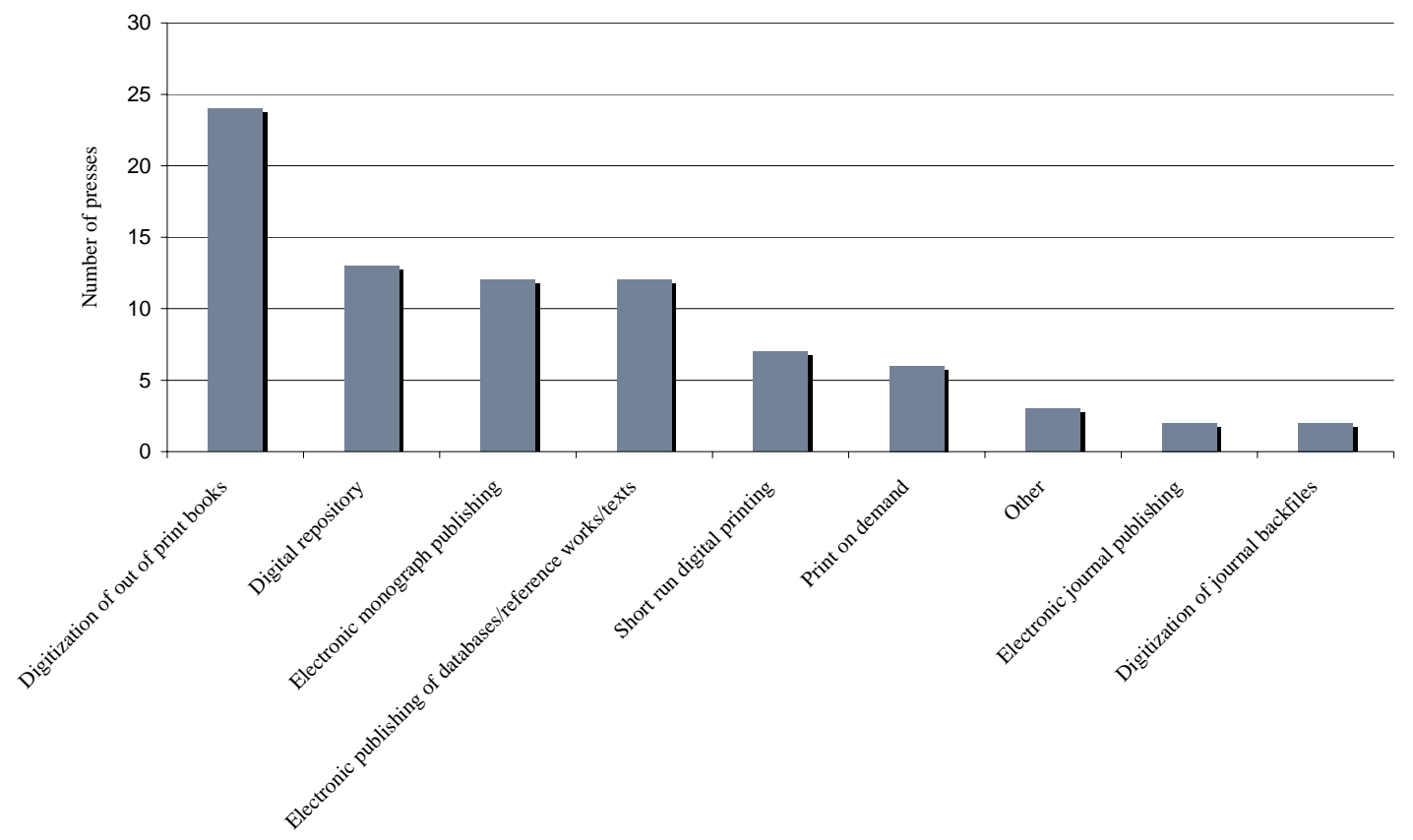

